\title{
The Evidence for a Neurobiological Model of Childhood Antisocial Behavior
}

\author{
Stephanie H. M. van Goozen \\ Cardiff University \\ Heddeke Snoek \\ University Medical Centre Utrecht
}

\author{
Graeme Fairchild \\ University of Cambridge \\ Gordon T. Harold \\ Cardiff University
}

\begin{abstract}
Children with persistent antisocial and aggressive behavior are diagnosed as having disruptive behavior disorder. The authors review evidence that antisocial children, and especially those who persist with this behavior as they grow older, have a range of neurobiological characteristics. It is argued that serotonergic functioning and stress-regulating mechanisms are important in explaining individual differences in antisocial behavior. Moreover, low fear of punishment and physiological underactivity may predispose antisocial individuals to seek out stimulation or take risks and may help to explain poor conditioning and socialization. The authors propose a theoretical model highlighting the interplay between neurobiological deficits and cognitive and emotional functioning as mediators of the link between early adversity and antisocial behavior problems in childhood. Implications for intervention programs are discussed.
\end{abstract}

Keywords: conduct disorder, aggression, serotonin, autonomic nervous system, cortisol

This review is concerned with the role of neurobiological systems in the development and maintenance of antisocial behavior. In considering neurobiological influences on behavior, the recognition that any behavior is the outcome of a complex interplay of individual, developmental, and social factors is important. In the case of the etiology of childhood aggression and antisocial behavior, contributing factors may play a more or less important role at different points in childhood and adolescence. For example, harsh parental discipline with cruel punishment appears to play a causal role in the development of antisocial behavior in childhood, whereas the absence of parental supervision appears to be an important factor in antisocial behavior in late childhood or adolescence (Lahey, McBurnett, Loeber, \& Hart, 1995). Another example is that the early (perinatal) hormonal environment is assumed to play a role in shaping temperament and its development before the onset of important social influences such as peer interactions.

With regard to young children, it is likely that the origin of antisocial behavior is to be found in a combination of difficult

Stephanie H. M. van Goozen and Gordon T. Harold, School of Psychology, Cardiff University, Cardiff, United Kingdom; Graeme Fairchild, Developmental Psychiatry Section, University of Cambridge, Cambridge, United Kingdom; Heddeke Snoek, Department of Child Psychiatry, University Medical Centre Utrecht, Utrecth, the Netherlands.

Preparation of this article was supported in part by a grant from the Wellcome Foundation. We thank Tony Manstead, Menno Kruk, and Katherine Shelton for their helpful comments on a version of this article.

Correspondence concerning this article should be addressed to Stephanie H. M. van Goozen, School of Psychology, Cardiff University, Tower Building, Park Place, Cardiff CF10 3AT, United Kingdom. E-mail: vangoozens@cardiff.ac.uk temperament and a nonoptimal environment in which ineffective socialization plays a key role: A difficult child is more likely to elicit harsh, inconsistent, and negative socialization behaviors, and as a result, a difficult temperament ultimately develops into antisocial behavior (Patterson, Reid, \& Dishion, 1992). Although there are factors that contribute to antisocial behavior in childhood becoming chronic, not all antisocial children become antisocial adolescents, and not all antisocial adolescents become antisocial adults (Robins, 1978). A study of the neurobiological factors involved in antisocial behavior can help explain why these behavioral patterns persist or desist over time.

In this review, we argue that serotonergic functioning and stressregulating mechanisms, including the hypothalamic-pituitaryadrenal (HPA) axis and the autonomic nervous system (ANS), are important in explaining individual differences in antisocial behavior. Moreover, low fear of punishment and physiological underactivity may predispose antisocial individuals to seek out stimulation or take risks and may help to explain poor social conditioning and socialization. In light of the findings from the studies that were to be reviewed, it was our firm belief that an investigation of the neurobiological factors involved in children's antisocial behavior would ultimately indicate which individuals are most at risk, which types of interventions are likely to be most beneficial, and which individuals are most likely to benefit from intervention.

\section{Terminology and Scope}

Antisocial behavior in children can be operationalized in different ways, and this has been the source of much debate. Antisocial behavior can be defined in terms of psychiatric diagnoses (oppositional defiant disorder [ODD], conduct disorder [CD], disruptive behavior disorder [DBD]; Diagnostic and Statistical Manual of Mental Disorders, 4th ed. [DSM-IV]; American Psychiatric Asso- 
ciation, 1994), in terms of the violation of social or legal norms (delinquency, criminality), or as aggressive behavior (Plomin, Nitz, \& Rowe, 1990). These operationalizations are related but not synonymous. Given that few studies have examined neurobiological factors in childhood-onset antisocial behavior, we decided to adopt relatively broad inclusion criteria, such that studies examining any of the four operationalizations are included in the present review (i.e., psychiatric, antisocial, violent, and aggressive; see Lynam, 1996; Moffitt, 1993, 2005). Following Rhee and Waldman's (2002) suggestion, we use the term antisocial behavior to refer to this omnibus operationalization.

\section{Antisocial Behavior and Aggression Subtypes}

Aggression, defined as behavior deliberately aimed at inflicting physical and/or psychological damage on persons or property, represents a problem of significant clinical and social concern. In psychiatry, aggression does not constitute a separate diagnostic entity itself, but it appears in several psychopathological conditions, the most important being $\mathrm{CD}$, substance use disorder, neurological disorders involving the frontal and temporal lobes, and personality disorders such as borderline and antisocial personality disorder (APD; as described in the DSM-IV; American Psychiatric Association, 1994).

Despite its common occurrence and clinical importance, there have been few attempts to classify aggressive behavior systematically for clinical purposes (Vitiello \& Stoff, 1997). The psychosocial complexity of this behavior and its etiological heterogeneity are major obstacles to any clinically valid subtyping. This situation contrasts with the literature on nonhuman species: Subtypes of aggression have been identified using behavioral, neuroanatomical, and biochemical approaches (Miczek, Fish, De Bold, \& de Almeida, 2002; Moyer, 1976). In humans, two major forms of aggression have been identified: an impulsivereactive-hostile-affective (impulsive) subtype and a controlledproactive-instrumental-predatory (controlled) subtype, which are qualitatively different from each other with respect to their phenomenology and neurobiological features (Vitiello \& Stoff, 1997).

Impulsive aggression is typically explosive, uncontrolled, accompanied by anger or fear, and characterized by high levels of arousal. It may also be self-destructive. There is an increasing body of research that has linked impulsive aggression and neurotransmitter abnormalities, specifically a reduction of serotonergic activity (Stoff \& Vitiello, 1996; see below). In contrast, individuals who manifest nonimpulsive, controlled (predatory) aggression are less likely to be affectively unstable; their aggression is instrumental, in the sense that it is normally used to achieve a goal beyond harming a victim. The level of arousal of individuals engaging in this form of aggression is thought to be low, as evidenced by their low baseline heart rate (HR) and skin conductance (SC) levels, although it is not known whether their arousal levels are also low during the commission of violent or antisocial acts themselves.

At present it is unclear whether the distinction between impulsive and controlled aggression applies to childhood aggression, although it has been suggested that child psychiatric cases with aggressive behavioral problems more often show impulsive aggression than controlled aggression (Vitiello \& Stoff, 1997). It is likely, however, that those individuals who employ instrumental forms of aggression under some circumstances will also behave aggressively when provoked. Thus, although the distinction between hostile and instrumental aggression has been appealing from a phenomenological or descriptive point of view, we should keep in mind that the different subtypes, if they exist at all (see Bushman \& Anderson, 2001), are not mutually exclusive, and that it may well be unreasonable to expect a dichotomy in a situation in which there is a complex interplay between different brain structures and multiple hormonal and arousal systems.

\section{Antisocial Behavior in Child Psychiatry}

When aggressive and antisocial behavior becomes a pervasive pattern that affects diverse domains of children's functioning, one refers either to an ODD or a CD (DSM-IV; see Table 1). The term disruptive behavior disorder encompasses both ODD and $\mathrm{CD}$. The prevalence of these disorders is relatively high: $2.0 \%$ for $\mathrm{CD}$ and $3.2 \%$ for ODD (Lahey, Waldman, \& McBurnett, 1999). The problem behavior of children with these disorders is often quite stable and persistent (Offord et al., 1992). Conduct problems in childhood are associated with a host of negative outcomes in adulthood; they predict not only future antisocial behavior (Fombonne, Wostear, Cooper, Harrington, \& Rutter, 2001; Zoccolillo, Pickles, Quinton, \& Rutter, 1992; Zoccolillo \& Rogers, 1991) but also substance abuse and dependence in adulthood (Kazdin, 1995; Offord \& Bennett, 1994), early pregnancy in antisocial girls (Bardone et al., 1998), persistent health problems (Bardone et al., 1998), and other forms of psychiatric illness such as depression.

Although the short-term effectiveness of intervention strategies (e.g., parent management training, cognitive behavioral therapy) has been demonstrated (Kazdin, 2001), the long-term effectiveness of treatment appears to be limited (Offord \& Bennett, 1994). In particular, the high persistence, poor prognosis, and limited effectiveness of treatments of childhood antisocial behavior lend importance to the investigation of biological correlates of antisocial behavior in childhood. An understanding of these factors in antisocial children should generate hypotheses concerning both the underlying neurobiological mechanisms and the etiology of antisocial behavior. Furthermore, biological studies of antisocial behavior could lead to new approaches to the treatment of psychiatric conditions that are associated with aggression. Such approaches might involve pharmacological interventions to manipulate indirectly or perhaps even directly the biological substrates of aggression or lead to hypotheses that influence the content of psychotherapy.

We critically evaluate the evidence that antisocial behavior, as observed in child psychiatric patients with DBD, stems partly from changes in the developing neurobiological systems of these children. In particular, we focus on the roles of the HPA axis and the 5-hydroxytryptamine (5-HT; serotonin) neurotransmitter system, the functions of which may be altered in children with antisocial behavior, particularly that which has its onset early in life.

\section{Clinical Subtyping and Overlap}

Conduct problems and attention-deficit/hyperactivity disorder (ADHD) are highly overlapping behavioral disorders, and have been found to co-occur in $30 \%-50 \%$ of cases in epidemiological and clinical samples (Lynam, 1996). Although the issue of whether DBD and ADHD are distinct categories is still controversial, 
Table 1

Diagnostic and Statistical Manual of Mental Disorders (4th ed.) Diagnostic Criteria for the Disruptive Behavior Disorders: Oppositional Defiant Disorder and Conduct Disorder

Criteria

Subcriteria

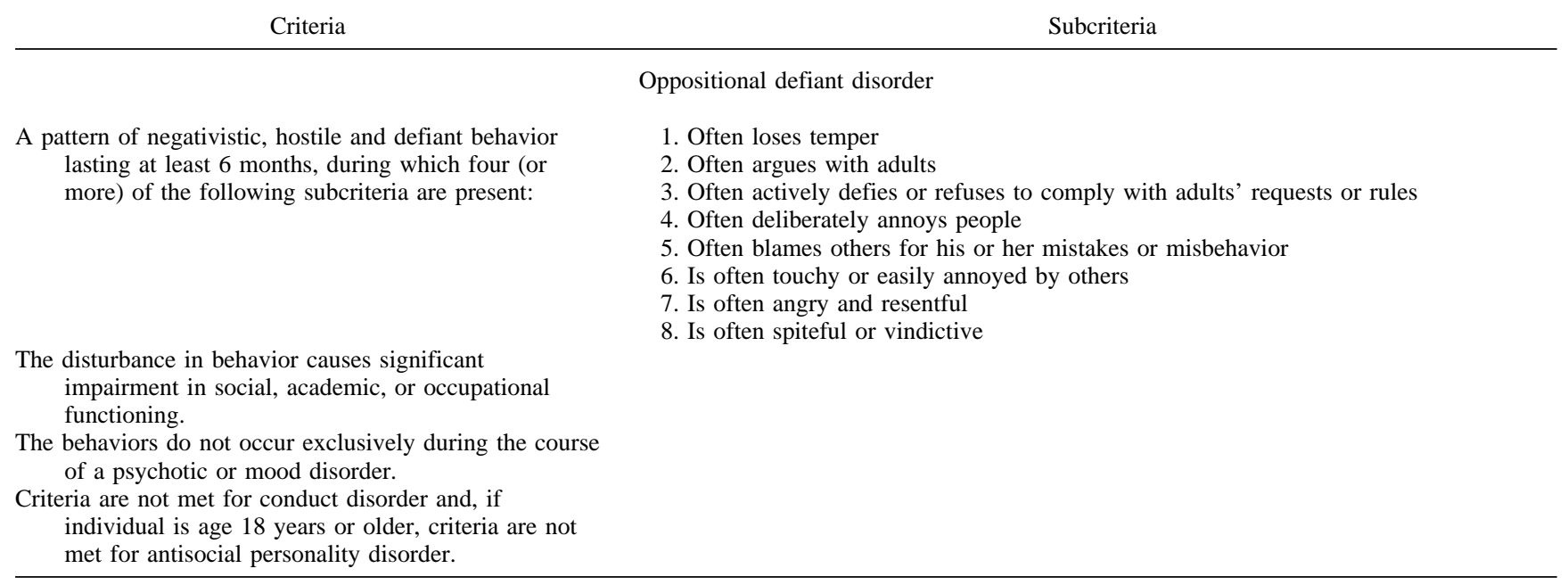

Conduct disorder

\section{A repetitive and persistent pattern of behavior in which either the basic rights of others or major age- appropriate societal norms or rules are violated, as manifested by the presence of three (or more) of the following subcriteria in the past 12 months, with at least one criterion present in the past 6 months: Aggression to people and animals}

Destruction of property

Deceitfulness or theft

Serious violations of rules

The disturbance in behavior causes significant impairment in social, academic, or occupational functioning.

If individual is age 18 years or older, criteria are not met for antisocial personality disorder.
1. Often bullies, threatens, or intimidates others

2. Often initiates physical fights

3. Has used a weapon that can cause serious physical harm to others (e.g., a bat, brick, broken bottle, knife, gun)

4. Has been physically cruel to people

5. Has been physically cruel to animals

6. Has stolen while confronting a victim (e.g., mugging, purse snatching, extortion, armed robbery)

7. Has forced someone into sexual activity

8. Has deliberately engaged in fire setting with the intention of causing serious damage

9. Has deliberately destroyed others' property (other than by fire setting)

10. Has broken into someone else's house, building, or car

11. Often lies to obtain goods or favors or to avoid obligations (i.e., "cons" others)

12. Has stolen items of nontrivial value without confronting a victim (e.g., shoplifting, but without breaking and entering; forgery)

13. Often stays out at night despite parental prohibitions, beginning before 13 years

14. Has run away from home overnight at least twice while living in parental or parental surrogate home (or once without returning for a lengthy period)

15. Often truant from school, beginning before age 13 years researchers accept the notion that the two domains are at least partially independent (Hinshaw, 1987). Of note is that ADHD and DBD have different background factors and correlates, including socioeconomic status, family hostility, parental antisocial behavior, and cognitive and achievement variables (Lynam, 1996). The focus of the present review is on antisocial behavior; thus, studies examining the role of neurobiological variables in clinical samples of ADHD (alone) will not be included. However, if a sample comprised children with comorbid DBD and ADHD, the study in question was included.
Indeed, an important objective of our review of the neurobiological bases of childhood antisocial behavior is to highlight evidence that ADHD and DBD are separate diagnostic categories with distinct neurobiological impairments.

\section{Antisocial Children: A Developmental Problem}

Robins's (1966) conclusion that tomorrow's antisocial adult can be found among today's antisocial children still poses one of the most challenging questions in developmental research. Childhood 
conduct problems are a major risk factor for adult disorders that are characterized by antisocial behavior, and aggression in general not only is predictive of antisocial outcomes in adulthood but also is stable across generations (Huesmann, Eron, Lefkowitz, \& Walder, 1984; Lynam, 1996; Robins, 1966). Lynam (1996) observed that "although all chronic offenders have a history of childhood antisocial behavior, childhood antisocial behavior is so common that it predicts chronic offending only weakly, if at all. This asymmetry hobbles researchers' attempts to identify the developmental correlates of the chronic offender ... The golden grail of high-risk research has become the identification of the minority of children who are most likely to persist in their antisocial behavior from among the multitude of children who engage in some antisocial acts" (p. 211).

Lynam (1996) identified children with a combination of ADHD and $\mathrm{CD}$ characteristics as being at greatest risk for chronic offending and explained their persistence by pointing out that their behavioral, neuropsychological, and physiological deficits are similar to those of adult psychopaths.

A decade has passed since the publication of Lynam's seminal paper and we are now in a position to provide a more comprehensive understanding of the nature of the (neurobiological) factors and processes that cause and maintain these deficits. In doing so, we attempt to explain why children with antisocial problems have neuropsychological problems and difficulties in response regulation (Newman \& Wallace, 1993; Van Goozen, Cohen-Kettenis, et al., 2004). We also explain why antisocial children have distinct social information-processing deficits that cause their behavioral problems to become persistent (Milich \& Dodge, 1984), and we propose an integrative theoretical model linking genetic factors, early adversity, cognitive and neurobiological regulatory mechanisms, and childhood antisocial behavior.

\section{The Present Review}

The primary goal of our review is to discuss the evidence that specific neurobiological systems are involved in childhood-onset antisocial behavior. These factors are responsible for the severity of the behavioral problems observed in antisocial children, but they also play a role in their persistence, because they influence children's interactions with their environment.

We first briefly introduce two main factors in the theoretical model that are presented later in the article (see Figure 1), namely genetic factors and early childhood adversity. In this section, we seek to explain how the children's genotype, through evocative gene-environment processes, can create environments that reinforce their antisocial behavior, thereby increasing the risk of persistence in behavioral problems.

Next, we present the evidence in support of the involvement of different hormonal parameters in adult antisocial behavior, before we proceed to describe and discuss the findings from research on children. We point out the implications of these findings for theory and clinical practice. In a similar fashion, data are reviewed suggesting that the ANS and serotonergic system are dysfunctional in individuals with pervasive antisocial behavior. We then discuss the possible causes of deviant biological correlates in childhood antisocial behavior, and toward the end of the review, we present an integrative theoretical model of the neurobiological bases of early-onset antisocial behavior.

\section{Etiological Factors: Genes and Family Environment}

Research on the etiology of antisocial behavior has focused almost exclusively on the role of dysfunctional family influences, such as economic problems, parental psychopathology, coercive parenting, physical abuse, and family conflict (Moffitt \& Caspi, 2001). Often, these variables are considered to be environmental influences, and the possibility that they may also reflect genetic influences is not considered (see Moffitt's, 2005, discussion of how bad parenting should be treated as a phenotype in future behavioral-genetic research on antisocial behavior). This is unfortunate because disentangling the influences of nature and nurture is a first step toward the goal of explaining the etiology of antisocial behavior (Rhee \& Waldman, 2002, p. 490).

It is well known that antisocial behavior is concentrated in a relatively small percentage of families (Farrington, Jolliffe, Loeber, Stouthamer-Loeber, \& Kalb, 2001), that children with disruptive behavioral problems are more likely to have parents who show antisocial behavior (e.g., Biederman, Munir, \& Knee, 1987; Lahey et al., 1987; Stewart, deBlois, \& Cummings, 1980), and that the intergenerational transmission of antisocial behavior has been well-documented (Huesmann et al., 1984).

Meta-analytic studies (Rhee \& Waldman, 2002) have concluded that genes influence $40 \%-50 \%$ of population variation in antisocial behavior, but the proportion is greater $(60 \%-65 \%)$ for aggressive antisociality (Tackett, Krueger, Iacono, \& McGue, 2005). Biological characteristics related to aggressive behavior may be the result of genetic variation. Within the domain of adolescent antisocial behavior, studies that have distinguished between aggression and delinquency or rule-breaking have reported a greater genetic component $(65 \%)$ for persistent aggressive behavior than for delinquent behavior (35\%; Eley, Lichtenstein, \& Moffitt, 2003). In terms of adult antisocial behavior, monozygotic twins have been shown to have a higher $(35 \%-52 \%)$ concordance rate for antisocial behavior and for criminal conviction than dizygotic twins (13\%-23\%). Adoption studies are also consistent in showing a genetic effect on adult criminality. For example, adoptees from a biological parent with a criminal conviction show a higher rate of criminality compared with adoptees whose biological parents do not exhibit antisocial behavior, even when the former group are separated from their biological parents soon after birth (Bohman, Cloninger, Sigvardsson, \& von Knorring, 1982; Cadoret, Yates, Troughton, Woodworth, \& Stewart, 1995). There also appears to be a genetic influence on $\mathrm{CD}$ in adolescence, although it is considerably smaller than that for adult APD (Lyons et al., 1995). This latter finding may reflect the fact that all the participants who engaged in antisocial behavior during adolescence were included in the analysis. According to Moffitt (1993), this strategy would run the risk of including a large proportion of adolescence-limited antisocials for whom the evidence for genetic influences is considerably weaker than it is for individuals with life-course persistent antisocial behavior.

In considering the possible role of genetic mechanisms, it is important to recognize that interactions between genetic predispositions and the environment in which they are expressed appear to be crucial in the etiology of antisocial behavior problems (Rutter, Silberg, O'Connor, \& Simonoff, 1999). A genetic predisposition toward aggressive or antisocial behavior may be expressed in adverse rearing environments in which the child receives harsh or 


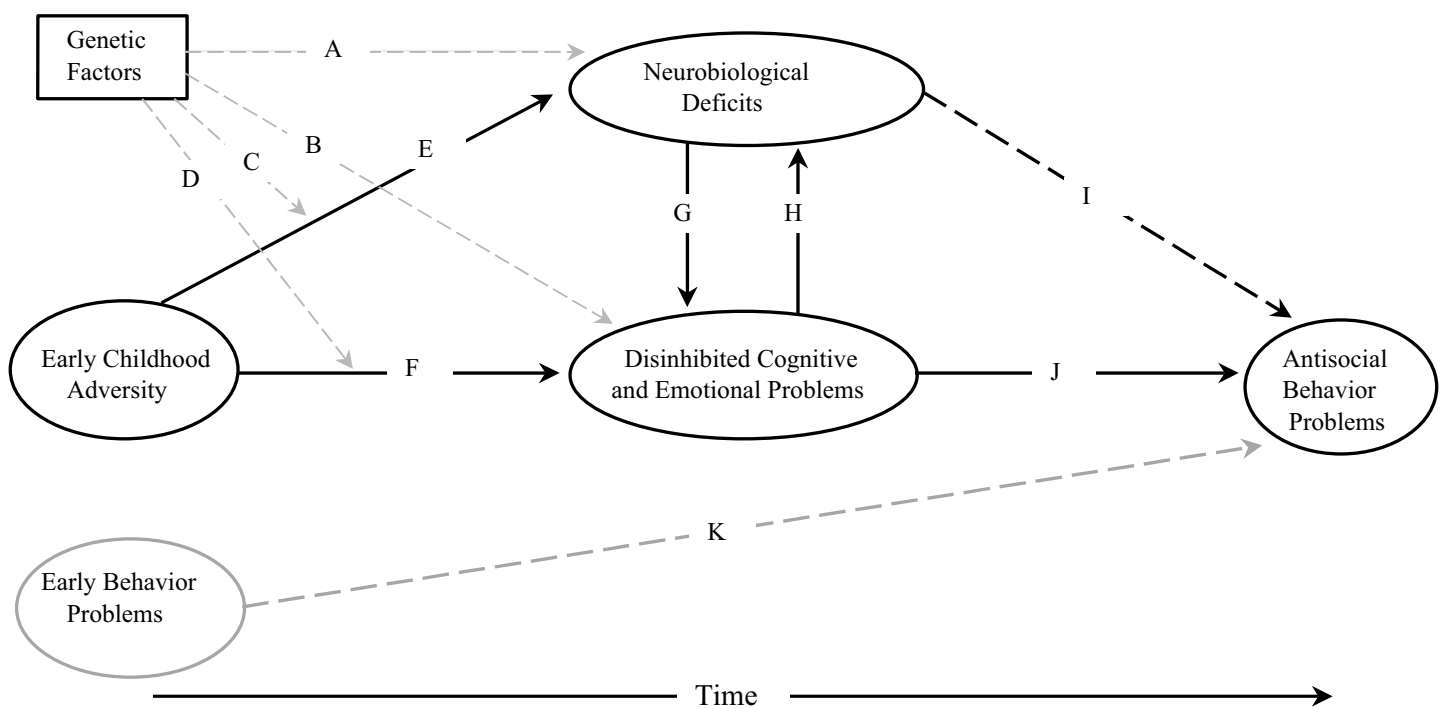

Figure 1. The proposed theoretical model represents the direct and indirect pathways through which family factors (early childhood adversity, genetic factors) are hypothesized to influence early-onset antisocial behavior problems. Bold paths in the model constitute theoretically informed and supported pathways on the basis of our review of the evidence. Dashed paths represent substantive influences that may vary on the basis of our review of prior evidence. Factors represented by circles (e.g., early childhood adversity) constitute latent indexes of primary theoretical constructs (i.e, they are respectively composed of correlated but conceptually distinct elements). Genetic factors constitute a manifest index and are therefore represented by a box (see Bollen, 1989, for conventions relating to path model representation). Paths from genetic factors and early problem behaviors are presented as light gray and dashed, not to suggest that they represent nonsignificant influences, but rather that they are secondary (genetic) or optional (estimation of initial symptom levels) in estimating this proposed theoretical model. Note also that this model highlights the important role of neurobiological mechanisms in the etiology of childhood antisocial behavior. It does not, however, represent a life-course model of the persistence and development of antisocial behavior across childhood, adolescence, and adulthood. Rather, by highlighting the role of neurobiological mechanisms underlying childhood antisocial behavior, this model identifies an important site of intervention. Effective intervention, of course, is linked to persistence and future development of antisocial behavior.

inconsistent discipline, or is exposed to high levels of interparental conflict or marital breakdown (El-Sheikh \& Harger, 2001; ElSheikh, Harger, \& Whitson, 2001). Conversely, the effects of such a predisposition may be minimized if the child is raised in a positive environment in which the parents express warmth toward their offspring and/or adopt a consistent, authoritative parenting style. Unfortunately, antisocial individuals are more likely than other people to provide an adverse rearing environment for their offspring (Rutter, Giller, \& Hagell, 1998). One study that provides some insight into the importance of Gene $\times$ Environment interactions in the etiology of antisocial behavior is that of Bohman (1996). In this adoptee study of petty criminality, it was shown that individuals lacking a genetic predisposition or environmental risk factors had only a $3 \%$ chance of becoming recidivist criminals in adulthood. Individuals exposed to environmental risk had a $6 \%$ rate of criminality, whereas those with a genetic predisposition had a $12 \%$ incidence of criminality. In contrast, the incidence of criminality in individuals with both genetic and environmental risk factors present was as high as $40 \%$. Other studies also illustrate the importance of considering Gene $\times$ Environment interactions in the development of aggressive or antisocial behavior (Cadoret, Yates, Troughton, Woodworth, \& Stewart, 1995; Caspi et al., 2002; Foley et al., 2004; see Raine, 2002, for a review).

The child's genotype can also evoke negative behavior from the environment (e.g., bad parenting, negative peer contacts), because the individual's genetically influenced behavior (i.e., temperament) leads him or her to create, seek out, or otherwise end up in environments that match the genotype (Rutter \& Silberg, 2002). Antisocial behavior can bring about each of these processes at any point in the life course, and these active evocative geneenvironment processes are of enormous importance in understanding the continuity of antisocial behavior (Caspi \& Moffitt, 1995; Moffitt, 2005).

\section{Temperament, Evocative Interactions, and Early Adverse Effects}

Early brain development is especially vulnerable to the effects of environmental stressors, and this applies to both prenatal and postnatal development (Dawson, Ashman, \& Carver, 2000; 
Huizink, Mulder, \& Buitelaar, 2004). Evidence for such environmental effects on brain development comes from studies examining pregnancies with elevated risk because of maternal smoking, poor nutrition, exposure to alcohol and drugs, or maternal psychopathology (e.g., Lundy et al., 1999), and atypical caretaker-child interactions such as those involving depressed mothers, irregular and unpredictable parenting, or exposure to abuse and neglect (e.g., Ashman, Dawson, Panagiotides, Yamada, \& Wilkinson, 2002; Carlson \& Earls, 1997). It is now known that such environmental effects can attenuate the infant's stress systems through the mediating effects of early learning and the amygdala (Susman, 2006). The dampening or downregulation of the stress system to chronic stressors over the first year of life is clearly an adaptive mechanism (Gunnar \& Donzella, 2002), avoiding chronic arousal and excessive energy expenditure that would ultimately result in serious pathophysiological consequences or even death.

Some children are born with a more easy-going temperament than others. It has been established that early temperament and later personality are related (Caspi, Henry, McGee, Moffitt, \& Silva, 1995) and that personality is in general highly stable (Caspi $\&$ Bem, 1990). In the case of difficult or hard-to-manage children, their behavior evokes distinctive responses from others (parents, peers, and teachers) that are more likely to exacerbate than to ameliorate the child's existing tendencies (Lynam, 1996; Moffitt, 1993). Moreover, environmental factors that are independent of the child's genetic makeup or temperament can act as contributory causes of persistence. Such factors include marital discord (Harold \& Conger, 1997), disrupted parenting (Erel \& Burman, 1995), or parental psychopathology (Downey \& Coyne, 1990).

\section{Neuroendocrine Features of Antisocial Behavior}

In line with findings from aggressive adults with APD (Virkkunen, 1985; Woodman, Hinton, \& O'Neill, 1978), which is almost always preceded by CD in childhood (Robins, 1978), there is now convincing evidence for changes in the functioning of several interrelated neuroendocrine systems in children with antisocial behavior. In this section, we focus on the androgens, testosterone, and dehydroepiandrosterone (DHEA), before discussing in detail the role of HPA axis hormones such as corticotropinreleasing hormone $(\mathrm{CRH})$, adrenocorticotropic hormone (ACTH), and cortisol.

\section{Androgens}

The rationale for considering androgens to be involved in aggressive behavior is that males have both higher concentrations of androgens and higher levels of aggressive behavior than females. Although an association between androgens and aggression has been clearly established in animals (e.g., Higley et al., 1996), the evidence in humans is less clear cut (Archer, 1991; Archer, Graham-Kevan, \& Davies, 2005). In adults, elevated testosterone levels in cerebrospinal fluid (CSF), plasma, and saliva have been linked to antisocial behavior and violent crime (e.g., Banks \& Dabbs, 1996; Dabbs, Frady, Carr, \& Besch, 1987; Dabbs, Jurkovic, \& Frady, 1991; Dabbs \& Morris, 1990; Ehrenkranz, Bliss, \& Sheard, 1974; Virkkunen et al., 1994). Studies of children and adolescents have yielded mixed results (e.g., Granger et al., 2003; Maras et al., 2003). Although testosterone levels in older adoles- cents (17-18 years) have sometimes been reported to be higher in aggressive individuals (Dabbs, Jurkovic, \& Frady, 1991; Scerbo \& Kolko, 1994), several studies of prepubertal children have not found a relationship between aggression and testosterone (Constantino et al., 1993; Van Goozen, Matthys, Cohen-Kettenis, Thijssen, \& Van Engeland, 1998). Moreover, lower levels of testosterone have been found in children at risk for substance abuse (Dawes et al., 1999). Furthermore, recent evidence indicates that testosterone levels are related to social dominance, rather than aggression per se (Mazur \& Booth, 1998; Rowe, Maughan, Worthman, Costello, \& Angold, 2004). Thus, high testosterone levels may be associated with peer group leadership, both within groups of healthy children and within antisocial groups, such as gangs (Rowe et al., 2004).

In prepubertal children, an important part of the androgenic activity is of adrenal rather than gonadal origin. From around the age of 6 , children exhibit a gradual increase in androgens of adrenal origin, a period called the adrenarche (C. R. Parker, 1999), and it is not until puberty that gonadal androgens, such as testosterone, become important. Therefore, it is quite likely that the testosterone-aggression relationship does not emerge until after puberty, and research in prepubertal children should therefore also focus on adrenal androgens, such as DHEA, its sulfate (DHEA-S) and androstenedione. Higher levels of DHEA-S have been found in both child and adolescent patients with CD (Dmitrieva, Oades, Hauffa, \& Eggers, 2001; Van Goozen, Matthys, Cohen-Kettenis, Thijssen, \& Van Engeland, 1998; Van Goozen, Van den Ban, et al., 2000). However, there are also studies that have not found differences in DHEA-S between aggressive and nonaggressive children (Constantino et al., 1993).

The positive relationship observed between DBD symptoms and plasma levels of DHEA-S is of interest because DHEA-S has $\mathrm{GABA}_{\mathrm{A}}$ antagonistic (i.e., neuroexcitatory) actions and could contribute to increased aggression (Majewska, Demirgoren, Spivak, \& London, 1990). It is also possible that higher DHEA-S levels add to a larger pool of endogenous testosterone. The results of the few studies conducted so far demonstrate that adrenal androgen functioning is an important topic for future research on the origins of aggression in children.

\section{HPA Axis Hormones}

The stress system has its peripheral limbs in the HPA axis and the sympathetic adrenal medullary systems. Psychological stress associated with various life events has been widely studied with respect to the concentration and secretion of the adrenal stress hormone cortisol. Events generally found to be stressful, as defined by an increase in cortisol, include anticipation of the death of a family member, hospital admission, surgery, mental performance tests, public speaking, and anticipation of strenuous exercise (L. N. Parker, 1989). However, considerable individual variation in cortisol reactivity is evident in most studies. The intensity and duration of a stress response and its long-term consequences appear to depend on the degree of stressor controllability, as perceived by the individual (Huether, 1996).

Adrenal cortisol secretion represents the final step in a neuroendocrine cascade beginning in the paraventricular nucleus (PVN) of the hypothalamus. In response to activation by limbic, cortical, and other afferent inputs, $\mathrm{CRH}$ is released into the portal venous 
system by the PVN. CRH stimulates the release of ACTH from the anterior pituitary. The release of ACTH, in turn, leads to activation of the adrenal glands, resulting in the synthesis and release of cortisol. Once secreted into general circulation, cortisol acts on a variety of target cells to mobilize the physiological response to stress. Cortisol also crosses the blood-brain barrier to act at sites in the central nervous system, where it activates negative feedback mechanisms that inhibit the release of $\mathrm{CRH}$ and $\mathrm{ACTH}$, thereby reducing HPA axis activity (e.g., Chrousos \& Gold, 1992).

The HPA system has a diurnal rhythm. Cortisol is secreted in pulses, and the frequency of these pulses varies with time of day, the highest frequency being in the early morning, resulting in high early-morning levels (Deuschle et al., 1997). As the day progresses, the pulses become less frequent and cortisol levels therefore decrease. The HPA system in children reaches functional maturity by the 4th year of life (Genazzani et al., 1983; Herman, Arthur-Smith, Hammock, \& Josephs, 1988), although recent experimental studies have observed a normal circadian rhythm in 12to 18-month-old infants (Goldberg et al., 2003).

\section{HPA Axis and Aggression}

Studies of antisocial adults have observed a negative relationship between cortisol levels and the magnitude of behavioral deviation (e.g., Bergman \& Brismar, 1994; Virkkunen, 1985; Woodman, Hinton, \& O'Neill, 1978). Lower levels of cortisol could mean that these individuals are physiologically underaroused (see Arousal Theories of Aggression section, below), that the negative feedback mechanisms acting on their HPA axes are hypersensitive, or that they have an increased threshold for stress (Kruesi, Schmidt, Donnelly, Hibbs, \& Hamburger, 1989). Most studies have focused on cortisol levels as an index of HPA axis activity. Although the measurement of cortisol provides important information in this respect, cortisol is secreted by the adrenal cortex and therefore reflects a relatively late response. Only four studies have measured ACTH or CRH in aggressive or antisocial individuals. Virkkunen and Linnoila (1993) and Virkkunen et al. (1994) found lower levels of ACTH in the CSF of alcoholic, impulsive offenders with an APD compared with healthy control participants, and they found no differences in CSF CRH levels. Susman et al. (1999) reported that CRH levels were lower in pregnant teenage mothers with DBDs compared with teenage mothers without symptoms of DBD. In contrast, Dmitrieva et al. (2001) found higher plasma ACTH levels in adolescents with CD.

Measuring ACTH and CRH for scientific purposes is challenging because the sampling has to be performed in plasma or CSF. Given the low tolerability of the measurement procedures involved, particularly lumbar puncture for ascertainment of CSF samples, and the accompanying ethical issues, relatively few studies have examined the role of these parameters in childhood aggression. However, given the importance of the HPA axis system in psychopathology in general, and antisocial behavior in particular, it will in future be necessary to develop methods of studying the influence of these higher level peptides and hormones.

\section{Empirical Findings in Children}

Few studies have been conducted on cortisol levels or the cortisol response to stress in aggressive children, and there have been equivocal findings across studies (see Table 2). Some studies have found associations between reduced basal cortisol concentrations and aggressive behavior (Kariyawasam, Zaw, \& Handley, 2002; McBurnett, Lahey, Rathouz, \& Loeber, 2000; Oosterlaan, Geurts, Knol, \& Sergeant, 2005; Pajer, Gardner, Rubin, Perel, \& Neal, 2001; Shoal, Giancola, \& Kirillova, 2003; Van de Wiel, Van Goozen, Matthys, Snoek, \& Van Engeland, 2004; Vanyukov et al., 1993); other studies found no such relationship (Azar et al., 2004; Kruesi et al., 1989; Scerbo \& Kolko, 1994; Schulz, Halperin, Newcorn, Sharma, \& Gabriel, 1997; Stoff et al., 1992; Van Goozen, Matthys, Cohen-Kettenis, Buitelaar, \& Van Engeland, 2000) or even a positive relationship (Van Bokhoven, Van Goozen, et al., 2005). There have also been studies that found associations between reduced basal cortisol concentrations and aggression toward peers (Tennes, Kreye, Avitable, \& Wells, 1986) and hostility towards teachers (Tennes \& Kreye, 1985) in healthy school children. Interestingly, McBurnett et al. (1991) found that anxious children with $\mathrm{CD}$ had higher cortisol levels than did children with $\mathrm{CD}$ alone.

In the majority of studies referred to above, the findings have been correlational in nature, with the result that it has not been possible to draw causal inferences between low cortisol concentrations and antisocial behavior. There have been very few studies with a design capable of showing that low cortisol levels precede the onset of antisocial or aggressive behavior and can therefore be used to predict which individuals will exhibit a pervasive pattern of antisocial behavior throughout adolescence and into young adulthood. The study that comes closest to demonstrating a longitudinal, albeit noncausal, link between low cortisol levels and aggressive behavior is that of Shoal et al. (2003). This was a 5-year longitudinal study investigating the relationship between cortisol concentrations at ages 10-12 years and aggressive behavior, as measured using the Youth Self-Report Scale (Achenbach, 1991), at ages 15-17 years. The results showed that low cortisol was moderately predictive of aggressive behavior 5 years later and, further, that this relationship appeared to be mediated by the effects of cortisol on a personality variable the authors termed low self control (Shoal et al., 2003). A further study with a longitudinal component was performed by McBurnett et al. (2000). They demonstrated that clinic-referred boys with consistently low cortisol levels in samples obtained 2 years apart showed the highest levels of aggressive CD symptoms over time. A limitation of this study was that it failed to control for the time of saliva collection.

Another point of interest is that basal glucocorticoid concentrations have been reported to be moderately heritable in humans (Inglis et al., 1999; Meikle, Stringham, Woodward, \& Bishop, 1988), so it seems unlikely that basal cortisol levels could fall after the onset of antisocial behavior. Finally, it should be noted that parental antisocial personality symptom counts have been shown to be inversely related to cortisol concentrations in their children (Vanyukov et al., 1993). This suggests that cortisol may be involved in the intergenerational transmission of antisocial behavior and provides further indirect evidence that this steroid plays a role in the etiology of antisocial behavior.

In addition to the difficulties arising from the correlational nature of the majority of studies, another feature of research in this area is that results have been relatively mixed. This may be due to the use of different methods for collecting cortisol (salivary vs. plasma vs. urinary free cortisol, and under basal conditions vs. 
Table 2

Studies on the Relationship Between Hypothalamic-Pituitary-Adrenal (HPA) Axis Indices in Aggressive Children and Adolescents

\begin{tabular}{|c|c|c|c|c|c|}
\hline \multirow[b]{2}{*}{ Study } & \multirow[b]{2}{*}{ HPA axis index } & \multicolumn{3}{|c|}{ Participants } & \multirow[b]{2}{*}{ Outcome } \\
\hline & & Sample & $\begin{array}{l}\text { Mean age } \\
\text { (years) }\end{array}$ & $\begin{array}{l}\text { Age range } \\
\text { (years) }\end{array}$ & \\
\hline Kruesi et al. (1989) & Urinary cortisol & $\begin{array}{l}19 \mathrm{ADHD} / \mathrm{CD} / \mathrm{ODD} \text { boys } \\
19 \mathrm{HC} \text { boys }\end{array}$ & $\begin{array}{l}10.5 \\
10.5\end{array}$ & & No differences \\
\hline McBurnett et al. (1991) & Saliva cortisol & 67 clinic-referred $\mathrm{CD}$ boys & & $8-13$ & $\mathrm{CD} / \mathrm{ANX}+>\mathrm{CD} / \mathrm{ANX}-$ \\
\hline Stoff et al. (1992) & Plasma cortisol & $\begin{array}{l}8 \text { male adolescent DBD boys } \\
8 \text { male adolescent HC boys }\end{array}$ & $\begin{array}{l}14.7 \\
15.3\end{array}$ & & No differences \\
\hline Vanyukov et al. (1993) & Saliva cortisol & $\begin{array}{l}78 \text { boys with PSUD father; } \\
72 \text { boys with HC father }\end{array}$ & & $10-12$ & $\begin{array}{l}\text { Negative correlation with } \mathrm{CD} \text { symptom } \\
\text { count }\end{array}$ \\
\hline Scerbo \& Kolko (1994) & Saliva cortisol & 40 clinic-referred DBD boys & & $7-14$ & $\begin{array}{l}\text { Negative correlation with inattention/ } \\
\text { overactivity; positive correlation } \\
\text { with internalizing behavior }\end{array}$ \\
\hline Moss et al. (1995) & $\begin{array}{l}\text { Saliva cortisol } \\
\text { Stress }\end{array}$ & $\begin{array}{l}81 \text { boys with PSUD father; } \\
103 \text { boys with HC father }\end{array}$ & & $10-12$ & $\begin{array}{l}\text { Boys with PSUD father (higher } \\
\text { aggressive and delinquency) }<\text { boys } \\
\text { with HC father }\end{array}$ \\
\hline Schulz et al. (1997) & Plasma cortisol & $\begin{array}{l}50 \text { clinic-referred ADHD boys: } \\
23 \text { aggressive } \\
27 \text { nonaggressive }\end{array}$ & $\begin{array}{l}9.0 \\
9.0\end{array}$ & & No differences \\
\hline $\begin{array}{l}\text { Van Goozen, Matthys, } \\
\text { Cohen-Kettenis, } \\
\text { Gispen-de Wied, et al. } \\
\text { (1998) }\end{array}$ & $\begin{array}{l}\text { Saliva cortisol } \\
\text { Stress }\end{array}$ & $\begin{array}{l}21 \text { ODD boys } \\
31 \text { HC boys }\end{array}$ & $\begin{array}{r}10.2 \\
9.6\end{array}$ & & $\begin{array}{l}\text { ODD }<\mathrm{NC} \text {; cortisol increase during } \\
\text { stress strongest in HE/HA; cortisol } \\
\text { decrease strongest in HE/LA }\end{array}$ \\
\hline Moss et al. (1999) & $\begin{array}{l}\text { Saliva cortisol } \\
\text { Stress }\end{array}$ & $\begin{array}{l}120 \text { boys with PSUD father } \\
178 \text { boys with HC father }\end{array}$ & $\begin{array}{l}10.8 \\
11.0\end{array}$ & & $\begin{array}{l}\text { Boys with PSUD father }<\text { boys with } \\
\text { HC father: cortisol response prior to } \\
\text { evoked related potential testing }\end{array}$ \\
\hline McBurnett et al. (2000) & $\begin{array}{l}\text { Saliva cortisol 2- } \\
\text { year follow-up }\end{array}$ & 38 clinic-referred DBD boys & & $\begin{array}{l}7-12 \text { (at } \\
\text { entry) }\end{array}$ & $\begin{array}{l}\text { Correlation between low cortisol and } \\
\text { persistence/early onset aggression }\end{array}$ \\
\hline $\begin{array}{l}\text { Van Goozen, Matthys, et } \\
\text { al. (2000) }\end{array}$ & $\begin{array}{l}\text { Saliva cortisol } \\
\text { Stress }\end{array}$ & $\begin{array}{l}26 \text { DBD children } \\
26 \mathrm{HC} \text { children }\end{array}$ & $\begin{array}{l}10.1 \\
10.0\end{array}$ & & $\begin{array}{l}\text { Baseline: DBD = HC } \\
\text { Stress: } \mathrm{DBD}<\mathrm{HC}\end{array}$ \\
\hline Dmitrieva et al. (2001) & Plasma ACTH & $\begin{array}{l}28 \text { CD boys } \\
13 \text { HC boys }\end{array}$ & $\begin{array}{l}13.2 \\
13.9\end{array}$ & & $\mathrm{CD}>\mathrm{NC}$ \\
\hline Pajer et al. (2001) & Plasma cortisol & $\begin{array}{l}47 \mathrm{CD} \text { girls } \\
37 \mathrm{HC} \text { girls }\end{array}$ & $\begin{array}{l}16.6 \\
16.0\end{array}$ & & $\mathrm{CD}<\mathrm{NC}$ \\
\hline $\begin{array}{l}\text { Kariyawasam et al. } \\
\text { (2002) }\end{array}$ & Saliva cortisol & $\begin{array}{l}32 \mathrm{ODD} / \mathrm{ADHD} \\
25 \mathrm{HC}\end{array}$ & $\begin{array}{l}10.6 \\
11.3\end{array}$ & & $\begin{array}{l}\text { ODD/ADHD (without stimulant } \\
\text { medication) }<\text { HC }\end{array}$ \\
\hline Shoal et al. (2003) & $\begin{array}{l}\text { Saliva cortisol } \\
\text { 5-year follow-up }\end{array}$ & 314 HC boys & & $10-12$ & $\begin{array}{l}\text { Low cortisol related to low self-control } \\
\text { and more aggressive behavior } 5 \\
\text { years later }\end{array}$ \\
\hline Snoek et al. (2004) & $\begin{array}{l}\text { Saliva cortisol } \\
\text { Stress }\end{array}$ & $\begin{array}{l}26 \mathrm{HC} \\
15 \mathrm{ODD} \\
31 \mathrm{ODD} / \mathrm{ADHD} \\
23 \mathrm{ADHD}\end{array}$ & & & $\begin{array}{l}\text { Baseline: no differences } \\
\text { Stress: } \mathrm{HC}=\mathrm{ADHD}>\mathrm{ODD}= \\
\text { ODD } / \mathrm{ADHD}\end{array}$ \\
\hline Van de Wiel et al. (2004) & $\begin{array}{l}\text { Saliva cortisol } \\
\text { Stress and treatment } \\
\quad \text { follow-up }\end{array}$ & 22 DBD children & & & $\begin{array}{l}\text { Low baseline cortisol related to more } \\
\text { severe DBD; low cortisol stress } \\
\text { response related to less improvement } \\
\text { after intervention }\end{array}$ \\
\hline Oosterlaan et al. (2005) & Saliva cortisol & $\begin{array}{l}25 \text { children varying in levels of } \\
\text { antisocial behavior }\end{array}$ & & $6-12$ & $\begin{array}{l}\text { High (aggressive) CD symptom } \\
\text { severity associated with low cortisol }\end{array}$ \\
\hline $\begin{array}{l}\text { Van Bokhoven, Van } \\
\text { Goozen, et al. (2005) }\end{array}$ & Saliva cortisol & 194 male youths & 13 & & $\begin{array}{l}\text { Higher cortisol in CD boys }(n=19) \text {; } \\
\text { higher cortisol in physically } \\
\text { aggressive boys }(n=75) \text {; higher } \\
\text { cortisol in high reactive aggressive } \\
\text { boys }(n=39)\end{array}$ \\
\hline
\end{tabular}

Note. $\mathrm{ADHD}=$ attention-deficit/hyperactivity disorder; $\mathrm{CD}=$ conduct disorder; $\mathrm{ODD}=$ oppositional defiant disorder; $\mathrm{HC}=$ healthy control subjects; $\mathrm{ANX}=$ anxiety; DBD = disruptive behavior disorder; PSUD = psychoactive substance use disorder; HE = high externalizing; HA = high anxiety; LA = low anxiety; $\mathrm{ACTH}=$ adrenocorticotropic hormone.

during stress), different definitions of antisocial behavior or aggression, and varying methods of assessing antisocial behavior (self-report vs. multiple informants, and using structured or semistructured diagnostic interviews, questionnaires, or police records). A large number of studies made only a single measurement of cortisol concentration, which is particularly problematic if they failed to control for the time of day of saliva or plasma collection. In addition, several studies did not include a healthy control group or used only healthy children or clinical cases as participants (and therefore may have looked for variability within a narrowly de- 
fined group differing only moderately in terms of behavioral deviance). Given these limitations and methodological differences, it is noteworthy that studies have nevertheless reported convergent findings of an inverse relationship between cortisol levels and antisocial behavior.

Wherever possible, we calculated effect sizes for the studies cited above investigating the relationship between basal cortisol levels and DBD or aggressive symptoms, and we found the mean effect size across studies to be $d=-0.79$. However, this value is biased by a number of small studies with disproportionately large effect sizes; the weighted average effect size, taking into account the effect of each study's sample size, was considerably lower at $d=-0.40$. This indicates that there is, on average, a small to moderate effect size (Cohen, 1988) across studies in the direction of an inverse relationship between basal cortisol levels and DBD symptoms. The range of effect sizes for these studies was between 0.48 and -3.70 , indicating that there was a great deal of variability in terms of the direction and size of effects observed. This appears consistent with the suggestion that there were numerous methodological differences and variations in sample characteristics between studies. Unfortunately, for three studies (McBurnett et al., 1991, 2000; Susman et al., 1999) we could not calculate the effect sizes because they did not provide values for the means or standard deviations of the respective groups' basal cortisol values, or they did not report a correlation (or $R^{2}$ equivalent) value for the relationship between cortisol and ODD/CD symptoms. It should also be noted that the correlation value used to yield an effect size for Scerbo and Kolko (1994) was that for the relationship between cortisol and staff-rated oppositional behavior; the other correlations between cortisol and measures of aggressive behavior (e.g., parent ratings) were not significant.

Findings of reduced basal levels of cortisol in antisocial individuals could support the stimulation-seeking theory (see below). This suggests that antisocial children seek out stressful situations, for example fights, to increase their aversive, low basal cortisol levels. On the other hand, the more often such children get involved in dangerous or stressful situations, the more likely they are eventually to habituate to these stimuli and subsequently show a blunted cortisol response to stress. The effect of frequent exposure (i.e., habituation) but also a lack of anticipatory fear, as suggested by the fearlessness theory (see below), would be better studied under stressful conditions.

Moss and colleagues found that at-risk sons of fathers with a psychoactive substance use disorder secreted less cortisol in anticipation of stress (Moss, Vanyukov, \& Martin, 1995; Moss, Vanyukov, Yao, \& Kirillova, 1999). In two psychological challenge studies, Van Goozen, Matthys, Cohen-Kettenis, Gispen-de Wied, et al. (1998) and Van Goozen, Matthys, et al. (2000) found that children with ODD had lower cortisol levels than did healthy control participants when exposed to frustration and provocation. Specifically, the latter study reported that children with ODD and healthy control subjects did not differ in terms of baseline cortisol levels, but the stress-induced increase in saliva cortisol observed in the control group was absent in the ODD group. Although increased cortisol stress reactivity has also been found in relation to aggressive behavior, this has been reported in only healthy subjects and community samples (Gerra et al., 1997; Scarpa, Fikretoglu, \& Luscher, 2000). These results suggest that a pattern of low cortisol reactivity during stress is a specific characteristic of antisocial patients (CD/ODD) and is not related to aggressive behavior per se. Indeed, Snoek, Van Goozen, Matthys, Buitelaar, and Van Engeland (2004) found that child psychiatric patients suffering from ADHD showed a typical stress-induced cortisol response, whereas children with DBD did not.

The effect size value for cortisol reactivity across the four studies that have investigated this (Van Goozen, Matthys, CohenKettenis, Gispen-de Wied, et al., 1998; Van Goozen, Matthys, et al., 2000; Moss et al., 1995, 1999) is $d=0.57$, which corresponds to a moderate effect size (after correcting for sample size the weighted mean effect size is $d=0.42$ ). The effect sizes for the group effects in Van Goozen and colleagues' (Van Goozen, Matthys, Cohen-Kettenis, Gispen-de Wied, et al., 1998; Van Goozen, Matthys, et al., 2000) studies, which used a stressor involving competition, social evaluation, and achievement stress were 0.98 (large effect) and 0.61 (moderate effect), respectively, whereas Moss et al. $(1995,1999)$ had smaller effect sizes $(d s=0.32$ and 0.36 , respectively), probably because the studies used a large, heterogeneous sample (the sons of fathers who had drug problems) and a relatively weak stressor.

It is known that children with DBD have often been exposed to adverse rearing circumstances involving neglect, abuse, and domestic violence, but it is of course also true that their own problem behavior elicits negative responses from peers, siblings, and parents, which might be experienced as stressful (Kazdin, 1995). It could be that frequent exposure to stressful situations has resulted in a habituation among these children to (some types) of stress, and as a result, they show low stress reactivity. In this context, it is important to study the individual interpretation of the stressful event to find out whether the subjective experience of the antisocial children is in line with their physiological experience. In two studies, antisocial children, who did not show a cortisol response during stress, reported and showed intense emotions (i.e., they reacted more aggressively towards their opponent), suggesting a mismatch between subjective and physiological arousal (Snoek et al., 2004; Van Goozen, Matthys, et al., 2000).

A recent study showed that antisocial children with a blunted or absent cortisol response to stress showed the least improvement following a therapeutic intervention (Van de Wiel et al., 2004). Children with similar levels of externalizing behaviors to the cortisol nonresponders, but who exhibited relatively typical cortisol responses in a stressful situation, were found to respond more favorably to treatment. These findings show that, despite manifesting similar levels of aggressive or oppositional behavior as did their disruptive peers, the children with attenuated HPA axis reactivity had a poorer prognosis. These data can be interpreted in two ways: First, children with HPA axis dysfunction simply have a more serious and ingrained form of the disorder, despite showing similar rates of externalizing behavior as their peers, or second, impairment of HPA axis functioning may prevent the types of cognitive or emotional processing that play a critical role in the therapeutic process. The latter interpretation suggests that children with early-onset antisocial behavior and either low basal cortisol levels or attenuated cortisol reactivity may be more effectively treated using pharmacologically based therapies that reinstate typical HPA axis functioning, perhaps as a precursor or an adjunct to psychological forms of treatment. 


\section{Interactions Between Cortisol and DHEA in Antisocial Children}

Although there is evidence that baseline cortisol levels and cortisol reactivity are reduced and DHEA-S levels are elevated in children with DBD (Van Goozen, Matthys, et al., 2000; Van Goozen, Matthys, Cohen-Kettenis, Gispen-de Wied, et al., 1998; Van Goozen, Matthys, Cohen-Kettenis, Thijssen, \& Van Engeland, 1998; Van Goozen, Van den Ban, et al., 2000), it is worth noting that there appear to be important functional interactions between these adrenal steroids in the CNS. In particular, DHEA appears to moderate some of the effects of cortisol, and it may even antagonize its effects in some brain areas, such as the hippocampus (Kimonides, Spillantini, Sofroniew, Fawcett, \& Herbert, 1999). It is therefore important to examine the interactions between these hormones in antisocial children. This approach has paid dividends in the study of adolescent depression, in which it has been found that an elevated cortisol/DHEA ratio predicts the onset of persistent depression (Goodyer, Herbert, \& Tamplin, 2003). The absolute levels of cortisol were found to be less important than the ratio between levels of cortisol and DHEA-S, leading to suggestions that depression might be associated with a syndrome of functional hypercortisolaemia, in which moderate increases in cortisol levels are amplified by reductions in the hormones that antagonize some of the effects of cortisol. DBDs may be associated with the reverse syndrome, a functional hypocortisolaemia, in which the effects of reduced cortisol levels are exacerbated by increases in DHEA-S concentrations.

\section{Stress-Induced and Pathological Aggression: Animal Research}

Stress is a primary factor in promoting aggression and violence in humans. Indeed, recent studies have suggested that aggression is associated with both stress and increased cortisol levels (Gerra et al., 1997). However, how stress mechanisms and the mechanisms involved in aggression interact on a neurobiological level has only recently received attention. Kruk, Halasz, Meelis, and Haller (2004) demonstrated a fast positive feedback loop between the adrenocortical stress response and the brain area that controls aggression, that is, the hypothalamus. Specifically, stimulation of the aggressive area in the hypothalamus rapidly activated the HPA axis, even in the absence of an opponent or in the context of physical fighting. Hypothalamic aggression was also quickly facilitated by an injection of corticosterone. The authors concluded that this fast, mutual, positive feedback system could contribute to the precipitation and the escalation of violent behavior under stressful conditions (Kruk et al., 2004). These findings have clear implications for aggression regulation and treatment. Hypothalamic aggression is selectively sensitive to serotonergic medication and the beta-blocker propranolol. Alternatively, regulation of the adrenocortical stress response with CRF antagonists or certain anxiolytics, which reduce different stress-induced behaviors, may be effective in counteracting acute stress-precipitated violence (Kruk et al., 2004).

Thus in healthy animals and humans, aggression is potentiated by high levels of arousal, an effect that is partly mediated by elevations in corticosteroid concentrations. In this respect this type of aggression can be thought of as reactive. However, we earlier reviewed evidence that pathological or persistent and deviant forms of aggression seem to be related to a reduced functioning of the HPA axis. How can these apparently opposing findings be reconciled? Haller and colleagues (Haller, Halász, Mikics, \& Kruk, 2004; Haller, van de Schraaf, \& Kruk, 2001) have developed a hypoarousal-driven aggression model in animals, which is intended to mimic human pathological aggression, specifically the consequences of chronically low levels of cortisol as observed in highly violent or psychopathic adults and aggressive children with CD. In this hypoarousal model, the animal behaves in a predatory fashion and appears to interpret the presence of any conspecific, even a much smaller animal that does not represent an equal opponent, as a threat. Haller and colleagues showed that although the central amygdala is not involved in aggression relating to hyperarousal (i.e., escalation of aggression in healthy, intact animals), it is strongly activated in the glucocorticoid deficient animal during fighting situations (see Figure 2). This may explain such animals' aberrant behavior and their evaluation of social situations as more threatening than is justified.

Specifically, Haller et al. (2001) removed the adrenal glands of rodents and implanted slow-release pellets to provide a continuous, low level of corticosterone (the main glucocorticoid hormone in rodents). Using this model of glucocorticoid deficiency, Haller and colleagues showed that rats with low concentrations of circulating corticosterone exhibit abnormal levels of aggressiveness and attempt to inflict the maximum amount of damage to a conspecific in a nonresident-intruder fighting situation (Halász, Liposits, Kruk, \& Haller, 2002; Haller et al., 2001, 2004). In normal circumstances, a resident animal confronted with a smaller intruder will provide threat cues to discourage the intruder from attempting to fight and will direct its blows to nonvulnerable areas of the body (Blanchard, Hori, Rodgers, Hendrie, \& Blanchard, 1989; Haller et al., 2001). In contrast, rats with glucocorticoid deficiency were shown to provide far fewer threat cues to the intruder and to direct the majority of their attacks to vulnerable parts of the opponent's body, such as the head, stomach, or neck (Haller et al., 2001). Acute injections of corticosterone prior to exposure to the fighting situation were shown to prevent this abnormal pattern of aggressive behavior. The authors concluded that an acute increase in cortisol is important in making the correct interpretation of the type of social conflict one is dealing with. If one fails to initiate an acute cortisol response, it may be more difficult to evaluate the true nature of the conflict.

In a subsequent study, Haller's group (Halász et al., 2002) investigated the neural background of glucocorticoid dysfunction in defensive aggression. They found that the abnormal behavior as shown by adrenalectomized rats did not involve activation of the brain areas that are normally involved in the control of aggression (cortex, amygdala, septum, hypothalamus, periaquaductal grey, and locus coeruleus). Instead, the brain areas involved in mediating the stress response (the parvocellular part of the PVN of the hypothalamus or pPVN) and fear reactions (central nucleus of the amygdala or CeA) were activated. Halász et al. (2002) concluded that abnormal aggressiveness due to glucocorticoid hypofunction is related to increased sensitivity to stressors and fear-eliciting stimuli, possibly in the sense that signals coming from the opponents are misinterpreted, resulting in a behavioral response that is characteristic of more critical situations.

How can these findings be applied to the human situation? First, we speculate that glucocorticoid hypofunction in antisocial children might enhance their fear reactions, resulting in an overreac- 


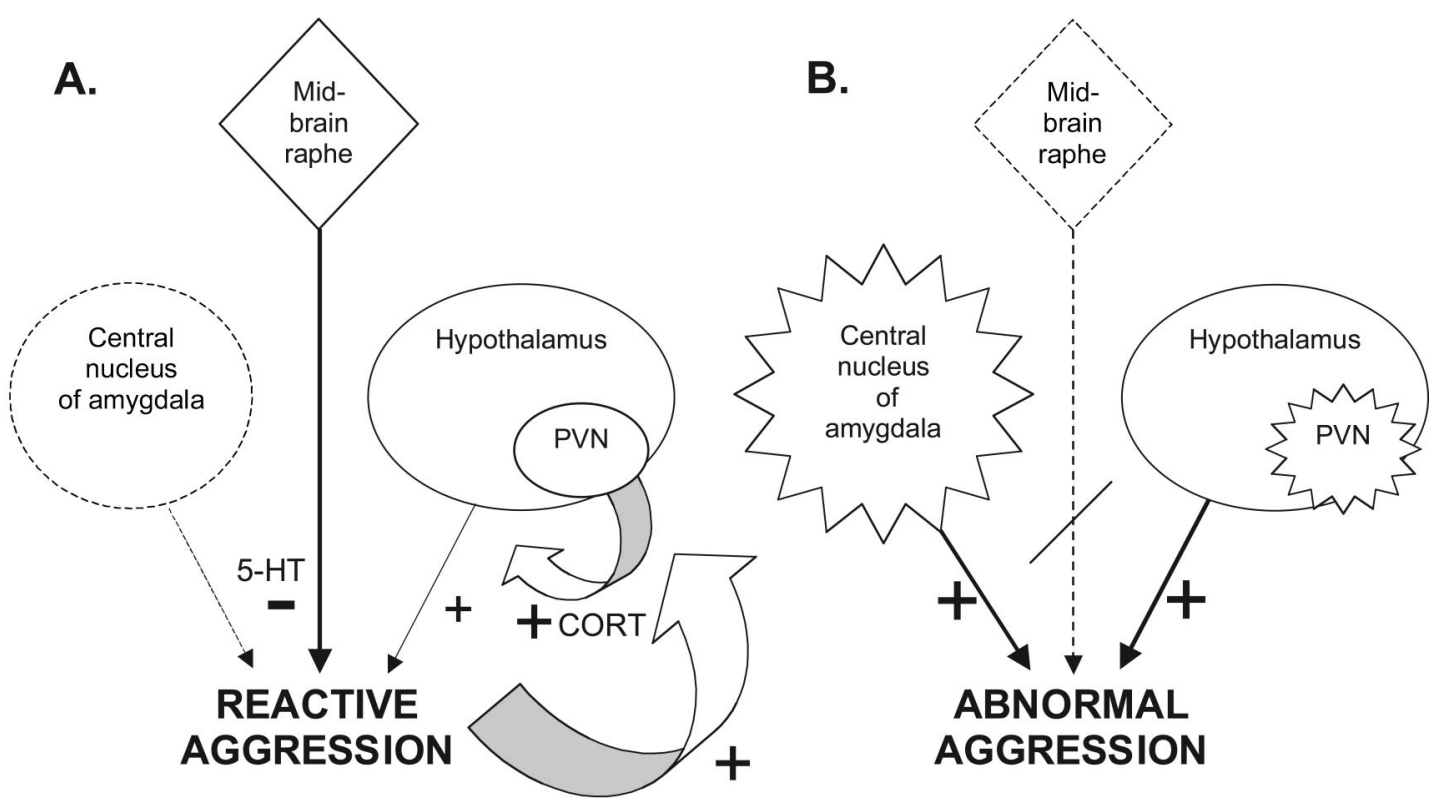

\begin{abstract}
Figure 2. Brain mechanisms thought to be involved in normal, reactive aggression (A) and abnormal forms of aggression (B) in the rat, according to Haller et al. (2005). In circumstances where reactive aggression is exhibited, there is an inverse relationship between serotonergic activity in the midbrain raphe and attack patterns towards non-vulnerable targets. This explains the efficacy of 5-HT enhancing drugs (such as SSRIs) in reducing reactive aggression. There is also a positive feedback loop between glucocorticoid secretion and reactive aggression, such that exposure to stressors increases the probability of aggressing. The very act of fighting is itself a stressor, leading to increased secretion of glucocorticoids. In contrast, glucocorticoid-deficient animals exhibit abnormal forms of aggression, fighting when they are far larger than their opponent and directing attacks towards vulnerable targets such as the head. Activity in neurons of the central nucleus of the amygdala and paraventricular nucleus $(\mathrm{PVN})$ of the hypothalamus is strongly enhanced while the restraining influence of raphe 5-HT neurons is removed. This lack of a relationship between 5-HT activity and abnormal aggression explains the failure of 5-HT-acting drugs to inhibit this form of aggression. Since 5-HT modulates the excitability of neurons in the amygdala, an effect that is glucocorticoid dependent, reduced efficacy of 5-HT to inhibit cellular activity may underlie the increased activation of the amygdala in glucocorticoid-deficient animals.
\end{abstract}

tion which could lead to abnormal aggression. Indeed, Van Goozen, Matthys, et al. (2000) showed that children with DBD, although showing no cortisol response to frustration and provocation, reported significantly more intense negative emotions than did healthy control participants and also responded more aggressively toward their opponent. Secondly, the animal findings fit with findings on social information-processing deficits in antisocial children: They appraise ambiguous or innocuous situations as threatening (e.g., Milich \& Dodge, 1984), they underestimate the risks involved in potentially dangerous situations, and they overestimate their chances of success in enacting aggressive responses (Matthys, Cuperus, \& Van Engeland, 1999). Moreover, evidence from an emotion recognition study shows that children with psychopathic tendencies exhibited a selective impairment in the recognition of fearful and sad facial expressions (Blair, Colledge, Murray, \& Mitchell, 2001). This is in line with behavioral research showing that antisocial individuals are insensitive to cues of threat or actual punishment (e.g., Newman \& Wallace, 1993; Van Goozen, Snoek, Matthys, Van Rossum, \& Van Engeland, 2004). Thus, antisocial children appear not only to interpret negative emotional situations incorrectly, leading to impulsive aggressive and hostile behavior, but they also fail to appraise the risks involved in displaying their aggressive behavior.
Although caution should be exercised in extrapolating from animal models to human behavior, it is possible to speculate that reduced basal cortisol levels and/or a failure in the ability of antisocial children to activate their HPA axis in response to stress may underlie their persistent aggressive behavior because they are oversensitive to stressful or fearful events, but at the same time do not take in (i.e., cognitively) or experience (physiologically) the negative consequences of their behavior. The animal studies also suggest that if a normal pattern of cortisol reactivity to stress were reinstated, this would reduce the level of aggression shown by children with DBDs. On the other hand, if it is true that one cause of HPA axis dysregulation relates to exposure to uncontrollable stress and unpredictable conflict, such as is the case in physical and sexual abuse or parental rejection, one can also see that a shutting down of the stress response may function as a protective mechanism in the cycle of violence.

\section{Glucocorticoids and Memory in Antisocial Children}

As well as playing an important role in the etiology of aggressive behavior, glucocorticoid deficiencies may also be involved in some of the learning and memory difficulties experienced by children with antisocial behavior (Moffitt \& Caspi, 2001; Raine et 
al., 2005; Vermeiren, De Clippele, Schwab-Stone, Ruchkin, \& Deboutte, 2002). Glucocorticoids modulate memory processes in a complex fashion, and while many studies have demonstrated that exogenous and endogenous glucocorticoids are capable of impairing some aspects of memory performance (de Quervain, Roozendaal, Nitsch, McGaugh, \& Hock, 2000; Kirschbaum, Wolf, May, Wippich, \& Hellhammer, 1996; Newcomer, Craft, Hershey, Atkins, \& Bardgett, 1994; Newcomer et al., 1999), there is also evidence that endogenous glucocorticoids are capable of enhancing memory performance under some conditions (Buchanan \& Lovallo, 2001; Sandi, Loscertales, \& Guaza, 1997; Shors, Weiss, $\&$ Thompson, 1992). This is particularly true when the memory tests in question involve the presentation of emotionally arousing material (Buchanan \& Lovallo, 2001). Furthermore, a recent study found improved memory performance in women who exhibited a noticeable cortisol response under test conditions, relative to those who did not show a cortisol increase (Domes, Heinrichs, Reichwald, \& Hautzinger, 2002). There are also several studies from the animal literature that demonstrate that corticosteroids exert a facilitatory effect on memory performance (Roozendaal, 2000), particularly involving aversive conditioning. Thus, the available evidence suggests that glucocorticoid deficiencies could adversely affect our learning and memory abilities, particularly under conditions that involve learning from punishment which are normally accompanied by high arousal states.

\section{Concluding Remarks on HPA Axis Activity in Aggressive Children}

Several studies support the notion that HPA axis activity is important in explaining the differences between disruptive, conduct-disordered, and nondisruptive children. In particular, early-onset forms of DBD seem to be associated with a blunted or absent cortisol response to stress and reduced basal cortisol secretion. However, there are some issues that require clarification.

First, it is not clear whether antisocial children are characterized by general hypoactivity of the HPA axis or whether their axis is specifically hyporesponsive during stress (or even during specific types of stressful situations, such as those involving aggression or threat). Future studies should characterize both basal cortisol levels and the cortisol response to stress within the same experimental design. With respect to basal cortisol levels, the assessment of the 24-hr cortisol rhythm would be the optimal strategy, because studies have generally assessed cortisol levels at a single point during the day (or even failed to control for the point in the diurnal cycle at which the plasma or saliva sample was taken). Thus, it is possible that negative findings in this respect merely reflect the choice of a sampling point at which hormone levels are similar across groups and that determination of hormone levels at a different time point would yield contrasting results (Pajer \& Gardner, 2004). In addition, studies characterizing the diurnal cycle of cortisol in children with DBD would be useful because they would provide indirect information about the mechanisms of negative feedback regulation operating in these individuals. For instance, it would also be instructive to examine the cortisol awakening response in these individuals (typically, salivary cortisol concentrations show a $50 \%-160 \%$ increase relative to waking levels within 30-45 min of awakening (Clow, Thorn, Evans, \& Hucklebridge, 2004), as one might expect a reduced, or more rapidly terminated, awakening response in DBD individuals because of the efficacy of their feedback mechanisms.

Second, the effects of different types of stressors (for example, shame, fear, or pain) on cortisol responsivity should be examined to ascertain whether attenuated cortisol responses to stress are a general feature of DBD, or whether they are specific to situations involving aggression. Third, HPA axis dysregulation has also been associated with other psychiatric disorders (such as major depressive disorder and posttraumatic stress disorder). Therefore, the diagnostic specificity of the pattern of HPA axis hypo(re)activity in persistently antisocial children should be investigated using different child psychiatric groups (see Snoek et al., 2004).

Fourth, although the measurement of salivary cortisol, as carried out in most studies, provides us with information on HPA axis reactivity, cortisol is secreted by the adrenals and therefore reflects a relatively late response. It would therefore be interesting to investigate the functioning of higher levels of the HPA axis, for example, at the level of the pituitary (ACTH) and/or the hypothalamus (CRH). This might be achieved through CRH challenge tests to examine the sensitivity of pituitary $\mathrm{CRH}$ receptors.

Finally, it is not clear whether interactions between DHEA-S and cortisol are altered in DBDs, although there is preliminary evidence that DHEA concentrations are elevated in children with antisocial behavior. Because the available evidence indicates that DHEA-S may moderate some effects of cortisol (Karishma \& Herbert, 2002) or even function to antagonize them (Kimonides et al., 1999), clarification of this relationship is important in understanding the biological foundations of early-onset antisocial behavior.

\section{The ANS}

The ANS, through its sympathetic and parasympathetic branches, regulates critical life functions on a moment-to-moment basis and governs the "fight or flight" reaction. In physiological terms, the parasympathetic nervous system is concerned with the conservation and restoration of energy; it causes a reduction in HR and blood pressure, and it facilitates digestion and absorption of nutrients, and consequently the excretion of waste products. In contrast, the sympathetic nervous system enables the body to prepare for fear, flight, or fight. Sympathetic responses include an increase in HR, blood pressure and cardiac output, a diversion of blood flow from the skin and splanchnic vessels to those supplying skeletal muscle, increased pupillary size, bronchiolar dilation, contraction of the sphincter, and metabolic changes such as the mobilization of fat and glycogen. Like other neurons, those of the ANS convey their messages to the appropriate end organs by releasing transmitter substances to which the receptors of the target cells are responsive. The most important of these transmitters are acetylcholine (parasympathetic) and norepinephrine ([NE] sympathetic).

\section{Arousal Theories of Aggression}

An extensive body of research has accumulated on ANS correlates of antisocial, delinquent, criminal, psychopathic, and violent behavior. In particular, SC and HR have frequently been used to assess the extent of autonomic arousal (Ortiz \& Raine, 2004; Raine, 1993, 1996). HR reflects both sympathetic and parasympa- 
thetic nervous system activity, unlike SC activity, which reflects only sympathetic processes. One influential psychophysiological theory of antisocial behavior is that antisocial individuals are chronically underaroused (Raine, 1993, 1996). There are two main theoretical interpretations of reduced arousal in antisocial individuals. The fearlessness theory claims that low levels of arousal are markers of low levels of fear (Raine, 1993). Fearless children are more likely to engage in physical fights to obtain rewards and social status because they are not concerned about the negative consequences of their aggressive actions (e.g., punishment by authority figures or physical injury).

A second theory of reduced arousal is the stimulation-seeking theory (Zuckerman, 1979), which argues that low arousal represents an aversive physiological state and that individuals with tonically low arousal levels seek out stimulation to raise their arousal to an optimal or normal level. According to this view, antisocial behavior is a form of sensation seeking, in that committing an assault, stealing a car, or perpetrating a robbery could be stimulating for certain individuals.

\section{Empirical Findings}

In a 9-year follow-up study, Raine, Venables, and Williams (1990) found significantly lower ANS (lower HR and SC) activity in adolescents who were convicted of crimes during the intervening period. Furthermore, a longitudinal study by the same group carried out in Mauritius demonstrated that low basal HR at age 3 years was consistently associated with increased aggressive behavior at age 11 (Raine, Venables, \& Mednick, 1997). However, there have also been studies that failed to demonstrate a relationship between HR and levels of aggressive or antisocial behavior (Fowles \& Furuseth, 1994; Raine \& Venables, 1984). The studies on children with CD reviewed by Lahey, McBurnett, Loeber, and Hart (1995) generally indicate lower levels of ANS activity in these children. Iaboni, Douglas, and Ditto (1997) also found lower levels of ANS activity in children with ADHD with or without CD/ODD. In one follow-up study, SC level was significantly negatively correlated with later institutionalization (Kruesi et al., 1992). A recent longitudinal study also showed that low basal SC level, measured in childhood, was the best predictor of poor outcome and serious antisocial behavior in adolescence, even within a study group who all met diagnostic criteria for DBD in childhood (Van Bokhoven, Matthys, Van Goozen, \& Van Engeland, 2005). However, Zahn and Kruesi (1993) found no evidence of lower ANS baselines in boys with CD/ODD and/or ADHD, although ANS reactivity was lower. Garralda, Connell, and Taylor (1991) studied patterns of SC and HR to sounds and situations with varying emotional and alertive connotations. They found that children with emotional disorders were particularly reactive to situations with aversive components, whereas children with $\mathrm{CD}$ showed enhanced reactivity to reward situations and lowered responses to neutral situations. In two studies, Van Goozen, Matthys, Cohen-Kettenis, Gispen-de Wied, et al. (1998) and Van Goozen, Matthys, et al. (2000) found that children with CD/ODD had lower baseline levels of HR and SC compared with healthy control children. The first study showed that HR levels during provocation and frustration were higher in the children with CD/ODD than in the control participants. In the second study, the importance of baseline levels of SCL was demonstrated by highly significant negative correlations with clinical measures of antisocial behavior. Of interest, autonomic hypoarousal is another characteristic of the glucocorticoid-deficiency model developed by Haller and colleagues (described above; Haller et al., 2001, 2004; see Figure 2). In addition to abnormal fighting patterns, these animals showed much smaller HR increases following exposure to a social stressor than controls (Haller et al., 2004). They also exhibited lower HR responses in a nonsocial stress test, the elevated-plus maze, which is thought to measure anxiety-like behavior. This appears consistent with the fearlessness interpretation of low autonomic activity in antisocial behavior.

Results of a recent meta-analysis indicate that low resting HR is one of the best-replicated biological markers of antisocial and aggressive behavior in childhood and adolescent community samples, with an average effect size of -0.44 from 40 independent studies comprising a total of 5,868 children (Ortiz \& Raine, 2004). The effect size for those studies measuring the increase in HR during a stressor was even greater in magnitude $(-0.76$ from 9 independent studies). There is also some indication that low HR is diagnostically specific to antisocial behavior, as no other psychiatric conditions have been linked to reduced HR. Further evidence for this assertion comes from studies that included a psychiatric control group: These yielded an effect size of -0.45 (Ortiz \& Raine, 2004). The low HR-aggression relationship also appears independent of any links with the comorbid condition of hyperactivity (Scarpa \& Raine, 1997). In another recent meta-analysis, Lorber (2004) found that conduct problems in children were associated with lower resting HR but increased HR reactivity. Conduct problems were also associated with lower levels of SC, both at rest and during task performance (Lorber, 2004). It is worth noting that conduct problems in adolescents were accompanied by a similar constellation of HR abnormalities, but no robust differences in SC levels were observed in this group. A final point of interest is that the pattern of autonomic deficits observed was quite different in children and adolescents with conduct problems, as compared with psychopathic adults, who showed reduced basal SC levels, reduced SC levels during task performance, and lower SC reactivity, but no consistent differences in resting $\mathrm{HR}$ or $\mathrm{HR}$ reactivity (Lorber, 2004). Thus, although there is some degree of continuity between CD in childhood/adolescence and APD or psychopathy in adulthood (Lynam, 1996), there are also important discontinuities in terms of the psychophysiological correlates of these conditions.

To summarize, these meta-analyses provide strong evidence that low resting HR and SC levels are robust correlates of antisocial behavior in children. There is less agreement regarding the direction of changes in HR reactivity or HR during stress, but lower SC levels during task performance are also consistently associated with conduct problems in children. Findings in adolescents appear to be restricted to HR changes, whereas studies of adult psychopaths fail to show consistent changes in HR but document a widespread pattern of reduced electrodermal activity.

\section{Neurotransmitters}

We now review the role of different neurotransmitters, in particular serotonin (5-HT), in antisocial behavior, again by first examining the evidence in adults with antisocial personality, before going on to present and critique relevant findings in children. 
This section ends with a discussion of the theoretical and clinical implications of these data. Although between 50 and 100 molecules have been identified as neurotransmitters in the CNS, only the monoamines (i.e., 5-HT, NE, and dopamine [DA]) have been systematically studied with respect to human aggression, and of these three monoamines, the most extensively studied is 5-HT. In this review, we only discuss the role of 5-HT in antisocial behavior. $^{1}$

\section{The Serotonergic System}

The 5-HT system is one of the most widely distributed neurotransmitter systems in the brain. The majority of 5-HT-containing neurons is localized along the midline of the brainstem and gives rise to long axons that innervate a huge variety of projection areas throughout the nervous system, from the spinal cord to the cortex. Forebrain 5-HT is derived almost entirely from neurons located in the dorsal and median raphe nuclei of the midbrain (Jacobs \& Azmitia, 1992). Prominent forebrain terminal regions include the hypothalamus, frontal cortex, hippocampus, amygdala, and striatum (Jacobs \& Azmitia, 1992; Lucki, 1998). The number of recognized 5-HT receptors has increased in the past 2 decades, reaching a total of 14 different receptors which have been classified into seven receptor families $\left(5-\mathrm{HT}_{1-7}\right)$ on the basis of their structural, functional, and to some extent, pharmacological characteristics (Barnes \& Sharp, 1999). Since the discovery of 5-HT in the brain, the amount of research on this neurotransmitter has expanded enormously. 5-HT has been shown to influence a broad range of physiological and psychological processes, such as cardiovascular function, respiration, and thermoregulation and a variety of behavioral functions, including circadian rhythm entrainment, the sleep-wake cycle, appetite, sexual behavior, sensorimotor reactivity, pain sensitivity, learning and aggression (Lucki, 1998). It is therefore not surprising that changes in the functioning of the 5-HT system are implicated in a wide range of psychiatric disorders. These disorders include depression, anxiety disorders, schizophrenia, and anorexia nervosa. In addition, a less-structured range of impulse-related disorders or personality features including aggression, substance abuse, and gambling have been associated with alterations of 5-HT function (Lucki, 1998).

\section{5-HT and Aggression}

In an influential thesis, Spoont (1992) argued that 5-HT stabilizes information processing in neural systems, resulting in controlled behavioral, affective, and cognitive output, whereas disturbances in 5-HT activity result in altered information processing tendencies. High levels of 5-HT were proposed to lead to excessive restraint, cognitive inflexibility and anxiety, whereas low levels were thought to lead to behavioral disinhibition and distractibility. Coccaro and Kavoussi (1996) proposed a model for impulsive aggression in which the threshold for aggressive action, given the proper environmental circumstances, is modulated by overall 5-HT system function. Diminished serotonergic function is thought to disinhibit aggression directed against the self and others, perhaps by sharpening sensitivity to stimuli that elicit irritation and aggression and blunting sensitivity to cues that signal punishment (Spoont, 1992). In addition, there appears to be a positive relationship between the degree of 5-HT system impairment and the severity of the aggression that is exhibited by the individual. It is therefore possible to speculate that 5-HT is involved in restraining prepotent impulses towards aggressive behavior. However, how 5-HT activity exactly influences aggressive or impulsive behavior in humans is not yet understood.

Returning to animal research, Haller, Mikics, Halasz, and Toth (2005) recently suggested that the role of serotonin could be different in normal and hypoarousal-driven aggression (see Figure 2). They showed that there was an inverse relationship between activation of 5-HT neurons in the dorsal raphe nucleus and attacks on nonvulnerable targets (offensive aggression), which is consistent with an inhibitory influence of 5-HT. In contrast, there was no relationship between 5-HT neuronal activation and attacks on vulnerable targets (this is considered an abnormal pattern of aggression consistent with defensive aggression or predator-like behavior). In addition, lesions of the raphe nuclei have been shown to modulate offensive but not defensive aggression (de Bruin, Van Oyen, \& Van de Poll, 1983). These findings are interesting because it is well known that serotonergic medication (effective in reducing aggression in certain personality disorders), has little or no effect on aggression in conduct and APDs (reviewed below). Haller et al. (2005) suggested that the reduced influence of 5-HT in hypoarousal-driven aggression could be due to the overriding effects of central amygdala activation or changes in prefrontal cortical functioning. Alternatively, it is possible that low glucocorticoid secretion impairs the functioning of the 5-HT system, which explains the low efficacy of raphe neurons in controlling aggression under these circumstances.

\section{Empirical Findings}

A substantial body of evidence has suggested that 5-HT plays a role in aggression directed towards others, other people's property (e.g., arson), and oneself (e.g., suicide). Clinical and preclinical studies together suggest that a decrease in 5-HT function relates to increased aggression (see Tuinier, Verhoeven, \& Van Praag, 1995, for a review of clinical findings; see Higley et al., 1992; Mehlman et al., 1994, for findings in nonhuman primates).

\section{CSF 5-HIAA}

Most neurochemical studies have found an inverse relationship between CSF 5-hydroxyindoleacetic acid (5-HIAA; a major metabolite of 5-HT) concentrations and aggressive behavior. Brown and colleagues were among the first to demonstrate low CSF

\footnotetext{
${ }^{1}$ Although biochemical studies in antisocial children (Kruesi et al., 1990, 1992; Rogeness, Javors, \& Pliszka, 1992) have not provided clear evidence of a relationship between NE or DA, on the one hand, and aggressive behavior, on the other, clinical findings have supported an involvement of these monoamines in aggressive behavior. One study (Klein et al., 1997) showed that methylphenidate, which stimulates the release of $\mathrm{NE}$ and $\mathrm{DA}$, reduced antisocial behavior reports in children with $\mathrm{CD}$ independent of ADHD symptoms. Moreover, the knowledge that the reward system in the brain and DA are implicated in the neurobiology of addiction (Dackis \& O'Brien, 2001) and that children with CD are at considerable risk of substance abuse (Kazdin, 1995) is consistent with an involvement of DA in the modulation of aggressive behavior in children. More research is needed to clarify the precise role of NE and DA in the instigation and regulation of aggressive behavior in children.
} 
5-HIAA levels in aggressive, personality-disordered subjects (Brown et al., 1982; Brown, Goodwin, Ballenger, Goyer, \& Major, 1979). Inverse relationships between CSF 5-HIAA and aggressive or violent behavior have been reported in a number of antisocial and both clinical and nonclinical samples, including alcoholic individuals (Limson et al., 1991), arsonists (Virkkunen, Nuutila, Goodwin, \& Linnoila, 1987), men who murder their sexual partners (Lidberg, Tuck, Asberg, Scalia-Tomba, \& Bertilsson, 1985), and research volunteers without psychopathology (Roy, Adinoff, \& Linnoila, 1988). It has been suggested that a deficit in 5-HT availability and/or turnover is mainly associated with impulsive forms of aggression. For example, Linnoila et al. (1983) found that impulsive violent offenders (with an APD) had lower CSF 5-HIAA levels than offenders who had committed nonimpulsive, premeditated acts of violence. However, there are also studies that failed to find an inverse relationship between CSF 5-HIAA levels and aggressive behavior in personality-disordered patients (Coccaro, Kavoussi, Cooper, \& Hauger, 1997).

To date, only three studies have measured 5-HIAA in CSF in children (Castellanós et al., 1994; Kruesi et al., 1990, 1992; see Table 3). Kruesi et al. (1990) found that children with DBD and/or ADHD had lower 5-HIAA levels compared with children suffering from obsessive-compulsive disorder. CSF 5-HIAA concentrations were also inversely correlated with ratings of aggressive behavior in the disruptive group. At the 2-year follow-up, CSF 5-HIAA levels were found to be a predictor of the severity of physical aggressive behavior and poor outcome (Kruesi et al., 1992). In contrast, Castellanós et al. (1994) found in their study of 29 boys with ADHD that CSF 5-HIAA levels were positively correlated with measures of aggression and impulsivity. The authors noted that their ADHD group was more hyperactive and less aggressive than the Kruesi et al. (1990) sample and speculated that 5-HT

Table 3

Studies on Central 5-Hydroxytryptamine (5-HT) Indices of Aggression in Aggressive Children and Adolescents

\begin{tabular}{|c|c|c|c|c|c|}
\hline \multirow[b]{2}{*}{ Study } & \multirow[b]{2}{*}{ 5-HT index } & \multicolumn{3}{|l|}{ Participants } & \multirow[b]{2}{*}{ Outcome } \\
\hline & & Sample & $\begin{array}{l}\text { Mean age } \\
\text { (years) }\end{array}$ & $\begin{array}{l}\text { Age range } \\
\text { (years) }\end{array}$ & \\
\hline $\begin{array}{l}\text { Kruesi et al. } \\
\quad(1990)\end{array}$ & CSF-5-HIAA & $\begin{array}{l}29 \text { ADHD, ODD or CD } \\
43 \text { OCD }\end{array}$ & & $\begin{array}{l}6.7-17.4 \\
6.5-19.8\end{array}$ & $\begin{array}{l}\text { ADHD, ODD, or CD }<\text { OCD; No correlation } \\
\text { with CBCL aggression; negative correlation } \\
\text { with DICA aggression }(r=-.40)\end{array}$ \\
\hline $\begin{array}{l}\text { Stoff et al. } \\
\quad(1992)\end{array}$ & $\begin{array}{l}\text { PRL response to } \\
\text { dl-fenfluramine }\end{array}$ & $\begin{array}{l}15 \text { male prepubertal } \mathrm{CD} / \mathrm{ODD} \pm \\
\mathrm{ADHD} \\
8 \text { male adolescent } \mathrm{CD} / \mathrm{ODD} \pm \\
\mathrm{ADHD} \\
8 \text { male adolescent } \mathrm{HC}\end{array}$ & $\begin{array}{l}10.2 \\
14.7 \\
15.3\end{array}$ & & $\begin{array}{l}\text { No differences, no correlations with } \\
\text { aggression ratings }\end{array}$ \\
\hline $\begin{array}{l}\text { Kruesi et al. } \\
\text { (1992) }\end{array}$ & CSF-5-HIAA & $\begin{array}{l}\text { 2-year prospective study of } 29 \\
\text { ADHD, ODD or CD }\end{array}$ & & & Predictive for physical aggression $(r=-.53)$ \\
\hline $\begin{array}{l}\text { Castellanós et } \\
\text { al. (1994) }\end{array}$ & $\begin{array}{l}\text { CSF, plasma, } \\
\text { urinary 5-HIAA }\end{array}$ & $\begin{array}{l}29 \text { boys with ADHD with or } \\
\text { without } \mathrm{CD} / \mathrm{ODD}\end{array}$ & 9.2 & & $\begin{array}{l}\text { Positive correlation between CSF-5-HIAA and } \\
\text { Brown-Goodwin scale for Aggression }(r= \\
\text {.42) and CBCL delinquency }(r=.42) \text { and } \\
\text { externalizing }(r=.38)\end{array}$ \\
\hline $\begin{array}{l}\text { Halperin et al. } \\
\text { (1994) }\end{array}$ & $\begin{array}{l}\text { PRL response to } \\
\text { dl-fenfluramine }\end{array}$ & $\begin{array}{l}25 \text { ADHD boys: } \\
10 \text { ADHD/aggressive and } \\
15 \text { ADHD/nonaggressive }\end{array}$ & $\begin{array}{l}8.6 \\
8.5\end{array}$ & & ADHD/aggressive $>$ ADHD/nonaggressive \\
\hline $\begin{array}{l}\text { Halperin et al. } \\
\text { (1997) }\end{array}$ & $\begin{array}{l}\text { PRL response to } \\
\text { dl-fenfluramine }\end{array}$ & $\begin{array}{l}25 \text { ADHD boys: } \\
13 \text { ADHD/aggressive and } \\
12 \text { ADHD/nonaggressive }\end{array}$ & $\begin{array}{l}9.5 \\
9.5\end{array}$ & & No differences \\
\hline $\begin{array}{l}\text { Pine et al. } \\
\quad(1997)\end{array}$ & $\begin{array}{l}\text { PRL reponse to } \\
\text { dl-fenfluramine }\end{array}$ & $\begin{array}{l}34 \text { younger brothers of convicted } \\
\text { delinquents: } 13 \text { CD/ODD, } 5 \\
\text { ADHD, } 16 \text { other psychiatric } \\
\text { diagnoses or no diagnosis }\end{array}$ & 10.0 & & $\begin{array}{l}\text { Positive correlation with CBCL aggression } \\
(r=.48) \text { and externalizing }(r=.47)\end{array}$ \\
\hline $\begin{array}{l}\text { Donovan et al. } \\
\text { (1999) }\end{array}$ & $\begin{array}{l}\text { Thermal response to } \\
\text { dl-fenfluramine }\end{array}$ & 27 ADHD prepubescent boys & & & $\begin{array}{l}\text { Negative correlation with teacher ratings of } \\
\text { aggression }\end{array}$ \\
\hline $\begin{array}{l}\text { Soloff et al. } \\
\quad(2000)\end{array}$ & $\begin{array}{l}\mathrm{PRL} / \mathrm{CORT} \\
\text { response to dl- } \\
\text { fenfluramine }\end{array}$ & $\begin{array}{l}36 \text { participants: } \\
18 \text { AUD, of whom } 9 \text { with comorbid } \\
\text { CD, and } 18 \mathrm{HC}\end{array}$ & $\begin{array}{l}19.4 \\
16.0\end{array}$ & & $\begin{array}{l}\text { No differences between AUD and HC; AUD } \\
\quad+\text { CD had elevated CORT response; CORT } \\
\text { response correlated positively with } \\
\text { measures of aggression }\end{array}$ \\
\hline $\begin{array}{l}\text { Schulz et al. } \\
\text { (2001) }\end{array}$ & $\begin{array}{l}\text { PRL response to } \\
\text { dl-fenfluramine }\end{array}$ & $\begin{array}{l}46 \text { boys: } \\
13 \text { nonaggressive ADHD } \\
28 \text { aggressive ADHD } \\
5 \text { aggressive without ADHD }\end{array}$ & $\begin{array}{r}9.3 \\
9.3 \\
10.4\end{array}$ & $7-11$ & No differences \\
\hline $\begin{array}{l}\text { Snoek et al. } \\
\quad(2002)\end{array}$ & $\begin{array}{l}\text { GH response to } \\
\text { sumatriptan }\end{array}$ & 35 children: $20 \mathrm{DBD}$ and $15 \mathrm{HC}$ & & $7-12$ & $\mathrm{DBD}>\mathrm{HC}$ \\
\hline
\end{tabular}

Note. 5 -hydroxytryptamine $=$ serotonin; $\mathrm{CSF}=$ cerebrospinal fluid; 5-HIAA $=5$-hydroxyindoleacetic acid; $\mathrm{ADHD}=$ attention-deficit/hyperactivity disorder; ODD = oppositional defiant disorder; $\mathrm{CD}=$ conduct disorder; $\mathrm{OCD}=$ obsessive compulsive disorder; DICA = Diagnostic Interview for Children and Adolescents; PRL $=$ Prolactin; $\mathrm{HC}=$ normal controls; $\mathrm{CBCL}=$ Child Behavior Checklist; CORT $=$ cortisol; $\mathrm{AUD}=$ alcohol use disorder; GH $=$ growth hormone; DBD = disruptive behavior disorder. 
measures may only correlate negatively with aggression in groups of children with a core aggression problem. These contrasting results on CSF 5-HIAA in different groups of externalizing children suggest that the 5-HT-aggression hypothesis could depend on various factors, including the severity of the aggressive behavioral problems and the precise characteristics of the sample (e.g., diagnostic status, age group).

\section{Peripheral Measures of 5-HT}

The advantages of peripheral measures of 5-HT function are that they are minimally invasive and therefore especially useful for research in children. Peripheral measurement strategies involve assaying whole blood 5-HT and measuring 5-HT receptors occurring on blood platelet cells (platelet imipramine or paroxetine binding site density). These latter elements appear to be similar to those in the brain and have been used as indexes of either preor postsynaptic central 5-HT receptor functioning (Berman, Kavoussi, \& Coccaro, 1997).

Platelet imipramine binding parameters in children with $\mathrm{CD}$ have been shown to be inversely correlated with aggressive behavior as measured by the Child Behavior Checklist (Birmaher et al., 1990; Stoff, Pollock, Vitiello, Behar, \& Bridger, 1987). These results are comparable with the negative relationship reported between platelet tritiated paroxetine binding and aggression in adult patients with personality disorder (Coccaro, Kavoussi, Sheline, Lish, \& Csernansky, 1996). However, in a further study, Stoff et al. (1991) failed to demonstrate this inverse relationship, possibly because of insufficient statistical power of the study or to the less severe CD symptomatology in the sample. Blumensohn et al. (1995) found lower platelet ketanserin binding in delinquent adolescents than in matched control participants, suggestive of either low density or low affinity of the platelet $5-\mathrm{HT}_{2 \mathrm{~A}}$ receptor. Pine et al. (1996) confirmed this finding of low density of $5 \mathrm{HT}_{2 \mathrm{~A}}$ receptors in boys whose parents had histories of either substance abuse or incarceration. These findings of low $5-\mathrm{HT}_{2 \mathrm{~A}}$ receptor binding contrast with the results of a study by Coccaro, Kavoussi, Sheline, Berman, and Csernansky (1997), which showed a positive relationship between $5-\mathrm{HT}_{2 \mathrm{~A}}$ receptor binding and self-reported assaultiveness in personality-disordered adults.

Moffitt et al. (1998) found support for a positive relationship between whole blood 5-HT and violence in an epidemiological study. Studies of aggressive children using whole-blood 5-HT assays have yielded mixed results: Some reported a negative correlation with aggression (Hanna, Yuwiler, \& Coates, 1995); others found higher levels or positive relationships with whole blood 5-HT (Hughes, Petty, Sheikha, \& Kramer, 1996; Pliszka, Rogeness, Renner, Sherman, \& Broussard, 1988; Unis et al., 1997) or no differences compared with healthy or psychiatric control participants (Cook, Stein, Ellison, Unis, \& Leventhal, 1995; Rogeness, Hernandez, Macedo, \& Mitchell, 1982; see Table 4). With respect to whole blood 5-HT, it is important to note that this 5-HT measure might be inversely related to CSF 5-HIAA (McBride et al., 1989). In two studies, Van Goozen, Matthys, Cohen-Kettenis, Westenberg, and Van Engeland (1999) found that plasma 5-HIAA was significantly lower in children with DBD than in healthy control children and strongly inversely correlated with aggression as observed by others and as elicited experimentally. A relatively recent study by Twitchell, Hanna, Cook, Fitzgerald, and Zucker
(2000) on children of alcoholic parents found that puberty moderated the relationship between 5-HT (whole blood 5-HT) and aggression, with a relationship found in pubescent children but not in prepubescent children.

Although these studies on various peripheral 5-HT measures provide evidence for a relationship with aggressive behavior, it is important to note that some authors have argued that peripheral measures of 5-HT functioning may not be related to central 5-HT measures (Mann, 1995). However, it could also be argued that if 5-HT dysfunction is a trait marker of aggression, and if it is caused by disorders in the synthesis or breakdown of 5-HT, it should also be readily apparent in peripheral measures (Van Goozen et al., 1999). Nevertheless, it is not entirely clear how the various peripheral 5-HT measures relate to each other and to indices of central 5-HT functioning. It is, therefore, difficult to compare the results of the different (central and peripheral) studies and to determine the direction of the relationship between 5-HT and aggressive behavior, particularly in children. Measuring peripheral and central 5-HT measures simultaneously in the same individuals should shed some light on this important issue.

\section{Pharmacological Challenge Studies}

Pharmacochallenge measurement techniques provide a useful alternative method of assessing the relationship between central 5-HT and aggression. Using a pharmacochallenge paradigm, one can obtain information about the dynamic functioning of neuroendocrine or neurotransmitter systems in the brain, such as the 5-HT system. In this method, a single dose of a centrally active agent that stimulates one specific neurotransmitter system is administered and an acute change in behavior or in circulating pituitary hormones is used as an index of synaptic activation by the agent. In these procedures, the site of action of the agent used is important; that is, are the effects mediated specifically by postsynaptic mechanisms, or a combination of pre- and postsynaptic ones? For example, the prolactin (PRL) response to acute challenge with fenfluramine is thought to reflect the integrated result of pre- and postsynaptic 5-HT mechanisms, as it causes 5-HT to be released into the synapse and also blocks its reuptake.

In adults with personality disorders, the PRL response to fenfluramine has been found to be inversely correlated with aggression, impulsivity, and irritability (e.g., Coccaro, 1989; Coccaro et al., 1989; Coccaro, Kavoussi, Cooper, \& Hauger, 1997). Similarly, O'Keane et al. (1992) reported a blunted PRL response to fenfluramine challenge in convicted murderers diagnosed as having APD relative to healthy control participants. The inverse relationship between PRL response to fenfluramine and aggressive behavior, however, has not been universally replicated. Fishbein, Lozovsky, and Jaffe (1989) found a positive correlation between PRL response to fenfluramine and self-reported aggressive behavior in substance abusers.

As mentioned above, the PRL response to fenfluramine challenge provides an index of the net 5-HT functioning, rather than information about the functioning of specific postsynaptic receptors. A few studies have investigated the effects of agonist probes that specifically stimulate postsynaptic receptors in aggressive individuals. For example, Coccaro, Gabriel, and Siever (1990) found an inverse relationship between the PRL response to a challenge with buspirone, an agonist that stimulates postsynaptic 
Table 4

Studies on Peripheral 5-Hydroxytryptamine (5-HT) Indices of Aggression in Aggressive Children and Adolescents

\begin{tabular}{|c|c|c|c|c|c|}
\hline \multirow[b]{2}{*}{ Study } & \multirow[b]{2}{*}{ 5-HT index } & \multicolumn{3}{|l|}{ Participants } & \multirow[b]{2}{*}{ Outcome } \\
\hline & & Sample & $\begin{array}{l}\text { Mean age } \\
\text { (years) }\end{array}$ & $\begin{array}{l}\text { Age range } \\
\text { (years) }\end{array}$ & \\
\hline $\begin{array}{r}\text { Rogeness et } \\
\text { al. (1982) }\end{array}$ & Whole blood 5-HT & $\begin{array}{l}\text { Male boys: } 9 \mathrm{CD} / \text { socialized, } 16 \mathrm{CD} / \\
\text { unsocialized, and } 20 \mathrm{HC}\end{array}$ & & $7-13$ & No differences \\
\hline $\begin{array}{l}\text { Stoff et al. } \\
\quad(1987)\end{array}$ & $\begin{array}{l}\text { Platelet }{ }^{3} \mathrm{H} \text {-imipramine } \\
\text { binding }\end{array}$ & $\begin{array}{l}17 \mathrm{CD} / \mathrm{ADHD} \\
15 \mathrm{HC}\end{array}$ & $\begin{array}{l}10.8 \\
10.7\end{array}$ & & $\begin{array}{c}\mathrm{CD}<\mathrm{HC} \text {; negative correlation with } \mathrm{CBCL} \\
\text { aggression }(r=-.72), \text { delinquency }(r= \\
-.70) \text { and externalizing }(r=-.72)\end{array}$ \\
\hline $\begin{array}{l}\text { Pliszka et } \\
\text { al. (1988) }\end{array}$ & Whole blood 5-HT & $\begin{array}{l}\text { Male adolescent offenders: } \\
19 \mathrm{CD} \\
8 \mathrm{CD} / \mathrm{MDD} / \text { anxiety } \\
17 \mathrm{MDD} / \text { anxiety }\end{array}$ & $\begin{array}{l}15.3 \\
15.7 \\
12.4\end{array}$ & & $\begin{array}{l}\mathrm{CD} \text { and } \mathrm{CD} / \mathrm{MDD} / \text { Anxiety }> \\
\mathrm{MDD} / \text { Anxiety; positive correlation with } \\
\mathrm{CD}(r=.53)\end{array}$ \\
\hline $\begin{array}{l}\text { Birmaher et } \\
\text { al. (1990) }\end{array}$ & $\begin{array}{l}\text { Platelet }{ }^{3} \mathrm{H} \text {-imipramine } \\
\text { binding }\end{array}$ & 23 boys: $7 \mathrm{CD}$ and $16 \mathrm{CD} / \mathrm{ADHD}$ & 12.6 & & $\begin{array}{l}\text { Negative correlation with CBCL aggression } \\
(r=-.50), \text { externalizing }(r=-.48), \\
\text { hostility }(r=-.53) \text { and total behavior }(r \\
\quad=-.47)\end{array}$ \\
\hline $\begin{array}{l}\text { Stoff et al. } \\
\quad(1991)\end{array}$ & $\begin{array}{l}\text { Platelet }{ }^{3} \mathrm{H} \text {-imipramine } \\
\text { binding }\end{array}$ & $\begin{array}{l}42 \text { boys with } \mathrm{CD} / \mathrm{ODD} \pm \mathrm{ADHD} \\
\text { or ADHD alone and } \\
26 \mathrm{HC}\end{array}$ & $\begin{array}{r}9.5 \\
10.2\end{array}$ & & No differences \\
\hline $\begin{array}{l}\text { Blumensohn } \\
\text { et al. } \\
\text { (1995) }\end{array}$ & $\begin{array}{l}\text { Platelet } 5-\mathrm{HT}_{2 \mathrm{~A}} \\
\text { binding }\left({ }^{3} \mathrm{H}-\right. \\
\text { ketanserin binding })\end{array}$ & $\begin{array}{l}28 \text { male adolescent delinquents with } \\
\mathrm{CD} \\
76 \text { male } \mathrm{HC}\end{array}$ & $\begin{array}{l}16.1 \\
15.2\end{array}$ & & $\mathrm{CD}<\mathrm{HC}$ \\
\hline $\begin{array}{l}\text { Cook et al. } \\
\quad(1995)\end{array}$ & Whole blood 5-HT & $\begin{array}{l}22 \text { ADHD children } \\
30 \text { ADHD + CD/ODD children }\end{array}$ & $\begin{array}{l}9.9 \\
8.2\end{array}$ & & No differences \\
\hline $\begin{array}{l}\text { Hanna et al. } \\
\text { (1995) }\end{array}$ & Whole blood 5-HT & $\begin{array}{l}6 \text { OCD/DBD boys } \\
12 \text { OCD boys and girls }\end{array}$ & $\begin{array}{l}14.5 \\
13.3\end{array}$ & & $\begin{array}{l}\mathrm{OCD} / \mathrm{DBD}<\mathrm{OCD} \text {; negative correlation } \\
\text { with CBCL aggression }(r=-.63) \text { and } \\
\text { externalizing }(r=-.59)\end{array}$ \\
\hline $\begin{array}{l}\text { Hughes et } \\
\text { al. (1996) }\end{array}$ & Whole blood 5-HT & $\begin{array}{l}30 \text { mood disorder } \\
27 \text { behavior disorder } \\
47 \text { mixed mood/behavior disorders } \\
14 \mathrm{HC}\end{array}$ & $\begin{array}{l}14.4 \\
13.3 \\
14.1 \\
15.4\end{array}$ & & $\begin{array}{l}\text { Behavior disorder }>\mathrm{HC}>\text { mood and mixed } \\
\text { disorder }\end{array}$ \\
\hline $\begin{array}{l}\text { Pine et al. } \\
\quad(1996)\end{array}$ & $\begin{array}{l}\text { Platelet } 5-\mathrm{HT}_{2 \mathrm{~A}} \\
\text { binding }\left({ }^{3} \mathrm{H}-\right. \\
\text { lysergic acid } \\
\text { diethylamide } \\
\text { binding) }\end{array}$ & $\begin{array}{l}34 \text { younger brothers of convicted } \\
\text { delinquents }\end{array}$ & 8.3 & & $\begin{array}{l}\text { Boys whose parents had history of substance } \\
\text { abuse or incarceration }<\text { boys of parents } \\
\text { without such a history; no relation with } \\
\text { diagnoses of CD/ODD/ADHD }\end{array}$ \\
\hline $\begin{array}{l}\text { Unis et al. } \\
\text { (1997) }\end{array}$ & $\begin{array}{l}\text { Whole blood } 5-\mathrm{HT} \\
\text { and platelet }{ }^{3} \mathrm{H}- \\
\text { paroxetine binding }\end{array}$ & $\begin{array}{l}29 \mathrm{CD} / \text { childhood onset } \\
13 \mathrm{CD} / \text { adolescent onset }\end{array}$ & $\begin{array}{l}14.7 \\
15.0\end{array}$ & & $\begin{array}{l}\text { Whole blood 5-HT: } \mathrm{CD} / \text { child onset }>\mathrm{CD} / \\
\text { adolescent onset; positive correlation with } \\
\text { violence rating }\end{array}$ \\
\hline $\begin{array}{l}\text { Van Goozen } \\
\text { et al. } \\
\text { (1999) }\end{array}$ & Plasma 5-HIAA & $\begin{array}{l}\text { Study } 1: \\
15 \mathrm{CD} / \mathrm{ODD} \\
25 \mathrm{HC}\end{array}$ & $\begin{array}{r}10.2 \\
9.6\end{array}$ & & $\begin{array}{l}\mathrm{CD}<\mathrm{HC} \text {; negative correlation with } \mathrm{CBCL} \\
\text { aggression and delinquency in Study } 1(r \\
=-.45 \text { and } r=-.44) \text { and Study } 2(r= \\
-.61 \text { and } r=-.59)\end{array}$ \\
\hline & & $\begin{array}{l}\text { Study } 2: \\
22 \mathrm{CD} / \mathrm{ODD} \\
25 \mathrm{HC}\end{array}$ & $\begin{array}{l}10.1 \\
10.2\end{array}$ & & \\
\hline $\begin{array}{l}\text { Twitchell et } \\
\text { al. (2000) }\end{array}$ & Whole blood 5-HT & 62 children of alcoholics & & & $\begin{array}{l}\text { Negative correlation with CBCL } \\
\text { disinhibition }(r=-.54) \text { in pubescent } \\
\text { children }(n=48) \text {, but not in prepubescent } \\
\text { children }(n=14)\end{array}$ \\
\hline
\end{tabular}

Note. 5-hydroxytryptamine $=$ serotonin; $\mathrm{CD}=$ conduct disorder; $\mathrm{HC}=$ normal control subjects; $\mathrm{ADHD}=$ attention-deficit/hyperactivity disorder; $\mathrm{CBCL}=$ Child Behavior Checklist; MDD = major depressive disorder; ODD = oppositional defiant disorder; OCD = obsessive compulsive disorder; $\mathrm{DBD}=$ disruptive behavior disorder.

$5-\mathrm{HT}_{1 \mathrm{~A}}$ receptors, and indices of impulsive aggression. However, the PRL response to buspirone may actually be mediated by dopaminergic, rather than serotonergic, mechanisms (Maskall, Zis, Lam, Clark, \& Kuan, 1995), so buspirone is not an ideal probe of 5-HT function. In another study, men with APD were found to exhibit a significantly reduced PRL response to metachlorophenylpiperazine (m-CPP), another postsynaptic 5-HT receptor agonist, compared with control subjects (Moss, Yao, \&
Panzak, 1990). No differences in PRL response to m-CPP, however, were found in aggressive patients with panic disorder or depression compared with nonaggressive patients (Wetzler, Kahn, Asnis, Korn, \& Van Praag, 1991). It is important to bear in mind that the presence of depression (Coccaro et al., 1989), substance abuse (Fishbein, Lozovsky, \& Jaffe, 1989), or anxiety disorders (Wetzler et al., 1991) may influence the direction or the degree of the relation between challenge indexes of 5-HT and aggression. 
In addition, reduced 5-HT postsynaptic receptor sensitivity is at variance with findings of lower CSF 5-HIAA and lower PRL responses to fenfluramine. Specifically, if low CSF 5-HIAA reflects a decreased 5-HT metabolism and if low PRL responses to fenfluramine can be interpreted as a decreased release of 5-HT, one would expect to find a postsynaptic receptor hypersensitivity. A postsynaptic receptor hyposensitivity would be more consistent with a chronic excessive release of 5-HT. Some challenge studies (the majority using fenfluramine) have been conducted in aggressive children or adolescents (see Table 3) and the findings are less clear cut than those in aggressive adults. In the studies of Halperin et al. (1994, 1997) a significantly enhanced PRL response to fenfluramine was observed in young $(<9.1$ years) aggressive ADHD boys, whereas the older ( $>9.1$ years) aggressive ADHD boys did not show an elevated response. The authors suggested that aggressive ADHD children, who initially have an enhanced PRL response to fenfluramine, do not undergo typical developmental changes in 5-HT function and subsequently have a blunted response. In line with this pattern of enhanced responsivity are the results of Pine et al.'s (1997) study, which investigated the serotonergic function in 34 younger brothers of convicted delinquents. They found that aggressive behavior, but also adverse rearing circumstances, were positively correlated with the PRL response to fenfluramine challenge. Castellanós et al. (1994) also demonstrated an increased PRL response to fenfluramine administration in children with ADHD. Furthermore, an elevated cortisol response to fenfluramine has been found in adolescents with alcohol abuse disorder and comorbid CD compared with participants with alcohol abuse disorder and no CD and healthy control participants (Soloff, Lynch, \& Moss, 2000), although no differences in the PRL response to fenfluramine were found between these groups.

Stoff et al. (1992) found no relationship between the PRL response to fenfluramine and aggression in prepubertal and adolescent boys with DBD with or without ADHD. In line with these results, a recent study by Schulz et al. (2001) failed to show a relationship between the PRL response to fenfluramine and aggression in clinically referred boys divided into nonaggressive ADHD, aggressive ADHD, and aggressive non-ADHD groups. However, because the study did not include a healthy control group, it was not possible to exclude an association of central 5-HT with some underlying, related construct like impulse control, a symptom that is associated with ADHD and disruptive behavior in children, rather than physical aggression per se. The only fenfluramine challenge study supporting the negative relationship between 5-HT and aggression in children was conducted by Donovan, Halperin, Newcorn, and Sharma (1999). They found a significant inverse relationship between the temperature response to fenfluramine and teacher ratings of aggression in prepubescent ADHD boys. However, they reported that the magnitude of the hyperthermic response was unrelated to changes in plasma levels of PRL and cortisol, suggesting that temperature and neuroendocrine responses to fenfluramine are mediated by distinct 5-HT mechanisms.

In addition to these studies examining the neuroendocrine response to fenfluramine administration, which is likely to reflect the activation of several different 5-HT receptor subtypes, a recent study has investigated the neuroendocrine response to the selective
5-HT $\mathrm{HB}_{1 \mathrm{BD}}$ receptor agonist, sumatriptan (Snoek et al., 2002). This receptor subtype is of particular interest because animal studies have suggested that $5-\mathrm{HT}_{1 \mathrm{~B} / 1 \mathrm{D}}$ receptor has a privileged role in the etiology of aggression (see below). Consistent with previous reports of 5-HT abnormalities in children with DBD and aggressive adults, the study demonstrated that the growth hormone response to sumatriptan was enhanced in children with DBD (Snoek et al., 2002). This suggests that the sensitivity of postsynaptic $5-\mathrm{HT}_{1 \mathrm{~B} / 1 \mathrm{D}}$ receptors is increased in children with DBD, perhaps as a result of a primary deficit in brain 5-HT levels, which subsequently leads to upregulation of 5-HT receptor number.

In summary, although some pharmacochallenge studies in children provide evidence for a relationship between 5-HT and aggression, the results of the majority of these studies appear to be in the opposite direction (with four studies showing an elevated hormonal response or a positive relationship and one study showing a negative relationship between 5-HT and aggression) compared with the results in aggressive adults. These discrepant findings may result from an aberrant development of the 5-HT system in aggressive children (Halperin et al., 1997; Pine et al., 1997). However, the samples of the abovementioned studies consisted largely of children with comorbid ADHD, and only two studies used a healthy control group as comparison (Snoek et al., 2002; Soloff et al., 2000). Moreover, the distinction between aggressive and nonaggressive groups was based mostly on questionnaire results and not on a positive or negative diagnosis of DBD. Because prevalence rates of comorbid ADHD and DBD range between 50\% and $90 \%$, it is almost impossible to completely avoid this contamination with ADHD in child psychiatric research samples. Future studies of children, however, should mainly focus on DBD samples because these disorders refer specifically to a pattern of aggressive behavior. DBD (with or without ADHD) and ADHD (without DBD) groups could be used to investigate possible differences in 5-HT activity between these diagnostic groups.

In addition, a criticism of pharmacochallenge measures is that the majority of probes currently in use lack specificity; that is, they typically activate more than a single neurotransmitter system or receptor subtype. It is also difficult to determine whether hormonal responses result from the stimulation of neurons (which would be an index of neurotransmitter receptor functioning) or whether the effects are produced by the direct activation of the glands that manufacture specific hormones (Coccaro \& Kavoussi, 1994). The development of selective neurotransmitter agonists that activate a specific receptor subtype will therefore be important in understanding the origins of the hormonal responses in question and why they are compromised in individuals with persistent antisocial and aggressive behavior.

\section{Effect of Manipulations of the Serotonergic System on Aggression in Humans}

Establishing a causal relationship between low 5-HT levels and aggression can be facilitated only by experimental studies in which it is shown that manipulations of the serotonergic system have a direct effect on aggressive behavior. Pharmacological manipulation of the 5-HT system through tryptophan depletion or supplementation (tryptophan is an amino acid necessary for the synthesis of 5-HT) resulted in changes in the predicted direction in aggres- 
sive individuals tested under laboratory conditions (Bjork, Dougherty, Moeller, Cherek, \& Swann, 1999; Bjork, Dougherty, Moeller, \& Swann, 2000). Various psychopharmacological agents including antipsychotics, lithium, anticonvulsants, benzodiazepines, and amphetamines have been shown to alter aggressive behavior in adults and children (Mann, 1995; McDougle, Stigler, \& Posey, 2003; Stoff \& Vitiello, 1996). In addition to the effect of these agents on several different neurotransmitter systems, many of them may have marked effects on the 5-HT system. A few studies investigating the anti-aggressive effect of agents that primarily affect the 5-HT system, like selective serotonin reuptake inhibitors (SSRIs), have demonstrated their efficacy in reducing aggression in adult psychiatric patients (Coccaro \& Kavoussi, 1997; Fava et al., 1993; Kavoussi, Liu, \& Coccaro, 1994; Salzman et al., 1995).

In children, however, the results are less clear. Controlled studies of the effects of serotonergic agents on aggression in pediatric samples are few in number. Most of the available data come from single case reports and open label trials in limited numbers of patients. Two open label studies have described favorable effects of trazodone in the treatment of aggressive behavior in pediatric inpatients (Ghaziuddin \& Alessi, 1992; Zubieta \& Alessi, 1992). One open pilot study showed a reduction in impulsive aggression in 11 children with DBD after treatment with the SSRI citalopram (Armenteros \& Lewis, 2002). However, one open label study found no improvement in aggressive behavior when investigating the effect of three different SSRIs (fluoxetine, paroxetine, and sertraline) on the aggressive behavior of 19 hospitalized adolescent psychiatric patients (Constantino, Liberman, \& Kincaid, 1997). In addition, an unpublished study showed that an 8-week treatment with the SSRI fluvoxamine had only limited effects on aggressive and oppositional symptoms in a group of 15 hospitalized children with DBD (Snoek, 2002). Fluvoxamine also did not affect the growth hormone response to the $5-\mathrm{HT}_{1 \mathrm{~B} / 1 \mathrm{D}}$ receptor agonist sumatriptan, which suggests that changes in the sensitivity of postsynaptic $5-\mathrm{HT}_{1 \mathrm{~B} / 1 \mathrm{D}}$ receptors in DBDs are relatively longlasting and not easily corrected by restoring normal levels of 5-HT. Considered together, these drug intervention studies suggest that currently available SSRI drugs are of limited use in the treatment of children with DBDs.

\section{The 5-HT $T_{1 B}$ Receptor and Serotonergic Genes}

As noted above, a total of 14 different 5-HT receptors have been described (Barnes \& Sharp, 1999). These various 5-HT receptor subtypes may mediate aggressive behavior in different ways. Studies on rodents have suggested that $5-\mathrm{HT}_{1 \mathrm{~A}}$ receptor stimulation leads to a decrease in aggressive behavior. Treatment with agonists of this receptor (such as buspirone) reduced offensive aggression (Mos, Olivier, Poth, Van Oorschot, \& Van Aken, 1993). Moreover, in humans a reduced sensitivity of $5-\mathrm{HT}_{1 \mathrm{~A}}$ receptors is associated with impulsive aggression (Coccaro et al., 1990), and $5-\mathrm{HT}_{2}$ receptor antagonists, which include most antipsychotic drugs, are known to have antiaggressive properties (Mann, 1995).

More recently, in preclinical research there has been a special interest in the 5- $\mathrm{HT}_{1 \mathrm{~B}}$ receptor (previously called $5-\mathrm{HT}_{1 \mathrm{D \beta}}$ receptor as the human equivalent of the rodent $5-\mathrm{HT}_{1 \mathrm{~B}}$ receptor). Specifically, 5- $\mathrm{HT}_{1 \mathrm{~B}}$ knockout mice appear to be more aggressive toward intruders than their conspecific wild-type mice (Bouwknecht et al., 2001; Ramboz et al., 1996; Saudou et al., 1994).
These findings are supported by the established antiaggressive properties of a class of 5-HT $\mathrm{HB}_{1 \mathrm{~B}}$ receptor agonists (such as eltoprazine), termed serenics, in animals (de Almeida \& Miczek, 2002; Olivier, Mos, Van Oorschot, \& Hen, 1995).

Because of the variety of behavioral contexts in which antisocial behaviors arise, and the diversity of neuromolecular mechanisms that contribute to these behaviors, we expect that numerous alleles will be found to influence aggressive and antisocial behavior. Aggression alleles per se (in other words, influencing aggression but nothing else) probably do not exist, but there are some alleles that have been associated with aggression or aggression-related disorders. $^{2}$ For example, a point mutation in the monoamine oxidase A gene (MAO-A is an enzyme that breaks down 5-HT, NE, and DA) was described in a Dutch family with borderline mental retardation and intermittent explosive aggression (Brunner, Nelen, van Zandvoort, et al., 1993; Brunner, Nelen, Breakefield, Ropers, $\&$ van Oost, 1993). Although this appears to be an extremely rare condition, recent studies have shown that polymorphisms in the MAO-A gene may also be important in the etiology of antisocial behavior, in combination with environmental factors such as exposure to maltreatment in childhood (Caspi et al., 2002). The low activity form of the MAO-A gene is found in approximately $30 \%-35 \%$ of the population and does not constitute a genetic risk factor by itself. However, antisocial behavior is observed in a very high proportion of individuals who both express the low activity MAO-A gene and have experienced severe maltreatment or other forms of chronic adversity in childhood (Foley et al., 2004). Although it is not understood why a reduction in functional MAO-A activity should lead to a reduced tolerance to life stress and environmental adversity, it has been reported that in MAO-A knock-out mice there are marked elevations in 5-HT concentrations in the developing brain (Cases et al., 1995). In light of the role 5-HT plays in shaping the developing brain, this deficiency in MAO-A activity may have negative consequences for brain development (Cases et al., 1996). Thus, it is possible to speculate that exposure to early adversity, which is known to cause subtle changes in 5-HT functioning (Gartside, Johnson, Leitch, Troakes, \& Ingram, 2003; Van Riel, Van Gemert, Meijer, \& Joëls, 2004), might interact with preexisting disruptions in 5-HT neurotransmission resulting from low MAO-A activity to produce enhanced impulsivity, aggressive behavior and even subtle brain abnormalities (Cases et al., 1995).

Variations in 5-HT measures related to aggressive behavior are also thought to be genetically determined. One heritability study carried out in Rhesus macaque monkeys detected a heritability of $50 \%$ for CSF 5-HIAA levels (Higley et al., 1993). A study by Twitchell et al. (2001) on children of alcoholic individuals suggested that aggressive behavior might be genetically influenced through the regulation of the 5-HT transporter. In humans, antisocial alcoholism has been found to be linked to the $5-\mathrm{HT}_{1 \mathrm{~B}}$ gene (Lappalainen et al., 1998), which is broadly consistent with findings in $5-\mathrm{HT}_{1 \mathrm{~B}}$ receptor mutant mice.

\footnotetext{
${ }^{2}$ Although several reports have suggested an association between dopamine receptor genes and personality traits such as novelty seeking, ADHD, or alcohol abuse problems, these molecular genetic findings are not discussed here because they are not related to aggression or CD per se but instead to some of its related disorders (e.g., ADHD or alcohol abuse).
} 
Finally, an interesting extension to a genetic perspective on antisocial behavior was presented by Hariri et al. (2002), who proposed that genetically driven variation in 5-HT transporter function (short SLC6A4 allele) and subsequent excitability of the amygdala to emotional stimuli may contribute to individual differences in fear. The relevance of the amygdala and of individual differences in sensitivity to fear is discussed below.

In conclusion, it is probably true that the more severe and persistent forms of antisocial behavior in humans are influenced by genetic factors, although environmental factors will also have a considerable role to play. Current molecular genetic findings suggest that an interaction between the low-activity form of the MAO-A gene and environmental adversity plays an important role in the etiology of antisocial behavior. However, this represents just part of the explanation, because only $30 \%-35 \%$ of the population carries this form of the gene, and antisocial behavior is also observed in those with the high activity form of the MAO-A gene (Caspi et al., 2002). Still, the MAO-A and 5-HT ${ }_{1 \mathrm{~B}}$ receptor genes will be interesting candidates for future research.

\section{Concluding Remarks on 5-HT Activity in Aggressive Children}

Several, but not all, peripheral and central measures of 5-HT activity provide evidence for a role of this neurotransmitter in the modulation of antisocial behavior in children. The different 5-HT measures used in the studies complicate the interpretation of the findings, because the exact association between the various 5-HT indices (peripheral and central) is not fully understood. In adults, there is compelling evidence for an inverse relationship between 5-HT measures (CSF 5-HIAA and PRL response to fenfluramine challenge) and antisocial behavior, but the direction of the relationship in children is less straightforward. The majority of the results of pharmacological challenge studies in children point to a positive relationship between the hormonal responses and aggressive behavior. It has been suggested that age is an important factor in explaining these inconsistent results and that antisocial behavior may be associated with developmental abnormalities of the 5-HT system. In addition, the contrasting results (between different studies of children and when child studies are compared with adult studies) may originate from differences in the composition of the antisocial samples and differences in the outcome measures used in the studies. Future challenge studies focusing on well-defined antisocial groups are needed to explore the 5-HT-aggression relationship more closely. As well as biochemical studies, there has been important recent research into the genetics of aggression and antisocial behavior: Animal studies have implicated the 5- $\mathrm{HT}_{1 \mathrm{~B}}$ receptor in aggressive behavior (Saudou et al., 1994), which complements evidence that the sensitivity of $5-\mathrm{HT}_{1 \mathrm{~B} / 1 \mathrm{D}}$ receptors is increased in children with DBD (Snoek et al., 2002). In addition, recent studies have pointed to a role for the gene encoding for MAO-A, such that the risk for antisocial behavior appears to be dramatically increased in individuals who carry the low activity form of the MAO-A gene and who have also been exposed to adverse life experiences such as abuse or neglect (Caspi et al., 2002; Foley et al., 2004). Finally, very few studies have examined the effects of specific 5-HT receptor agonists and antagonists on disruptive behavior in children. Although evidence from studies investigating the anti-aggressive properties of SSRIs in children with DBD suggests that these drugs are ineffective in this respect, it is possible that novel antidepressant drugs with actions on the 5-HT system will be useful in the treatment of DBDs.

\section{Interactions Between the 5-HT System and the HPA Axis}

So far, we have described evidence for reduced basal cortisol levels, attenuated cortisol reactivity, and 5-HT system impairments in children and adults with persistent antisocial behavior. It should be noted that these systems interact at several levels. For example, activation of postsynaptic 5-HT receptors in the hypothalamus (particularly the $5-\mathrm{HT}_{1 \mathrm{~A}}$ and $5-\mathrm{HT}_{2 \mathrm{~A}}$ subtypes) stimulates HPA axis activity and causes an elevation in ACTH and cortisol (Bagdy, 1996; Fuller, 1992). In humans, it has been shown that administration of the SSRI fluoxetine for 6 days enhances the cortisol response to awakening (Harmer, Bhagwagar, Shelley, \& Cowen, 2003). Conversely, a disruption of 5-HT neurotransmission by tryptophan depletion impairs normal HPA axis functioning (i.e., the cortisol-elevating effect of a speech stressor was blunted; Sobczak, Honig, Nicolson, \& Riedel, 2002). Vielhaber et al. (2005) showed that tryptophan depletion in the evening significantly lowered salivary cortisol levels the following morning. Although these findings await replication, they have implications for the etiology of antisocial behavior, because it appears that cortisol reactivity is impaired when 5-HT neurotransmission is disrupted.

In addition to the effects of 5-HT manipulations on HPA axis activity, there is a large body of evidence showing that glucocorticoids modulate $5-\mathrm{HT}_{1 \mathrm{~A}}$ receptor binding and messenger RNA expression in animals (Chalmers, Kwak, Mansour, Akil, \& Watson, 1993; see Chaouloff, 1995, for a review). Recent evidence has suggested that $5-\mathrm{HT}_{1 \mathrm{~A}}$ receptor sensitivity in the dorsal raphe nucleus and the hippocampus may be altered by prolonged glucocorticoid administration (Fairchild, Leitch, \& Ingram, 2003; Karten, Nair, van Essen, Sibug, \& Joëls, 1999), and this may have consequences for 5-HT neurotransmission in key projection regions such as the frontal cortex (Gartside, Leitch, \& Young, 2003; see Porter, Gallagher, Watson, \& Young, 2004, for a review of the evidence for effects of glucocorticoids on 5-HT function in humans).

Although it is difficult to extrapolate from these studies, in which glucocorticoid levels have been experimentally manipulated or 5-HT neurotransmission enhanced or disrupted, to humans with a constellation of HPA axis abnormalities and 5-HT impairments, it is possible that these interactions play a role in the etiology of antisocial behavior. Chronic reductions in basal glucocorticoid concentrations could underlie some of the 5-HT abnormalities seen in these individuals. Similarly, 5-HT system disturbances could impair normal HPA axis functioning, particularly with respect to cortisol reactivity to stress. Future research should study interactions between the 5-HT system and the HPA axis in children with antisocial behavior.

\section{Endophenotypes}

Antisocial behavior, like all complex behaviors, is phenotypically and etiologically heterogeneous. As a result, there has been increasing interest in distinguishing specific phenotypic traits or markers, also called endophenotypes, thought to represent biolog- 
ical systems underlying the behavior concerned (Moffitt, 2005). It is assumed that these endophenotypes are under greater genetic influence than the behavior at large. The advantage of this approach is that endophenotypes are better distributed than disorders and that they can be studied in healthy populations. Some possible endophenotypes for antisocial behavior are fearlessness, sensation seeking, stress responsivity, punishment insensitivity, reward oversensitivity, serotonergic dysfunction, DHEA-S-cortisol imbalance, elevated testosterone levels, negative trait emotionality, impulsivity, and executive dysfunction (see Moffitt, 2005). An important next step is to establish whether (and which) endophenotypes mediate the pathways between measured genes and antisocial behavior.

\section{Early Adverse Experiences and Their Effects on Biological Correlates of Aggression}

As mentioned before, the etiology of antisocial behavior cannot be entirely explained by underlying genetic or biological factors; environmental factors also contribute. Some risk factors are prenatal, such as exposure to maternal smoking in utero (Silberg et al., 2003; Thapar et al., 2003), low birth weight/gestational age; others are postnatal, such as maltreatment (Caspi et al., 2002), or adversity, consisting of a combination of parental neglect, interparental violence, and inconsistent discipline (Foley et al., 2004). Some of the best candidate environmental risks are those with evidence of a plausible effect on biological systems in psychopathology; stress responsiveness, variations in parental care, maternal psychopathology, maternal negativity, child abuse and neglect, poverty, exposure to parental violence and conflict, and parental separation and divorce (Moffitt, 2005).

Animal studies in nonhuman primates and rodents consistently show that early life stressors have long-term neurobiological consequences, including effects on the HPA axis and the noradrenergic, dopaminergic and serotonergic systems, that persist into adult life (reviewed by Bremner \& Vermetten, 2001; Sanchez, Ladd, \& Plotsky, 2001). Kraemer, Ebert, Schmidt, and McKinney (1989) showed in their study of rhesus monkeys that disruption of early social attachment, an important factor in the development of vulnerability to psychopathology, produced changes in CSF measures of biogenic amine system activity. Rosenblum et al. (1994) administered the noradrenergic agonist yohimbine and the serotonergic agonist m-CPP to two groups of adult primates that had been reared under conditions of normal or disrupted social development. The animals exposed to social deprivation were hyperresponsive to yohimbine and hyporesponsive to $\mathrm{m}$-CPP. There is also evidence for impairments of 5-HT neurotransmission in male rats exposed to maternal separation early in the postnatal period (Gartside, Johnson, et al., 2003). Finally, Liu et al. (1997) found that, as adults, the offspring of mothers that exhibited more licking and grooming of pups during the first 10 days of life showed reduced plasma ACTH and glucocorticoid responses to acute stress, increased hippocampal glucocorticoid receptor messenger RNA expression, enhanced glucocorticoid feedback sensitivity, and decreased levels of hypothalamic CRH messenger RNA. Liu et al. concluded that maternal behavior serves to program HPA responses to stress in the offspring and variations in maternal care may affect the development of individual differences in neuroendocrine responses to stress in rats. Another very interesting finding is that long-term outcomes can be different (even opposite: hypofunctional vs. hyperfunctional), depending on the developmental state of the HPA axis at the time of the stressor and on the duration, frequency, and intensity of the early stressor (see Sanchez et al., 2001). Although it has been more difficult to demonstrate lasting alterations in primate HPA axis functioning following exposure to early adversity, in recent years it has become clear that manipulations that disrupt the quality of mother-infant interactions (such as unpredictable foraging demand conditions or repeated separation of the mother from the infant's social group) are capable of inducing long-term changes in HPA axis activity. CSF cortisol concentrations in the infant were reported to be reduced following maternal exposure to chronic stress (Coplan et al., 1996), and urinary cortisol levels were lower following a period of repeated maternal separation (Dettling, Feldon, \& Pryce, 2002). In addition, a flattened diurnal profile of cortisol was observed in monkeys that had previously undergone repeated maternal separation 6-18 months earlier (Sanchez et al., 2005).

The few studies of the effects of early stress on neurobiological systems conducted in clinical populations of traumatized children have generally been consistent with findings from animal studies. Studies of various adult psychiatric patients with a history of early childhood abuse have revealed long-term changes in HPA axis activity (Heim, Newport, Bonsall, Miller, \& Nemeroff, 2001), noradrenergic function (see Bremner \& Vermetten, 2001), and the serotonergic system (Rinne, Westenberg, den Boer, \& Van den Brink, 2000). There is also evidence for long-term changes in HPA axis functioning in children and adolescents with a history of abuse (Cicchetti \& Rogosch, 2001; De Bellis et al., 1999; Duval et al., 2004), and a recent study showed an association between childhood maltreatment, neglect, and subtle brain abnormalities in the cingulate cortex and corpus callosum (Teicher, Dumont, Vaituzis, Giedd, \& Andersen, 2004). Different studies of severely socially deprived children raised in Romanian orphanages during the Ceaucescu era showed that these children failed to show a normal daily pattern of cortisol secretion, compared to healthy children raised at home with their parents (Carlson \& Earls, 1997; Gunnar, Morison, Chisholm, \& Schuder, 2001). Rather than experiencing a morning peak and an evening trough in cortisol levels, the institutionalized children exhibited a relatively flat diurnal profile (Carlson \& Earls, 1997). These findings have been paralleled in nonhuman primates and provide evidence that a lack of stimulation in the early years of life may lead to drastic changes in HPA axis function, particularly in terms of cortisol reactivity.

An intriguing issue is why some individuals exposed to early adversity exhibit elevated basal cortisol levels, exaggerated HPA axis reactivity (i.e., increased glucocorticoid secretion), and autonomic responses to psychosocial stress, and are therefore at risk of developing mood and anxiety disorders (Heim et al., 2001; Heim, Newport, et al., 2000), whereas others appear to show the opposite pattern of reduced basal cortisol and attenuated physiological and endocrine responses to stress (Carlson \& Earls, 1997; Gunnar \& Donzella, 2002; Gunnar, Morison, Chisholm, \& Schuder, 2001) We assert that a number of factors could be involved in the development of these opposite patterns of HPA axis functioning.

A first factor that could be involved in the development of opposite patterns of HPA functioning is gender. There are clear gender differences in the prevalence rates for psychopathology, with females being more prone to develop internalizing disorders, 
such as depression, anxiety, and eating disorders, and males showing a greater tendency to develop externalizing disorders, such as ODD and CD (Cyranowski, Frank, Young, \& Shear, 2000). These internalizing and externalizing disorders are associated with opposite patterns of HPA axis functioning (as has been explained above). Research has shown that males and females differ not only in their neuroendocrine responses to stress (Kirschbaum, Kudielka, Gaab, Schommer, \& Hellhammer, 1999) but also in sensitivity to different types of stressors (Stroud, Salovey, \& Epel, 2002). Thus gender could play a moderating role in the relation between early adversity and psychopathology. Second, the type of stressor involved-for example, physical or sexual abuse, neglect, or maltreatment - could be an important determinant. Recently, Lee, Geracioti, Kascow, and Coccaro (2005), examining retrospectively physical and emotional abuse, and physical and emotional neglect in men with personality disorders, found a positive relationship specifically between emotional neglect and CSF CRH concentration, which is suggestive of an increased HPA axis function. According to the authors, emotional neglect is analogous to the disruptions in maternal care as administered in the rodent handling and separation paradigms (Meaney et al., 1996) and the primate variable foraging paradigms (Coplan et al., 1996). Future research should address this issue and examine the effects of different types of stressors on HPA axis development and functioning.

A third factor that could influence long-term HPA functioning is the timing or the duration of the stressor(s). To our knowledge, no human research has examined the neurobiological effects of stress at different developmental stages. The animal literature suggests that the timing of exposure to adversity, and its intensity, has a critical influence on the eventual outcome. For example, rats separated for $24 \mathrm{hr}$ at postnatal days (PND) 3-4 exhibit an enhanced ACTH response to a mild stressor relative to controls, whereas those separated at PND 11-12 show an attenuated ACTH response (Van Oers, de Kloet, \& Levine, 1998). Furthermore, animals subjected to long-term social isolation after weaning show reduced responses to restraint stress (Sanchez, Aguado, SanchezToscano, \& Saphier, 1998). This is in sharp contrast with animals experiencing repeated maternal separation at PND 2-20, which show an exaggerated HPA axis response to stress (Ladd, Owens, \& Nemeroff, 1996). These studies illustrate the importance of examining the consequences of different types of early life stress and the timing of such experiences in naturalistic studies in humans. With respect to chronicity, Heim, Ehlert, and Hellhammer (2000) described evidence that hypocortisolism was observed in otherwise healthy individuals living under conditions of ongoing stress. A pattern of decreased ACTH and corticosterone secretion and reduced responsiveness to challenge has also been found in rodents living under conditions of chronic stress due to exposure to continuous electric shocks or immobilization. In recognizing that antisocial children often come from problematic backgrounds, and that many of them have been neglected or abused (Kazdin, 1995), it is reasonable to assume that they have often been exposed to prolonged or uncontrollable stress and that these experiences have had a lasting effect on the developing neurobiological systems of the brain, including the HPA axis and the 5-HT system. At present, however, it is unclear whether such experiences, if it can be established (retrospectively) that these have occurred in children with antisocial behavior, have altered their basal cortisol secretion (daily rhythm), their HPA axis response to stress, or both. This is clearly an important topic for future research.

\section{Is the Amygdala Dysfunctional in Early-Onset Antisocial Behavior?}

The amygdala is thought to play a key role in the perception of threat signals in the environment (Amaral, 2003), since localized bilateral amygdala lesions abolish the response to fear-inducing stimuli, such as replica snakes, in nonhuman primates (Prather et al., 2001). In addition, amygdalectomized primates show far more socially affiliative behavior and less anxiety when confronted with a novel conspecific than control primates (Emery et al., 2001). Thus, the amygdala appears to be involved in evaluating the environment for potential threats, such as natural predators and novel conspecifics (members of the same species). This general principle has been supported by neuropsychological studies of humans with amygdala damage demonstrating that the recognition of fear and anger is impaired in these patients (Adolphs, Tranel, Damasio, \& Damasio, 1994, 1995; Calder et al., 1996) and neuroimaging studies in which the amygdala has been shown to be activated by the viewing of fearful facial expressions (Morris et al., 1996; Whalen et al., 1998) and negatively valenced pictures (Lane et al., 1997).

A number of studies have provided indirect evidence for deficits in amygdala functioning in children with early-onset CD or psychopathic tendencies. For example, in one study it was shown that children with DBD had a blunted response to auditory stimuli that normally elicit a startle reflex (Van Goozen, Snoek, et al., 2004). Furthermore, there was an inverse relationship between delinquency ratings and the magnitude of startle responses measured while viewing unpleasant pictures (Van Goozen, Snoek, et al., 2004). The interpretation that these findings are due to amygdala impairment is consistent with a report showing that damage to the right amygdala dramatically reduces startle amplitude to an aversive auditory stimulus, and prevents the potentiating effect of negatively-valenced pictures on the startle response (Angrilli et al., 1996). In a study of facial expression recognition in boys with psychopathic tendencies (and probably some form of DBD, since they were recruited from schools for children with emotional and behavioral difficulties), it was reported that participants scoring highly on the Psychopathy Screening Device (PSD) showed a selective impairment in the recognition of sad and fearful expressions (Blair, Colledge, Murray, \& Mitchell, 2001). These findings have therefore been interpreted as supporting amygdala-based accounts of DBD, in which deficits in amygdala function render the individual relatively "fearless" and unable to recognize cues from the environment that signal either threat or submission.

A recent neuroimaging study directly tested the possibility that amygdala function may be impaired in $\mathrm{CD}$ by examining the neural response to viewing negatively valenced pictures from the International Affective Pictures System (Sterzer, Stadler, Krebs, Kleinschmidt, \& Poustka, 2005). Stertzer et al. reported reduced activation in the left amygdala of children with severe CD when viewing these pictures, although this result became significant only when they corrected for the influence of anxiety and depressive symptoms (Sterzer et al., 2005). It is also worth noting that an unusual deactivation of the right dorsal anterior cingulate cortex was observed in these patients during viewing of negative pictures, 
which may relate to their difficulties in regulating emotional behavior. Hariri, Mattay, Tessitore, Fera, and Weinberger (2003) suggested that the anterior cingulate cortex and the ventral prefrontal cortex comprise an important network involved in the regulation of amygdala activity. Together with the evidence for impairments in amygdala function and recent preliminary data suggesting that prefrontal cortical volumes may be reduced in children with CD (Kruesi, Casanova, Mannheim, \& JohnsonBilder, 2004), it is possible to speculate that this network less effectively regulates amygdala activity in individuals with $C D$, thereby preventing them from exercising cognitive control over their emotional behavior. The combination of insensitivity to cues signaling threat and submission (such as sad facial expressions) and impaired emotion regulation may mean that children with early-onset CD are not governed by the same external or internal constraints as are other children.

A further point of interest is that the prefrontal cortex and amygdala both exert considerable control over HPA axis activity (Herman et al., 2003). The amygdala has an excitatory influence on CRH-secreting cells in the PVN of the hypothalamus that drive the HPA axis, while the prefrontal cortex inhibits HPA axis activation (Herman et al., 2003). Thus an underactive amygdala (or at least its principal output region, the central nucleus of the amygdala) or deficits in the functioning of prefrontal cortex-anterior cingulate cortex-amygdala circuitry, possibly due to prefrontal cortex volume reductions (Kruesi et al., 2004; Raine, Lencz, Bihrle, LaCasse, \& Colletti, 2000), could underlie some of the problems with stress response systems observed in antisocial individuals.

\section{Integrative Theoretical Model}

\section{The Role of Neurobiological Mechanisms in the Etiology of Childhood Antisocial Behavior}

An integrative theoretical model is proposed linking familial factors (e.g., genetic influences, early childhood adversity) to negative behavioral outputs (e.g., antisocial behavior problems) through the mediating and transactional interplay between (a) neurobiological deficits (e.g., 5-HT; HPA axis, ANS) and (b) disinhibited cognitive and emotional problems (e.g., learning and memory impairments or hostile attributional processes). This model incorporates three primary components identified by Morton and Frith (1995) and Krol, Morton, and De Bruyn (2004) in accounting for the etiological foundations of childhood antisocial behavior-biological, cognitive and emotional, and behavioral output. Rather than represent these components as simple correlates, our model proposes that biological, cognitive, and emotional factors serve as mediating elements in the link between early family influences and later behavioral output (see Figure 1). Specifically, we hypothesized that rather than early childhood adversity (e.g., hostile parenting, parental conflict and violence, or negative life events) exerting a main or direct effect on childhood antisocial behavior (behavioral output), effects are mediated by neurobiological deficits (Path E) as well as disinhibited cognitive and emotional functioning (Path F). These factors, in turn, exert effects on early-onset antisocial behavior, with evidence suggesting that effects may emanate more from disinhibited cognitive problems (Path $\mathbf{J}$ ) over time than from neurobiological deficits
(Path I). This does not negate the importance of this latter factor, however, as a mechanism through which variation in children's behavior problems may be explained. Indeed, the impact of early childhood adversity on neurobiological function may serve as a catalyst for disruptions in children's cognitive and emotional functioning, an outcome determined by initial neurobiological dysfunction. Rather than represent this interplay as unidirectional, this relationship is represented as bidirectional, reciprocal or transactional in nature. That is, initial disruptions in neurobiological functioning facilitate disruptions in cognitive and emotional functioning (Path G), which in turn affect further disruption at a neurobiological level (Path $\mathrm{H}$ ). Genetic factors are also emphasized in this model as a source of familial influence on children's neurobiological and cognitive and emotional functioning. Consistent with recent proposals (Moffitt, Caspi, \& Rutter, 2005; Rutter $\&$ Silberg, 2002), variation in the genetic makeup of children likely interacts with early childhood adversity to adversely affect neurobiological development and functioning (Paths D and C). In addition, evidence suggests that genetic factors may exert direct effects on neurobiological deficits (Path A) and disinhibited cognitive and emotional problems (Rutter \& Silberg, 2002). Through this combination of genetic and family environmental factors, the primary pathways by which early childhood adversity affects childhood disruptive behavior problems are through the reciprocal interplay between neurobiological deficits and disinhibited cognitive and emotional problems, with the latter serving as the psychological gateway through which neurobiological deficits express their impact on childhood antisocial behavior. Importantly, this model also proposes that for these hypothesized direction of effects to be established, these processes must be considered as unfolding over time. Future longitudinal research, therefore, is essential.

\section{Correlation Versus Causality: The Need for Longitudinal Research}

As has already been mentioned, the majority of studies considered in this review, and representative of the state-of-the-art research regarding the neurobiological bases of childhood antisocial behavior, are cross-sectional and correlational in nature, thereby limiting any conclusions regarding the causal nature of neurobiological influences on behavior. Although only experimental research can unambiguously address questions of cause and effect, longitudinal correlational designs can investigate whether changes in one variable predict changes in another variable and can test hypotheses representing different causal relations between variables (Grych, Harold, \& Miles, 2003). The theoretical model proposed in Figure 1 explicitly hypothesizes that early childhood adversity and genetic factors act as precursors to disruptions in neurobiological, cognitive and emotional functioning which, through a bidirectional interplay, transfer effects to disruptive behaviors. It is possible, of course, that antisocial behavior may feed into the family system such that a child may experience heightened levels of family disruption (e.g., hostile parenting; Patterson \& Stouthamer-Loeber, 1984), which in turn may interact with genetic susceptibility to adversely affect neurobiological, cognitive, and emotional functioning. In addition, it may also be the case that children experiencing higher levels of behavioral disruption tend to view many situations, including family adversity 
(e.g., family conflict and negative parenting), as more threatening than do less behaviorally distressed children (see also our earlier discussion of appraisal patterns in antisocial children). Watson and Pennebaker (1989) noted that an individual's report of physical or psychological well-being may be affected by trait-level characteristics that determine long-term individual differences in affectivity in addition to state-level fluctuations in mood. According to Watson and Pennebaker, individuals who score high on trait negative affectivity are likely to experience a higher level of distress than others, even in the absence of any overt stress. As a result, these individuals tend to have a less favorable self-view and a more negative view of others (such as parents), and are generally less satisfied with themselves and their lives (i.e., disrupted cognitive and emotional functioning; Harold, Shelton, Goeke-Morey, \& Cummings, 2004). Thus, a trait-like negative affectivity could inflate the associations between self-reports of family adversity and any index of cognitive, emotional, or behavioral functioning.

Given that concurrent data cannot distinguish between these substantively different interpretations of the associations between family factors, neurobiological, cognitive, emotional, and behavioral functioning, a critical next step in building this area of research is to conduct prospective longitudinal studies that permit tests of the mediating and moderating factors that underlie early adverse influences on antisocial behavior in childhood. Collecting prospective data improves the confidence with which one can infer cause-and-effect relations because it provides an opportunity to examine changes in constructs over time, allows for tests of the influence of children's behavior on family adversity and vice versa, and makes it possible to control for a negative affectivity bias that might artifactually inflate zero-order associations between measures of cognitive, emotional, and behavioral functioning in childhood. In addition, a longitudinal research design also provides opportunity to control for initial levels of behavioral disruption (e.g., aggression) so that the impact of such disruption on neurobiological, cognitive, and emotional functioning may be assessed over time. For example, by including an initial estimate of behavior problems in assessment of the pathways hypothesized in our proposed theoretical model (see Figure 1, Path K), an estimate of change in later behavior as a function of all proposed mediating factors may be determined (Kessler \& Greenberg, 1981). Longitudinal studies, however, cannot provide definitive support for a causal relation between constructs because of the possibility that an unmeasured third variable could account for the associations, both concurrently and over time. Complementing longitudinal correlational studies with carefully designed and conducted experimental studies (a multimethod approach) serves as the gold standard by which future research in this area may be evaluated.

\section{Implications of the Model: The Mediating Role of Neurobiological Functioning}

We believe that a combination of genetic factors, either directly influencing the development of stress response systems (chiefly the HPA axis and the sympathetic nervous system) and the 5-HT neurotransmitter system or together with early exposure to adversity, act to predispose the individual towards more severe and persistent antisocial behavior. We also propose that an early deficit in HPA axis functioning and ANS system activity is particularly crucial in this developmental sequence (Raine et al., 1997) because it results in the individual becoming emotionally detached from his or her actions and unable to learn from what others might experience as negative events (e.g., punishment situations). If, as discussed before, the cortisol (HPA) and ANS responses to stress act as a form of warning signal to restrain ongoing behavior in situations of (psychological or physical) danger, then children who fail to activate these systems are likely to behave in a more disinhibited fashion. Again, this could arise because of genetic factors (such as polymorphisms in the gene encoding the glucocorticoid receptor, which confer increased sensitivity of HPA axis feedback mechanisms) or through exposure to uncontrollable stress or maltreatment in early childhood. Together these factors permanently compromise HPA axis and ANS function.

As explained above, we do not claim that antisocial children consistently fail to realize they are in danger or face punishment. These individuals have been shown not only to have a hostility bias, which leads them to appraise even ambiguous or innocuous situations as threatening (e.g., Milich \& Dodge, 1984), but also to experience more intense negative emotions than control participants when stressed (Van Goozen, Matthys, et al., 2000). What therefore seems to be the case is that their appraisal of the situation, that is, their understanding and appraisal of the danger, is not accompanied by contextually-appropriate patterns of emotional arousal, and does not lead to activation of autonomic or endocrine stress response systems. Moreover, children who, as a result of their risky or impulsive behavior, place themselves in threatening or dangerous situations might gradually become further desensitized to stress because of habituation. This leads to a vicious cycle in which the child becomes increasingly resistant to stress and is therefore able to place him- or herself in increasingly threatening situations. As a result of this genetically based hypersensitivity of the HPA axis, the experience of negative life events, and the frequent exposure to situations which other children experience as stressful, antisocial individuals may become unable to initiate normal stress responses in conditions that typically evoke anger, fear, or embarrassment.

It is also important to note that disturbances in HPA axis functioning could lead to 5-HT system impairments, which are associated with problems in impulse regulation and reactive aggression (see Figure 2). Given the key role of the prefrontal cortex in behavioral inhibition and the modulation of amygdala activity, reductions in 5-HT concentrations and changes in receptor sensitivity in the prefrontal cortex may be particularly important in this respect (Davidson, Putnam, \& Larson, 2000). In addition to the influence of the HPA axis on the development and functioning of the 5-HT system, it is of interest that there are important reciprocal connections between brain regions and systems implicated in aggression, that is, the amygdala, the prefrontal cortex, components of the 5-HT system, and the CRH neurons of the PVN which drive HPA axis activity (Herman et al., 2003). 5-HT receptors and glucocorticoid receptors are both expressed in the amygdala (Ahima, Krozowski, \& Harlan, 1991; Wright, Seroogy, Lundgren, Davis, \& Jennes, 1995), the amygdala being sensitive to circulating levels of glucocorticoids and receiving an extensive 5-HT innervation from the midbrain raphe (Kawahara, Yoshida, Yokoo, Nishi, \& Tanaka, 1993). It has been shown that 5-HT normally inhibits the excitability of amygdala neurons, an effect that is 
dependent on moderate concentrations of glucocorticoid hormones (Stutzmann, McEwen, \& LeDoux, 1998). In individuals with low basal cortisol levels and impaired 5-HT neurotransmission, amygdala function may be dysregulated, an effect that could be compounded by impairment of anterior cingulate function.

These neurobiological consequences of genetically based hypersensitivity of the HPA axis, early exposure to chronic stress, and self-selection for exciting but often dangerous or punishing environments have predictive power in terms of discriminating between those who persist in antisocial behavior and those who desist from such activities. Those individuals who are considered high risk because of the presence of early-life adversity, parental criminality, or APD, but who exhibit preserved or even enhanced basal ANS or HPA axis activity or emotional, ANS, and HPA axis reactivity to stress, seem to be protected from engaging in antisocial behavior or exhibit desistence from such behavior (Brennan et al., 1997; Van de Wiel et al., 2004). Interestingly, this finding holds even in adolescents who were already engaging in antisocial behavior (Raine, Venables, \& Williams, 1995) or who were clinically diagnosed with DBD in childhood (Van Bokhoven, Matthys, et al., 2005). Thus normal HPA axis functioning and high autonomic reactivity both appear to serve as protective factors that permit the individual to exercise a greater degree of self-control over behavior. Raine, Brennan, and Farrington (1997) proposed that those who desist from antisocial behavior have a more open attentional stance to the environment as opposed to the narrowly focused attention of the persistent offender. Because of their attentional openness, the desisting group could be more responsive to new situations or to new behavioral contingencies and could also be more fearful and conscientious (see also Babcock, Green, Webb, \& Yerington, 2005).

\section{Implications for Intervention}

As with any theory, it is important that our proposed model generates hypotheses that can be tested in a causal context. One prediction arising from the model is that reinstatement of normal HPA axis functioning, perhaps by temporarily saturating glucocorticoid receptors to reduce their sensitivity in the long term, should ameliorate some forms of disruptive behavior and enhance the response to therapeutic interventions. By restoring stress response systems to a relatively normal state of activity, it may be possible to repair the apparent disjunction between strong emotional reactions (often inappropriate or seemingly out of proportion to the precipitating conditions) and weak or nonexistent stress responses to situations that normally elicit anger, embarrassment, or fear. This connection between the cognitive and emotional components of an experience and the accompanying physiological reaction may be crucial for some aspects of emotional regulation and development. Clearly, to accomplish this reinstatement of stress reactivity, we need to know more about the functioning of stress response systems in children and adolescents with DBDs. In particular, further research is required to investigate the regulatory mechanisms acting on the HPA axis in these individuals, as low basal cortisol concentrations or reduced cortisol reactivity could result from changes at several different levels of the axis (e.g., blunting of the ACTH response to $\mathrm{CRH}$, ACTH receptor downregulation in the anterior pituitary, or increased sensitivity of the negative feedback mechanisms which restrain HPA axis activity).
In affective disorders such as unipolar depression, the HPA axis appears to be dysregulated at several levels, and both structural and functional elements of the system are affected (Holsboer, 2000). Given the heterogeneity of groups of children with antisocial behavior, and the high rates of comorbidity with affective disorders, anxiety, and posttraumatic stress, it is likely that the situation is even more complex in aggressive and antisocial individuals. It will also be instructive to understand more about the temporal characteristics of the HPA axis dysregulation observed in these individuals. For example, does impairment of the autonomic and endocrine response to stress precede the onset of antisocial behavior, or is it a consequence of engaging in such behavior? We would assert that it is the former, but longitudinal studies examining this question are needed. They would allow further identification of endocrine or neurobiological markers that would aid prediction of life outcomes, prioritization of treatment resources, development of new types of psychological intervention, and discovery of novel pharmacological treatment targets (e.g., the glucocorticoid receptor or CRH receptor). In addition, such studies would enable us to develop early interventions that are effective in deflecting the path of the would-be life-course persistent offender.

In conclusion, despite massive efforts to eliminate antisocial behavior we are still confronted by aggression, antisocial behavior and violence in our everyday lives (World Health Organization, 2002). Moreover, very costly interventions designed to reduce or prevent antisocial behavior often prove on average only modestly successful. As Moffitt (2005) recently put it, "Valuable resources have been wasted because intervention programs have proceeded on the basis of risk factors without sufficient research to understand causal processes" (p. 534). We believe that a better understanding of the neurobiological correlates of antisocial and aggressive behavior will prove essential for the prevention and treatment of persistent antisocial behavior in children and adults.

\section{References}

Achenbach, T. (1991). Manual for the Youth Self Report and 1991 Profile. Burlington, VT: University of Vermont, Department of Psychiatry.

Adolphs, R., Tranel, D., Damasio, H., \& Damasio, A. R. (1994, December 15). Impaired recognition of emotion in facial expressions following bilateral damage to the human amygdala. Nature, 372, 669-672.

Adolphs, R., Tranel, D., Damasio, H., \& Damasio, A.R. (1995). Fear and the human amygdala. Journal of Neuroscience, 15, 5879-5891.

Ahima, R., Krozowski, Z., \& Harlan, R. (1991). Type I corticosteroid receptor-like immunoreactivity in the rat CNS: Distribution and regulation by corticosteroids. Journal of Comparative Neurology, 313, 522538.

Amaral, D. G. (2003). The amygdala, social behaviour, and danger detection. Annals of the New York Academy of Sciences, 1000, 337-347.

American Psychiatric Association. (1994). Diagnostic and statistical manual of mental disorders (4th ed.). Washington, DC: Author.

Angrilli, A., Mauri, A., Palomba, D., Flor, H., Birbaumer, N., Sartori, G., et al. (1996). Startle reflex and emotion modulation impairment after a right amygdala lesion. Brain, 119, 1991-2000.

Archer, J. (1991). The influence of testosterone on human aggression. British Journal of Psychology, 82, 1-28.

Archer, J., Graham-Kevan, N., \& Davies, M. (2005). Testosterone and aggression: A reanalysis of Book, Starzyk, and Quinsey's (2001) study. Aggression and Violent Behavior, 10, 241-261.

Armenteros, J. L., \& Lewis, J. E. (2002). Citalopram treatment for impulsive aggression in children and adolescents: An open pilot study. Journal 
of the American Academy of Child and Adolescent Psychiatry, 41, 522-529.

Ashman, S. B., Dawson, G., Panagiotides, H., Yamada, E., \& Wilkinson, C. W. (2002). Stress hormone levels of children of depressed mothers. Development and Psychopathology, 14, 333-349.

Azar, R., Zoccolillo, M., Paquette, D., Quiros, E., Baltzer, F., \& Tremblay, R. E. (2004). Cortisol levels and conduct disorder in adolescent mothers. Journal of the American Academy of Child and Adolescent Psychiatry, 43, 461-468.

Babcock, J. C., Green, C. E., Webb, S. A., \& Yerington, T. P. (2005). Psychophysiological profiles of batterers: Autonomic emotional reactivity as it predicts the antisocial spectrum of behavior among intimate partner abusers. Journal of Abnormal Psychology, 114, 444-455.

Bagdy, G. (1996). Role of the hypothalamic paraventricular nucleus in 5-HT1A, 5-HT2A and 5-HT2C receptor-mediated oxytocin, prolactin and ACTH/corticosterone responses. Behavioral Brain Research, 73, 277-280.

Banks, T., \& Dabbs, J. M., Jr. (1996). Salivary testosterone and cortisol in a delinquent and violent urban subculture. Journal of Social Psychology, 136, 49-56.

Bardone, A. M., Moffitt, T. E., Caspi, A., Dickson, N., Stanton, W. R., \& Silva, P. A. (1998). Adult physical health outcomes of adolescent girls with conduct disorder, depression and anxiety. Journal of the American Academy of Child and Adolescent Psychiatry, 37, 594-601.

Barnes, N. M., \& Sharp, T. (1999). A review of central 5-HT receptors and their function. Neuropharmacology, 38, 1083-1152.

Bergman, B., \& Brismar, B. (1994). Hormone levels and personality traits in abusive and suicidal male alcoholics. Alcoholism, Clinical and Experimental Research, 18, 311-316.

Berman, M. E., Kavoussi, R. J., \& Coccaro, E. F. (1997). Neurotransmitter correlates of human aggression. In D. M. Stoff, J. Breiling, \& J. D. Maser (Eds.), Handbook of antisocial behavior (pp. 305-313). New York: Wiley.

Biederman, J., Munir, K., \& Knee, D. (1987). Conduct and oppositional disorder in clinic referred children with attention deficit disorder: A controlled family study. Journal of the American Academy of Child and Adolescent Psychiatry, 26, 724-727.

Birmaher, B., Stanley, M., Greenhill, L., Twomey, J., Gavrilescu, A., \& Rabinovich, H. (1990). Platelet imipramine binding in children and adolescents with impulsive behavior. Journal of the American Academy of Child and Adolescent Psychiatry, 29, 914-918.

Bjork, J. M., Dougherty, D. M., Moeller, F. G., Cherek, D. R., \& Swann, A. C. (1999). The effects of tryptophan depletion and loading on laboratory aggression in men: Time course and a food-restricted control. Psychopharmacology, 142, 24-30.

Bjork, J. M., Dougherty, D. M., Moeller, F. G., \& Swann, A. C. (2000). Differential behavioral effects of plasma tryptophan depletion and loading in aggressive and non-aggressive men. Neuropsychopharmacology, 22, 357-369.

Blair, R. J. R., Colledge, E., Murray, L., \& Mitchell, D. G. V. (2001). A selective impairment in the processing of sad and fearful expressions in children with psychopathic tendencies. Journal of Abnormal Child Psychology, 29, 491-498.

Blanchard, D. C., Hori, K., Rodgers, R. J., Hendrie, C. A., \& Blanchard, R. J. (1989). Attenuation of defensive threat and attack in wild rats (Rattus rattus) by benzodiazepines. Psychopharmacology, 97, 392-401. Blumensohn, R., Ratzoni, G., Weizman, A., Israeli, M., Greuner, N., Apter, A., et al. (1995). Reduction in serotonin 5-HT2 receptor binding on platelets of delinquent adolescents. Psychopharmacology, 118, 354356.

Bohman, M. (1996). Predisposition to criminality: Swedish adoption studies in retrospect. In G. R. Bock \& J. A. Goode (Eds.), Genetics of criminal and antisocial behaviour (pp. 99-114). Chichester, England: Wiley.
Bohman, M., Cloninger, C. R., Sigvardsson, S., \& von Knorring, A. L. (1982). Predisposition to petty criminality in Swedish adoptees: I. Genetic and environmental heterogeneity. Archives of General Psychiatry, 39, 1233-1241.

Bollen, K. A. (1989). Structural equations with latent variables. New York: Wiley.

Bouwknecht, J. A., Hijzen, T. H., Van der Gugten, J., Maes, R. A., Hen, R., \& Olivier, B. (2001). Absence of 5-HT(1B) receptors is associated with impaired impulse control in male 5-HT(1B) knockout mice. Biological Psychiatry, 49, 557-568.

Bremner, J. D., \& Vermetten, E. (2001). Stress and development: Behavioral and biological consequences. Development and Psychopathology, $13,473-489$.

Brennan P. A., Raine, A., Schulsinger, F., Kirkegaard-Sorensen, L., Knop, J., Hutchings, B., et al. (1997). Psychophysiological protective factors for male subjects at high risk for criminal behavior. American Journal of Psychiatry, 154, 853-855.

Brown, G. L., Ebert, M. H., Goyer, P. F., Jimerson, D. C., Klein, W. J., Bunney, W. E., et al. (1982). Aggression, suicide, and serotonin: Relationships to CSF amine metabolites. American Journal of Psychiatry, 139, 741-746.

Brown, G. L., Goodwin, F. K., Ballenger, J. C., Goyer, P. F., \& Major, L. F. (1979). Aggression in humans correlates with cerebrospinal fluid amine metabolites. Psychiatry Research, 1, 131-139.

Brunner, H. G., Nelen, M., Breakefield, X. O., Ropers, H. H., \& van Oost, B. A. (1993, October 22). Abnormal behavior associated with a point mutation in the structural gene for monoamine oxidase A. Science, 262, $578-580$.

Brunner, H. G., Nelen, M. R., van Zandvoort, P., Abeling, N. G., van Gennip, A. H., Walters, E. C., et al. (1993). X-linked borderline mental retardation with prominent behavioral disturbance: Phenotype, genetic localization, and evidence for disturbed monoamine metabolism. American Journal of Human Genetics, 52, 1032-1039.

Buchanan, T. W., \& Lovallo, W. R. (2001). Enhanced memory for emotional material following stress-level cortisol treatment in humans. Psychoneuroendocrinology, 26, 307-317.

Bushman, B. J., \& Anderson, C. A. (2001). Is it time to pull the plug on the hostile versus instrumental aggression dichotomy? Psychological Review, 108, 273-279.

Cadoret, R. J., Yates, W. R., Troughton, E., Woodworth, G., \& Stewart, M. A. (1995). Genetic-environmental interaction in the genesis of aggressivity and conduct disorders. Archives of General Psychiatry, 52, 916-924.

Calder, A. J., Young, A. W., Rowland, D., Perrett, D. I., Hodges, J. R., \& Etcoff, N. L. (1996). Facial emotion recognition after bilateral amygdala damage: Differentially severe impairment of fear. Cognitive Neuropsychology, 13, 699-745.

Carlson, M., \& Earls, F. (1997). Psychological and neuroendocrinological sequelae of early social deprivation in institutionalized children in Romania. Annals of the New York Academy of Sciences, 807, 419-428.

Cases, O., Seif, I., Grimsby, J., Gaspar, P., Chen, K., Pournin, S., et al. (1995, June 23). Aggressive behavior and altered amounts of brain serotonin and norepinephrine in mice lacking MAO-A. Science, 268, $1763-1766$

Cases, O., Vitalis, T., Seif, I., De Maeyer, E., Sotelo, C., \& Gaspar, P. (1996). Lack of barrels in somatosensory cortex of monoamineoxidase-A deficient mice: Role of a serotonin excess during the critical period. Neuron, 16, 297-307.

Caspi, A., \& Bem, D. (1990). Personality continuity and change across the life course. In L. Pervin (Ed.), Handbook of personality: Theory and research (pp. 549-575). New York: Guilford Press.

Caspi, A., Henry, B., McGee, R. O., Moffitt, T. E., \& Silva, P. A. (1995). Temperamental origins of child and adolescent behavior problems: From age three to age fifteen. Child Development, 66, 55-68. 
Caspi, A., McClay, J., Moffitt, T. E., Mill, J., Martin, J., Craig, I. W., et al. (2002, August 2). Role of the genotype in the cycle of violence in maltreated children. Science, 297, 851-854.

Caspi, A., \& Moffitt, T. E. (1995). The continuity of maladaptive behavior: From description to understanding in the study of antisocial behavior. In D. Cicchetti \& D. Cohen (Eds.), Manual of developmental psychopathology (pp. 472-511). New York: Wiley.

Castellanós, F. X., Elia, J., Kruesi, M. J., Gulotta, C. S., Mefford, I. N., Potter, W. Z., et al. (1994). Cerebrospinal fluid monoamine metabolites in boys with attention-deficit hyperactivity disorder. Psychiatry Research, 52, 305-316.

Chalmers, D. T., Kwak, S. P., Mansour, A., Akil, H., \& Watson, S. J. (1993). Corticosteroids regulate brain hippocampal 5-HT1A receptor mRNA expression. Journal of Neuroscience, 13, 914-923.

Chaouloff, F. (1995). Regulation of 5-HT receptors by corticosteroids: Where do we stand? Fundamental and Clinical Pharmacology, 9, 219233.

Chrousos, G. P., \& Gold, P. W. (1992). The concepts of stress and stress system disorders: Overview of physical and behavioral homeostasis. Journal of the American Medical Association, 267, 1244-1252.

Cicchetti, D., \& Rogosch, F. A. (2001). The impact of child maltreatment and psychopathology on neuroendocrine functioning. Development and Psychopathology, 13, 783-804.

Clow, A., Thorn, L., Evans, P., \& Hucklebridge, F. (2004). The awakening cortisol response: Methodological issues and significance. Stress, 7 , 29-37.

Coccaro, E. F. (1989). Central serotonin and impulsive aggression. British Journal of Psychiatry Supplement, 8, 52-62.

Coccaro, E. F., Gabriel, S., \& Siever, L. J. (1990). Buspirone challenge: Preliminary evidence for a role for central 5-HT1a receptor function in impulsive aggressive behavior in humans. Psychopharmacology Bulletin, 26, 393-405.

Coccaro, E. F., \& Kavoussi, R. J. (1994). Neuropsychopharmacologic challenge in biological psychiatry. Clinical Chemistry, 40, 319-327.

Coccaro, E. F., \& Kavoussi, R. J. (1996). Neurotransmitter correlates of impulsive aggression. In D. M. Stoff \& R. B. Cairns (Eds.), Aggression and violence: Genetic, neurobiological and biological perspectives ( $\mathrm{pp}$. 67-85). Mahwah, NJ: Erlbaum.

Coccaro, E. F., \& Kavoussi, R. J. (1997). Fluoxetine and impulsive aggressive behavior in personality-disordered subjects. Archives of General Psychiatry, 54, 1081-1088.

Coccaro, E. F., Kavoussi, R. J., Cooper, T. B., \& Hauger, R. L. (1997). Central serotonin activity and aggression: Inverse relationship with prolactin response to d-fenfluramine, but not CSF 5-HIAA concentration, in human subjects. American Journal of Psychiatry, 154, 14301435.

Coccaro, E. F., Kavoussi, R. J., Sheline, Y. I., Berman, M. E., \& Csernansky, J. G. (1997). Impulsive aggression in personality disorder correlates with platelet 5-HT2A receptor binding. Neuropsychopharmacology, 16, 211-216.

Coccaro, E. F., Kavoussi, R. J., Sheline, Y. I., Lish, J. D., \& Csernansky, J. G. (1996). Impulsive aggression in personality disorder correlates with tritiated paroxetine binding in the platelet. Archives of General Psychiatry, 53, 531-536.

Coccaro, E. F., Siever, L. J., Klar, H. M., Maurer, G., Cochrane, K., Cooper, T. B., et al. (1989). Serotonergic studies in patients with affective and personality disorders: Correlates with suicidal and impulsive aggressive behavior. Archives of General Psychiatry, 46, 587-599.

Cohen, J. (1988). Statistical power analysis for the behavioral sciences. Hillsdale, NJ: Erlbaum.

Constantino, J. N., Grosz, D., Saenger, P., Chandler, D. W., Nandi, R., \& Earls, F. J. (1993). Testosterone and aggression in children. Journal of the American Academy of Child and Adolescent Psychiatry, 32, 12171222.
Constantino, J. N., Liberman, M., \& Kincaid, M. (1997). Effects of serotonin reuptake inhibitors on aggressive behavior in psychiatrically hospitalized adolescents: Results of an open trial. Journal of Child and Adolescent Psychopharmacology, 7, 31-44.

Cook, E. H., Jr., Stein, M. A., Ellison, T., Unis, A. S., \& Leventhal, B. L. (1995). Attention deficit hypeactivity disorder and whole-blood serotonin levels: Effects of comorbidity. Psychiatry Research, 57, 13-20.

Coplan, J. D., Andrews, M. W., Rosenblum, L. A., Owens, M. J., Friedman, S., Gorman, J. M., et al. (1996). Persistent elevations of cerebrospinal fluid concentrations of corticotropin-releasing factor in adult nonhuman primates exposed to early-life stressors: Implications for the pathophysiology of mood and anxiety disorders. Proceedings of the National Academy of Sciences, USA, 93, 1619-1623.

Cyranowski, J. M., Frank, E., Young, E., \& Shear, K. (2000). Adolescent onset of the gender difference in lifetime rates of major depression. Archives of General Psychiatry, 57, 21-27.

Dabbs, J. M., Jr., Frady, R. L., Carr, T. S., \& Besch, N. F. (1987). Saliva testosterone and criminal violence in young adult prison inmates. Psychosomatic Medicine, 49, 174-182.

Dabbs, J. M., Jr., Jurkovic, G. J., \& Frady, R. L. (1991). Salivary testosterone and cortisol among late adolescent male offenders. Journal of Abnormal Child Psychology, 19, 469-478.

Dabbs, J. M., \& Morris, R. (1990). Testosterone, social class, and antisocial behavior in a sample of 4462 men. Psychological Science, 1, 209-211

Dackis, C. A., \& O'Brien, C. P. (2001). Cocaine dependence: A disease of the brain's reward centers. Journal of Substance Abuse Treatment, 21, 111-117.

Davidson, R. J., Putnam, K. M., \& Larson, C. L. (2000, July 28). Dysfunction in the neural circuitry of emotion regulation-a possible prelude to violence. Science, 289, 591-594.

Dawes, M. A., Dorn, L. D., Moss, H. B., Yao, J. K., Kirisci, L., Ammerman, R. T., \& Tarter, R. E. (1999). Hormonal and behavioral homeostasis in boys at risk for substance abuse. Drug and Alcohol Dependence, 55, 165-176.

Dawson, G., Ashman, S. B., \& Carver, L. J. (2000). The role of early experience in shaping behavioral and brain development and its implications for social policy. Development and Psychopathology, 12, 695712 .

de Almeida, R. M. M., \& Miczek, K. A. (2002). Aggression escalated by social instigation or by discontinuation of reinforcement ("frustration") in mice: Inhibition by anpirtoline-a $5-\mathrm{HT}_{1 \mathrm{~B}}$ receptor agonist. Neuropsychopharmacology, 27, 171-181.

De Bellis, M. H., Baum, A. S., Birmaher, B., Keshavan, M. S., Eccard, C. H., Boring, A. M., et al. (1999). Developmental traumatology Part I: Biological stress systems. Biological Psychiatry, 45, 1259-1270.

de Bruin, J. P., Van Oyen, H. G., \& Van de Poll, N. (1983). Behavioural changes following lesions of the orbital prefrontal cortex in male rats. Behavioural Brain Research, 10, 209-232.

de Quervain, D. J.-F., Roozendaal, B., Nitsch, R. M., McGaugh, J. L., \& Hock, C. (2000). Acute cortisone administration impairs retrieval of long-term declarative memory in humans. Nature Neuroscience, 3, 313314 .

Dettling, A. C., Feldon, J., \& Pryce, C. R. (2002). Repeated parental deprivation in the infant common marmoset (callithrix jacchus, primates) and analysis of its effects on early development. Biological Psychiatry, 52, 1037-1046.

Deuschle, M., Schweiger, U., Weber, B., Gotthardt, U., Korner, A., Schmider, J., et al. (1997). Diurnal activity and pulsatility of the hypothalamus-pituitary-adrenal system in male depressed patients and healthy controls. Journal of Clinical Endocrinology and Metabolism, 82, 234-238.

Dmitrieva, T. N., Oades, R. D., Hauffa, B. P., \& Eggers, C. (2001). Dehydro-epiandrosterone sulphate and corticotropin levels are high in young male patients with conduct disorder: Comparisons for growth 
factors, thyroid and gonadal hormones. Neuropsychobiology, 43, 134140.

Domes, G., Heinrichs, M., Reichwald, U., \& Hautzinger, M. (2002). Hypothalamic-pituitary-adrenal axis reactivity to psychological stress and memory in middle-aged women: High responders exhibit enhanced declarative memory performance. Psychoneuroendocrinology, 27, 843853.

Donovan, A. M., Halperin, J. M., Newcorn, J. H., \& Sharma, V. (1999). Thermal response to sertonergic challenge and aggression in attention deficit hyperactivity disorder children. Journal of Child and Adolescent Psychopharmacology, 9, 85-91.

Downey, G. \& Coyne, J. C. (1990). Children of depressed parents: An integrative review. Psychological Bulletin, 108, 50-76.

Duval, F., Crocq, M. A., Guillon, M. S., Mokrani, M. C., Monreal, J., Bailey, P., et al. (2004). Increased adrenocorticotropin suppression following dexamethasone administration in sexually abused adolescents with posttraumatic stress disorder. Psychoneuroendocrinology, 29, $1281-1289$

Ehrenkranz, J., Bliss, E., \& Sheard, M. H. (1974). Plasma testosterone: Correlation with aggressive behavior and social dominance in man. Psychosomatic Medicine, 36, 469-475.

Eley, T. C., Lichtenstein, P., \& Moffitt, T. E. (2003). A longitudinal behavioral genetic analysis of the etiology of aggressive and nonaggressive antisocial behavior. Development and Psychopathology, 15, 383-402.

El-Sheikh, M., \& Harger, J. (2001). Appraisals of marital conflict and children's adjustment, health, and physiological reactivity. Developmental Psychology, 37, 875-885.

El-Sheikh, M., Harger, J., \& Whitson, S. (2001). Exposure to interparental conflict and children's adjustment and physical health: The moderating role of vagal tone. Child Development, 72, 1617-1636.

Emery, N. J., Capitanio, J. P., Mason, W. A., Machado, C. J., Mendoza, S. P., \& Amaral, D. G. (2001). The effects of bilateral lesions of the amygdala on dyadic social interactions in rhesus monkeys (Macaca mulatta). Behavioral Neuroscience, 115, 515-544.

Erel, O., \& Burman, B. (1995). Interrelatedness of marital relations and parent-child relations: A meta-analytic review. Psychological Bulletin, $118,108-132$.

Fairchild, G., Leitch, M. M., \& Ingram, C. D. (2003). Acute and chronic effects of corticosterone on 5-HT1A receptor-mediated autoinhibition in the rat dorsal raphe nucleus. Neuropharmacology, 45, 925-934.

Farrington, D. P., Jolliffe, D., Loeber, R., Stouthamer-Loeber, M., \& Kalb, L. (2001). The concentration of offenders in families, and family criminality in the prediction of boys' delinquency. Journal of Adolescence, $24,579-596$

Fava, M., Rosenblum, J. F., Pava, J. A., McCarthy, M. K., Steingard, R. J., \& Bouffides, E. (1993). Anger attacks in unipolar depression: Part 1. Clinical correlates and response to fluoxetine treatment. American Journal of Psychiatry, 150, 1158-1163.

Fishbein, D. H., Lozovsky, D., \& Jaffe, J. H. (1989). Impulsivity, aggression, and neuroendocrine responses to serotonergic stimulation in substance abusers. Biological Psychiatry, 25, 1049-1066.

Foley, D. L., Eaves, L. J., Wormley, B., Silberg, J. L., Maes, H. H., Kuhn, J., et al. (2004). Childhood adversity, monoamine oxidase A genotype, and risk for conduct disorder. Archives of General Psychiatry, 61, $738-744$.

Fombonne, E., Wostear, G., Cooper, V., Harrington, R., \& Rutter, M. (2001). The Maudsley long-term follow-up of child and adolescent depression: I. Psychiatric outcomes in adulthood. British Journal of Psychiatry, 179, 210-217.

Fowles, D. C., \& Furuseth, A. M. (1994). Electrodermal hyporeactivity and antisocial behavior. In D. K. Routh (Ed.), Disruptive behavior disorders in childhood (pp. 181-205). New York: Plenum Press.

Fuller, R. W. (1992). The involvement of serotonin in regulation of pituitary-adrenocortical function. Frontiers in Neuroendocrinology, 13, $250-270$.

Garralda, M. E., Connell, J., \& Taylor, D. C. (1991). Psychophysiological anomalies in children with emotional and conduct disorders. Psychological Medicine, 21, 947-957.

Gartside, S. E., Johnson, D. A., Leitch, M. M., Troakes, C., \& Ingram, C. D. (2003). Early life adversity programs changes in central 5-HT neuronal function in adulthood. European Journal of Neuroscience, 17, 2401-2408.

Gartside, S. E., Leitch, M. M., \& Young, A. H. (2003). Altered glucocorticoid rhythm attenuates the ability of a chronic SSRI to elevate forebrain 5-HT: Implication for the treatment of depression. Neuropsychopharmacology, 28, 1572-1578.

Genazzani, A. R., Facchinetti, F., Pintor, C., Puggioni, R., Parrini, D., Petraglia, F., et al. (1983). Proopiocortin-related peptide plasma levels throughout prepuberty and prepuberty. Journal of Clinical Endocrinology and Metabolism, 57, 56-61.

Gerra, G., Zaimovic, A., Avanzini, P., Chittolini, B., Giucastro, G., Palladino, M., et al. (1997). Neurotransmitter-neuroendocrine responses to experimentally induced aggression in humans: Influence of personality variable. Psychiatry Research, 66, 33-43.

Ghaziuddin, N., \& Alessi, N. E. (1992). An open clinical trial of trazodone in aggressive children. Journal of Child and Adolescent Psychopharmacology, 2, 291-298.

Goldberg, S., Levitan, R., Leung, E., Masellis, M., Basile, V. S., Nemeroff, C. B., et al. (2003). Cortisol concentrations in 12- to 18-month-old infants: Stability over time, location and stressor. Biological Psychiatry, 54, 719-726.

Goodyer, I. M., Herbert, J., \& Tamplin, A. (2003). Psychoendocrine antecedents of persistent first-episode major depression in adolescents: A community-based longitudinal enquiry. Psychological Medicine, 33, 601-610.

Granger, D. A., Shirtcliff, E. A., Zahn-Waxler, C., Usher, B., KlimesDougan, B., \& Hastings, P. (2003). Salivary testosterone diurnal variation and psychopathology in adolescent males and females: Individual differences and developmental effects. Development and Psychopathology, 15, 431-449.

Grych, J. H., Harold, G. T., \& Miles, C. J. (2003). A prospective investigation of appraisals as mediators of the link between interparental conflict and child adjustment. Child Development, 74, 1176-1193.

Gunnar, M. R., \& Donzella, B. (2002). Social regulation of the cortisol levels in early human development. Psychoneuroendocrinology, 27, 199-220.

Gunnar, M. R., Morison, S. J., Chisholm, K., \& Schuder, M. (2001). Salivary cortisol levels in children adopted from Romanian orphanages. Development and Psychopathology, 13, 611-628.

Halász, J., Liposits, Z., Kruk, M. R., \& Haller, J. (2002). Neural background of glucocorticoid dysfunction-induced abnormal aggression in rats: Involvement of fear- and stress-related structures. European Journal of Neuroscience, 15, 561-569.

Haller, J., Halász, J., Mikics, E., \& Kruk, M. R. (2004). Chronic glucocorticoid deficiency-induced abnormal aggression, autonomic hypoarousal, and social deficit in rats. Journal of Neuroendocrinology, 16, 550-557.

Haller, J., Mikics, E., Halasz, J., \& Toth, M. (2005). Mechanisms differentiating normal from abnormal aggression: Glucocorticoids and serotonin. European Journal of Pharmacology, 526, 89-100.

Haller, J., van de Schraaf, J., \& Kruk, M. R. (2001). Deviant forms of aggression in glucocorticoid hyporeactive rats: A model for 'pathological' aggression? Journal of Neuroendocrinology, 13, 102-107.

Halperin, J. M., Newcorn, J. H., Kopstein, I., McKay, K. E., Schwartz, S. T., Siever, L. J., et al. (1997). Serotonin, aggression, and parental psychopathology in children with attention-deficit hyperactivity disorder. Journal of the American Academy of Child and Adolescent Psychiatry, 36, 1391-1398. 
Halperin, J. M., Sharma, V., Siever, L. J., Schwartz, S. T., Matier, K., Wornell, G., et al. (1994). Serotonergic function in aggressive and nonaggressive boys with attention deficit hyperactivity disorder. American Journal of Psychiatry, 151, 243-248.

Hanna, G. L., Yuwiler, A., \& Coates, J. K. (1995). Whole blood serotonin and disruptive behaviors in juvenile obsessive-compulsive disorder. Journal of the American Academy of Child and Adolescent Psychiatry, 34, 28-35.

Hariri, A. R., Mattay, V. S., Tessitore, A., Fera, F., \& Weinberger, D. R. (2003). Neocortical modulation of the amygdala response to fearful stimuli. Biological Psychiatry, 53, 494-501.

Hariri, A. R., Mattay, V. S., Tessitore, A., Kolachana, B., Fera, F., Goldman, D., et al. (2002, July 19). Serotonin transporter genetic variation and the response of the human amygdala. Science, 297, 400-403.

Harmer, C. J., Bhagwagar, Z., Shelley, N., \& Cowen, P. J. (2003). Contrasting effects of citalopram and reboxetine on waking salivary cortisol. Psychopharmacology, 167, 112-114.

Harold, G. T., \& Conger, R. D. (1997). Marital conflict and adolescent distress: The role of adolescent awareness. Child Development, 68, 333-350.

Harold, G. T., Shelton, K. H., Goeke-Morey, M. C., \& Cummings, E. M. (2004). Marital conflict, child emotional security about family relationships and child adjustment. Social Development, 13, 350-376.

Heim, C., Ehlert, U., \& Hellhammer, D. H. (2000). The potential role of hypocortisolism in the pathophysiology of stress-related bodily disorders. Psychoneuroendocrinology, 25, 1-35.

Heim, C., Newport, D. J., Bonsall, R., Miller, A. H., \& Nemeroff, C. B. (2001). Altered pituitary-adrenal axis responses to provocative challenge tests in adult survivors of childhood abuse. American Journal of Psychiatry, $158,575-581$.

Heim, C., Newport, D. J., Heit, S., Graham, Y. P., Wilcox, M., Bonsall, R., et al. (2000). Pituitary-adrenal and autonomic responses to stress in women after sexual and physical abuse in childhood. Journal of the American Medical Association, 284, 592-597.

Herman, B. H., Arthur-Smith, A., Hammock, M. K., \& Josephs, S. (1988). Ontogeny of beta-endorphin and cortisol in the plasma of children and adolescents. Journal of Clinical Endocrinology and Metabolism, 67, $186-190$

Herman, J. P., Figueiredo, H., Mueller, N. K., Ulrich-Lai, Y., Ostrander, M. M., Choi, D. C., et al. (2003). Central mechanisms of stress integration: Hierarchical circuitry controlling hypothalamo-pituitaryadrenocortical responsiveness. Frontiers in Neuroendocrinology, 24, 151-180.

Higley, J. D., Mehlman, P. T., Poland, R. E., Taub, D. M., Vickers, J., Suomi, S. J., et al. (1996). CSF testosterone and 5-HIAA correlate with different types of aggressive behaviours. Biological Psychiatry, 40, 1067-1082

Higley, J. D., Mehlman, P. T., Taub, D. M., Higley, S. B., Suomi, S. J., Vickers, J. H., et al. (1992). Cerebrospinal fluid monoamine and adrenal correlates of aggression in free-ranging rhesus monkeys. Archives of General Psychiatry, 49, 436-441.

Higley, J. D., Thompson, W. W., Champoux, M., Goldman, D., Hasert, M. F., Kraemer, G. W., et al. (1993). Paternal and maternal genetic and environmental contributions to cerebrospinal fluid monoamine metabolites in rhesus monkeys (Macaca mulatta). Archives of General Psychiatry, 50, 615-623.

Hinshaw, S. P. (1987). On the distinction between attentional deficits/ hyperactivity and conduct problems/aggression in child psychopathology. Psychological Bulletin, 101, 443-446.

Holsboer, F. (2000). The corticosteroid receptor hypothesis of depression. Neuropsychopharmacology, 23, 477-501.

Huesmann, L. R., Eron, L. D., Lefkowitz, M. M., \& Walder, L. O. (1984). Stability of aggression over time and generations. Developmental Psychology, 20, 1120-1134.
Huether, G. (1996). The central adaptation syndrome: Psychosocial stress as a trigger for adaptive modifications of brain structure and brain function. Progress in Neurobiology, 48, 569-612.

Hughes, C. W., Petty, F., Sheikha, S., \& Kramer, G. L. (1996). Wholeblood serotonin in children and adolescents with mood and behavior disorders. Psychiatry Research, 65, 79-95.

Huizink, A. C., Mulder, E. J. H., \& Buitelaar, J. K. (2004). Prenatal stress and risk for psychopathology: Specific effects or induction of general susceptibility. Psychological Bulletin, 130, 115-142.

Iaboni, F., Douglas, V. I., \& Ditto, B. (1997). Psychophysiological response of ADHD children to reward and extinction. Psychophysiology, $34,116-123$.

Inglis, G. C., Ingram, M. C., Holloway, C. D., Swan, L., Birnie, D., Hillis, W. S., et al. (1999). Familial pattern of corticosteroids and their metabolism in adult human subjects: The Scottish Adult Twin Study. Journal of Clinical Endocrinology and Metabolism, 84, 4132-4137.

Jacobs, B. L., \& Azmitia, E. C. (1992). Structure and function of the brain serotonin system. Physiological Reviews, 72, 165-229.

Karishma, K. K., \& Herbert, J. (2002). Dehydroepiandrosterone (DHEA) stimulates neurogenesis in the hippocampus of the rat, promotes survival of newly formed neurons and prevents corticosterone-induced suppression. European Journal of Neuroscience, 16, 445-453.

Kariyawasam, S. H., Zaw, F., \& Handley, S. L. (2002). Reduced salivary cortisol in children with comorbid attention deficit hyperactivity disorder and oppositional defiant disorder. Neuroendocrinology Letters, 23, $45-48$.

Karten, Y. J., Nair, S. M., van Essen, L. Sibug, R., \& Joëls, M. (1999). Long-term exposure to high corticosterone levels attenuates serotonin responses in rat hippocampal CA1 neurons. Proceedings of the National Academy of Sciences, USA, 96, 13456-13461.

Kavoussi, R. J., Liu, J., \& Coccaro, E. F. (1994). An open trial of sertraline in personality disordered patients with impulsive aggression. Journal of Clinical Psychiatry, 55, 137-141.

Kawahara, H., Yoshida, M., Yokoo, H., Nishi, M., \& Tanaka, M. (1993). Psychological stress increases serotonin release in the rat amygdala and prefrontal cortex assessed by in vivo microdialysis. Neuroscience Letters, 162, 81-84.

Kazdin, A. (1995). Conduct disorders in childhood and adolescence (2nd ed.). Thousand Oaks, CA: Sage.

Kazdin, A. (2001). Treatment of conduct disorders. In J. Hill \& B. Maughan (Eds.), Conduct disorders in childhood and adolescence (pp. 408-448). Cambridge, England: Cambridge University Press.

Kessler, R. C., \& Greenberg, D. F. (1981). Linear panel analysis. New York: Academic Press.

Kimonides, V. G., Spillantini, M. G., Sofroniew, M. V., Fawcett, J. W., \& Herbert, J. (1999). Dehydroepiandrosterone antagonizes the neurotoxic effects of corticosterone and translocation of stress-activated protein kinase 3 in hippocampal primary cultures. Neuroscience, 89, 429-436.

Kirschbaum, C., Kudielka, B., Gaab, J., Schommer, N., \& Hellhammer, D. H. (1999). Impact of gender, menstrual cycle phase and oral contraceptives on the activity of the hypothalamus-pituitary-adrenal axis. Psychosomatic Medicine, 61, 154-162.

Kirschbaum, C., Wolf, O. T., May, M., Wippich, W., \& Hellhammer, D. H. (1996). Stress- and treatment-induced elevations of cortisol levels associated with impaired declarative memory in healthy adults. Life Sciences, 58, 1475-1483.

Klein, R. G., Abikoff, H., Klass, E., Ganeles, D., Seese, L. M., \& Pollack, S. (1997). Clinical efficacy of methylphenidate in conduct disorder with or without attention deficit hyperactivity disorder. Archives of General Psychiatry, 54, 1073-1080.

Kraemer, G. W., Ebert, M. H., Schmidt, D. E., \& McKinney, W. T. (1989). A longitudinal study of the effect of different social rearing conditions on cerebrospinal fluid norepinephrine and biogenic amine metabolites in rhesus monkeys. Neuropsychopharmacology, 2, 175-189. 
Krol, N., Morton, J., \& De Bruyn, E. (2004). Theories of conduct disorder: A causal modelling analysis. Journal of Child Psychology and Psychiatry, 45, 727-742.

Kruesi, M. J., Casanova, M. F., Mannheim, G., \& Johnson-Bilder, A. (2004). Reduced temporal lobe volume in early onset conduct disorder. Psychiatry Research, 132, 1-11.

Kruesi, M. J., Hibbs, E. D., Zahn, T. P., Keysor, C. S., Hamburger, S. D., Bartko, J. J., et al. (1992). A 2-year prospective follow-up study of children and adolescents with disruptive behavior disorders: Prediction by cerebrospinal fluid 5-hydroxyindole-acetic acid, homovanillic acid, and autonomic measures? Archives of General Psychiatry, 49, 429-435.

Kruesi, M. J., Rapoport, J. L., Hamburger, S., Hibbs, E., Potter, W. Z., Lenane, M., et al. (1990). Cerebrospinal fluid monoamine metabolites, aggression, and impulsivity in disruptive behavior disorders of children and adolescents. Archives of General Psychiatry, 47, 419-426.

Kruesi, M. J., Schmidt, M. E., Donnelly, M., Hibbs, E. D., \& Hamburger, S. D. (1989). Urinary free cortisol output and disruptive behavior in children. Journal of the American Academy of Child and Adolescent Psychiatry, 28, 441-443.

Kruk, M. R., Halasz, J., Meelis, W., \& Haller, J. (2004). Fast positive feedback between the adrenocortical stress response and a brain mechanism involved in aggressive behavior. Behavioral Neuroscience, 118, 1062-1070.

Ladd, C. O., Owens, M. J., \& Nemeroff, C. B. (1996). Persistent changes in corticotropin-releasing factor neuronal systems induced by maternal deprivation. Endocrinology, 137, 1212-1218.

Lahey, B. B., McBurnett, K., Loeber, R., \& Hart, E. L. (1995). Psychobiology. In G. Perooz Sholevar (Ed.), Conduct disorders in children and adolescents (pp. 27-44). Washington, DC: American Psychiatric Press.

Lahey, B. B., Piacentini, J. C., McBurnett, K., Stone, P., Hartdagen, S., \& Hynd, G. (1987). Psychopathology in the parents of children with conduct disorder and hyperactivity. Journal of the American Academy of Child and Adolescent Psychiatry, 27, 163-170.

Lahey, B. B., Waldman, I. D., \& McBurnett, K. (1999). Annotation: The development of antisocial behavior: An integrative causal model. Journal of Child Psychology and Psychiatry, 40, 669-682.

Lane, R. D., Reiman, E. M., Bradley, M. M., Lang, P. J., Ahern, G. L., Davidson, R. J., et al. (1997). Neuroanatomical correlates of pleasant and unpleasant emotion. Neuropsychologia, 35, 1437-1444.

Lappalainen, J., Long, J. C., Eggert, M., Ozaki, N., Robin, R. W., Brown, G. L., et al. (1998). Linkage of antisocial alcoholism to the serotonin 5-HT1B receptor gene in 2 populations. Archives of General Psychiatry, $55,989-994$

Lee, R., Geracioti, T. D., Kascow, J. W., \& Coccaro, E. F. (2005). Childhood trauma and personality disorder: Positive correlation with adult CSF corticotropin-releasing factor concentrations. American Journal of Psychiatry, 162, 995-997.

Lidberg, L., Tuck, J. R., Asberg, M., Scalia-Tomba, G. P., \& Bertilsson, L. (1985). Homicide, suicide and CSF 5-HIAA. Acta Psychiatrica Scandinavica, 71, 230-236.

Limson, R., Goldman, D., Roy, A., Lamparski, D., Ravitz, B., Adinoff, B., et al. (1991). Personality and cerebrospinal fluid monoamine metabolites in alcoholics and controls. Archives of General Psychiatry, 48, 437-441.

Linnoila, M., Virkkunen, M., Scheinin, M., Nuutila, A., Rimon, R., \& Goodwin, F. K. (1983). Low cerebrospinal fluid 5-hydroxyindoleacetic acid concentration differentiates impulsive from nonimpulsive violent behavior. Life Sciences, 33, 2609-2614.

Liu, D., Diorio, J., Tannenbaum, B., Caldji, C., Francis, D., Freedman, A., et al. (1997, September 12). Maternal care, hippocampal glucocorticoid receptors, and hypothalamic-pituitary-adrenal responses to stress. Science, $277,1659-1662$.

Lorber, M. (2004). The psychophysiology of aggression, psychopathy, and conduct problems: A meta-analysis. Psychological Bulletin, 130, 531552.
Lucki, I. (1998). The spectrum of behaviors influenced by serotonin. Biological Psychiatry, 44, 151-162.

Lundy, B. L., Jones, N. A., Field, T., Nearing, G., Davalos, M., Pietro, P. A., et al. (1999). Prenatal depression effects on neonates. Infant Behavior and Development, 22, 119-129.

Lynam, D. R. (1996). Early identification of early offenders: Who is the fledgling psychopath? Psychological Bulletin, 120, 209-234.

Lyons, M. J., True, W. R., Eisen, S. A., Goldberg, J., Meyer, J. M., Faraone, S. V., et al. (1995). Differential heritability of adult and juvenile antisocial traits. Archives of General Psychiatry, 52, 906-915.

Majewska, M. D., Demirgoren, S., Spivak, C. E., \& London, E. D. (1990). The neurosteroid dehydroepiandrosterone sulfate is an allosteric antagonist of the GABA receptor. Brain Research, 526, 143-146.

Mann, J. J. (1995). Violence and aggression. In F. E. Bloom \& D. J. Kupfer (Eds.), Psychopharmacology: The fourth generation of progress (pp. 1919-1928). New York: Raven Press.

Maras, A., Laucht, M., Gerdes, D., Wilhelm, C., Lewicka, S., Haack, D., et al. (2003). Association of testosterone and dihydrotestosterone with externalizing behavior in adolescent boys and girls. Psychoneuroendocrinology, 28, 932-940.

Maskall, D. D., Zis, A. P., Lam, R. W., Clark, C. M., \& Kuan, A. J. (1995). Prolactin response to buspirone challenge in the presence of dopaminergic blockade. Biological Psychiatry, 38, 235-239.

Matthys, W., Cuperus, J. M., \& Van Engeland, H. (1999). Deficient social problem-solving in boys with ODD/CD, with ADHD, and with both disorders. Journal of the American Academy of Child and Adolescent Psychiatry, 38, 311-321.

Mazur, A., \& Booth, A. (1998). Testosterone and dominance in men. Behavioral and Brain Sciences, 21, 353-397.

McBride, P. A., Anderson, G. M., Hertzig, M. E., Sweeney, J. A., Kream, J., Cohen, D. J., et al. (1989). Serotonergic responsivity in male young adults with autistic disorder. Results of a pilot study. Archives of General Psychiatry, 46, 213-221.

McBurnett, K., Lahey, B. B., Frick, P. J., Risch, C., Loeber, R., Hart, E. L., et al. (1991). Anxiety, inhibition, and conduct disorder in children: II. Relation to salivary cortisol. Journal of the American Academy of Child and Adolescent Psychiatry, 30, 192-196.

McBurnett, K., Lahey, B. B., Rathouz, P. J., \& Loeber, R. (2000). Low salivary cortisol and persistent aggression in boys referred for disruptive behavior. Archives of General Psychiatry, 57, 38-43.

McDougle, C. J., Stigler, K. A., \& Posey, D. J. (2003). Treatment of aggression in children and adolescents with autism and conduct disorder. Journal of Clinical Psychiatry, 64, 16-25.

Meaney, M. J., Diorio, J., Francis, D., Widdowson, J., Laplante, P., Caldji, C., et al. (1996). Early environmental regulation of forebrain glucocorticoid receptor gene expression: Implications for adrenocortical responses to stress. Developmental Neuroscience, 18, 49-72.

Mehlman, P. T., Higley, P. T., Faucher, I., Lilly, A. A., Taub, D. M., Vickers, J., et al. (1994). Low CSF 5-HIAA concentrations and severe aggression and impaired impulse control in nonhuman primates. American Journal of Psychiatry, 151, 1485-1491.

Meikle, A. W., Stringham, J. D., Woodward, M. G., \& Bishop, D. T. (1988). Heritability of variation of plasma cortisol levels. Metabolism, $37,514-517$.

Miczek, K. A., Fish, E. W., de Bold, J. F., \& de Almeida, R. M. (2002), Social and neural determinants of aggressive behavior: Pharmacotherapeutic targets at serotonin, dopamine and gamma-butyric acid systems. Psychopharmacology, 163, 459-466.

Milich, R., \& Dodge, K. (1984). Social information processing in child psychiatric populations. Journal of Abnormal Child Psychology, 12, 471-490.

Moffitt, T. E. (1993). Adolescence-limited and life-course persistent antisocial behavior: A developmental taxonomy. Psychological Review, 100, 674-701. 
Moffitt, T. E. (2005). The new look of behavioral genetics in developmental psychopathology: Gene-environment interplay in antisocial behaviors. Psychological Bulletin, 131, 533-554.

Moffitt, T. E., Brammer, G. L., Caspi, A., Fawcett, J. P., Raleigh, M., Yuwiler, A., et al. (1998). Whole blood serotonin relates to violence in an epidemiological study. Biological Psychiatry, 43, 446-457.

Moffitt, T. E., \& Caspi, A. (2001). Childhood predictors differentiate life-course persistent and adolescence-limited antisocial pathways among males and females. Development and Psychopathology, 13, 355375 .

Moffitt, T. E., Caspi, A., \& Rutter, M. (2005). Strategy for investigating interactions between measured genes and measured environments. Archives of General Psychiatry, 62, 473-480.

Morris, J. S., Frith, C. D., Perrett, D. I., Rowland, D., Young, A. W., Calder, A. J., et al. (1996, October 31). A differential neural response in the human amygdala to fearful and happy facial expression. Nature, 383 , 812-815.

Morton, J., \& Frith, U. (1995). Causal modelling: A structural approach to developmental psychopathology. In D. Cicchetti \& D. J. Cohen (Eds.), Developmental psychopathology: Vol. 1. Theory and methods (pp. 357390). New York: Wiley.

Mos, J., Olivier, B., Poth, M., Van Oorschot, R., \& Van Aken, H. (1993). The effects of dorsal raphe administration of eltoprazine, TFMPP and 8-OH-DPAT on resident intruder aggression in the rat. European Journal of Pharmacology, 238, 411-415.

Moss, H. B., Vanyukov, M., Yao, J. K., \& Kirillova, G. P. (1999). Salivary cortisol responses in prepubertal boys: The effects of parental substance abuse and association with drug use behavior during adolescence. Biological Psychiatry, 45, 1293-1299.

Moss, H. B., Vanyukov, M. M., \& Martin, C. S. (1995). Salivary cortisol responses and the risk for substance abuse in prepubertal boys. Biological Psychiatry, 38, 547-555.

Moss, H. B., Yao, J. K., \& Panzak, G. L. (1990). Serotonergic responsivity and behavioral dimensions in antisocial personality disorder with substance abuse. Biological Psychiatry, 28, 325-338.

Moyer, K. E. (1976). The psychobiology of aggression. New York: Harper $\&$ Row.

Newcomer, J. W., Craft, S., Hershey, T., Atkins, K., \& Bardgett, M. E. (1994). Glucocorticoid-induced impairment in declarative memory performance in adult humans. Journal of Neuroscience, 14, 2047-2053.

Newcomer, J. W., Selke, G., Melson, A. K., Hershey, A. K., Craft, S., Richards, K., et al. (1999). Decreased memory performance in healthy humans induced by stress-level cortisol treatment. Archives of General Psychiatry, 56, 527-533.

Newman, J. P., \& Wallace, J. F. (1993). Diverse pathways to deficient self-regulation: Implications for disinhibitory psychopathology in children. Clinical Psychology Review, 13, 690-720.

O'Keane, V., Moloney, E., O'Neill, H., O'Connor, A., Smith, C., \& Dinan, T. G. (1992). Blunted prolactin responses to d-fenfluramine in sociopathy. Evidence for subsensitivity of central serotonergic function. British Journal of Psychiatry, 160, 643-646.

Offord, D. R., \& Bennett, K. J. (1994). Conduct disorder: Long-term outcomes and intervention effectiveness. Journal of the American Academy of Child and Adolescent Psychiatry, 33, 1069-1078.

Offord, D. R., Boyle, M. H., Racine, Y. A., Fleming, J. E., Cadman, D. T., Blum, H. M., et al. (1992). Outcome, prognosis, and risk in a longitudinal follow-up study. Journal of the American Academy of Child and Adolescent Psychiatry, 31, 916-923.

Olivier, B., Mos, J., Van Oorschot, R., \& Hen, R. (1995). Serotonin receptors and animal models of aggressive behavior. Pharmacopsychiatry, 28(Suppl. 2), 80-90.

Oosterlaan, J., Geurts, H. M., Knol, D. L., \& Sergeant, J. A. (2005). Low basal salivary cortisol is associated with teacher-reported symptoms of conduct disorder. Psychiatry Research, 134, 1-10.
Ortiz, J., \& Raine, A. (2004). Heart rate level and antisocial behavior in children and adolescents: A meta-analysis. Journal of the American Academy of Child and Adolescent Psychiatry, 43, 154-162.

Pajer, K., \& Gardner, W. (2004). Commentary: Cortisol levels and conduct disorder in adolescent mothers. Journal of the American Academy of Child and Adolescent Psychiatry, 43, 469-472.

Pajer, K., Gardner, W., Rubin, R. T., Perel, J., \& Neal, S. (2001). Decreased cortisol levels in adolescent girls with conduct disorder. Archives of General Psychiatry, 58, 297-302.

Parker, C. R., Jr. (1999). Dehydroepiandrosterone and dehydroepiandrosterone sulfate production in the human adrenal during development and aging. Steroids, 64, 640-647.

Parker, L. N. (1989). Adrenal androgen metabolism. In L. N. Parker, Adrenal androgens in clinical medicine (pp. 3-28). San Diego, CA: Academic Press.

Patterson, G. R., Reid, J., \& Dishion, T. J. (1992). Antisocial boys. Eugene, OR: Castalia Press.

Patterson, G. R., \& Stouthamer-Loeber, M. (1984). The correlation of family management practices and delinquency. Child Development, 55, 1299-1307.

Pine, D. S., Coplan, J. D., Wasserman, G. A., Miller, L. S., Fried, J. E., Davies, M., et al. (1997). Neuroendocrine response to fenfluramine challenge in boys. Associations with aggressive behavior and adverse rearing. Archives of General Psychiatry, 54, 839-846.

Pine, D. S., Wasserman, G. A., Coplan, J., Fried, J. A., Huang, Y. Y., Kassir, S., et al. (1996). Platelet serotonin 2A (5-HT2A) receptor characteristics and parenting factors for boys at risk for delinquency: A preliminary report. American Journal of Psychiatry, 153, 538-544.

Pliszka, S. R., Rogeness, G. A., Renner, P., Sherman, J., \& Broussard, T. (1988). Plasma neurochemistry in juvenile offenders. Journal of the American Academy of Child and Adolescent Psychiatry, 27, 588-594.

Plomin, R., Nitz, K., \& Rowe, D. C. (1990). Behavioral genetics and aggressive behavior in childhood. In M. Lewis \& S. M. Miller (Eds.), Handbook of developmental psychopathology (pp. 119-133). New York: Plenum Press.

Porter, R. J., Gallagher, P., Watson, S., \& Young, A. H. (2004). Corticosteroid-serotonin interactions in depression: A review of the human evidence. Psychopharmacology, 173, 1-17.

Prather, M. D., Lavenex, P., Mauldin-Jourdain, M. L., Mason, W. A., Capitanio, J. P., Mendoza, S. P., et al. (2001). Increased social fear and decreased fear of objects in monkeys with neonatal amygdala lesions. Neuroscience, 106, 653-658.

Raine, A. (1993). The psychopathology of crime: Criminal behavior as a clinical disorder. San Diego, CA: Academic Press.

Raine, A. (1996). Autonomic nervous system activity and violence. In D. M. Stoff \& R. B. Cairns (Eds.), Aggression and violence: Genetic, neurobiological and biological perspectives (pp. 145-168). Mahwah, NJ: Erlbaum.

Raine, A. (2002). Biosocial studies of antisocial and violent behaviour in children and adults: A review. Journal of Abnormal Child Psychology, 30, 311-326.

Raine, A., Brennan, P. A., \& Farrington, D. P. (1997). Biosocial bases of violence: Conceptual and theoretical issues. In A. Raine, P. A. Brennan, D. P. Farrington, \& S. A. Mednick (Eds.), Biosocial bases of violence (pp. 1-20). New York: Plenum.

Raine, A., Lencz, T., Bihrle, S., LaCasse, L., \& Colletti, P. (2000). Reduced prefrontal gray matter and reduced autonomic activity in antisocial personality disorder. Archives of General Psychiatry, 57, 119127.

Raine, A., Moffitt, T. E., Caspi, A., Loeber, R., Stouthamer-Loeber, M., \& Lynam, D. (2005). Neurocognitive impairments in boys on the lifecourse persistent antisocial path. Journal of Abnormal Psychology, 114, $38-49$.

Raine, A., \& Venables, P. H. (1984). Eletrodermal nonresponding, antiso- 
cial behavior, and schizoid tendencies in adolescents. Psychophysiology, 21, 424-433.

Raine, A., Venables, P. H., \& Mednick, S. A. (1997). Low resting heart rate at age 3 years predisposes to aggression at age 11 years: Evidence from the Mauritius Child Health Project. Journal of the American Academy of Child and Adolescent Psychiatry, 36, 1457-1464.

Raine, A., Venables, P. H., \& Williams, M. (1990). Relationships between central and autonomic measures of arousal at age 15 years and criminality at age 24 years. Archives of General Psychiatry, 47, 1003-1007.

Raine, A., Venables, P. H., \& Williams, M. (1995). High autonomic arousal and electrodermal orienting at age 15 years as protective factors against criminal behavior at age 29 years. American Journal of Psychiatry, 152, 1595-1600.

Ramboz, S., Saudou, F., Amara, D. A., Belzung, C., Segu, L., Misslin, R., et al. (1996). 5-HT1B receptor knock out-behavioral consequences. Behavioral Brain Research, 73, 305-312.

Rhee, S. H., \& Waldman, I. D. (2002). Genetic and environmental influences on antisocial behavior: A meta-analysis of twin and adoption studies. Psychological Bulletin, 128, 490-529.

Rinne, T., Westenberg, H. G., den Boer, J. A., \& Van den Brink, W. (2000). Serotonergic blunting to meta-chlorophenylpiperazine (m-CPP) highly correlates with sustained childhood abuse in impulsive and autoaggressive female borderline patients. Biological Psychiatry, 47, 548556

Robins, L. N. (1966). Deviant children grown up. Baltimore, MD: Williams and Wilkins.

Robins, L. N. (1978). Sturdy childhood predictors of adult antisocial behavior: Replications from longitudinal studies. Psychological Medicine, 8, 611-622.

Rogeness, G. A., Hernandez, J. M., Macedo, C. A., \& Mitchell, E. L. (1982). Biochemical differences in children with conduct disorder socialized and undersocialized. American Journal of Psychiatry, 139, 307-311.

Rogeness, G. A., Javors, M. A., \& Pliszka, S. R. (1992). Neurochemistry and child and adolescent psychiatry. Journal of the American Academy of Child and Adolescent Psychiatry, 31, 765-781.

Roozendaal, B. (2000). Glucocorticoids and the regulation of memory consolidation. Psychoneuroendocrinology, 25, 213-238.

Rosenblum, L. A., Coplan, J. D., Friedman, S., Bassoff, T., Gorman, J. M., \& Andrews, M. W. (1994). Adverse early experiences affect noradrenergic and serotonergic functioning in adult primates. Biological Psychiatry, 35, 221-227.

Rowe, R., Maughan, B., Worthman, C. M., Costello, E. J., \& Angold, A. (2004). Testosterone, antisocial behavior, and social dominance in boys: Pubertal development and biosocial interaction. Biological Psychiatry, 55, 546-552.

Roy, A., Adinoff, B., \& Linnoila, M. (1988). Acting out hostility in normal volunteers: Negative correlation with levels of 5-HIAA in cerebrospinal fluid. Psychiatry Research, 24, 187-194.

Rutter, M., Giller, H., \& Hagell, A. (1998). Antisocial behavior by young people. Cambridge, England: Cambridge University Press.

Rutter, M., \& Silberg, J. (2002). Gene-environment interplay in relation to emotional and behavioral disturbance. Annual Review of Psychology, 53, 463-490.

Rutter, M., Silberg, J., O'Connor, T., \& Simonoff, E. (1999). Genetics and child psychiatry: II Empirical research findings. Journal of Child Psychology and Psychiatry, 40, 19-55.

Salzman, C., Wolfson, A. N., Schatzberg, A., Looper, J., Henke, R., Albanese, M., et al. (1995). Effect of fluoxetine on anger in symptomatic volunteers with borderline personality disorder. Journal of Clinical Psychopharmacology, 15, 23-29.

Sanchez, M. M., Aguado, F., Sanchez-Toscano, F., \& Saphier, D. (1998). Neuroendocrine and immunocytochemical demonstrations of decreased hypothalamo-pituitary-adrenal axis responsiveness to restraint stress after long-term social isolation. Endocrinology, 139, 579-587.

Sanchez, M. M., Ladd, C. O., \& Plotsky, P. M. (2001). Early adverse experience as a developmental risk factor for later psychopathology: Evidence from rodent and primate models. Development and Psychopathology, 13, 419-449.

Sanchez, M. M., Noble, P. M., Lyon, C. K., Plotsky, P. M., Davis, M., Nemeroff, C. B., et al. (2005). Alterations in diurnal cortisol rhythm and acoustic startle response in nonhuman primates with adverse rearing. Biological Psychiatry, 57, 373-381.

Sandi, C., Loscertales, M., \& Guaza, C. (1997). Experience-dependent facilitating effect of corticosterone on spatial memory formation in the water maze. European Journal of Neuroscience, 9, 637-642.

Saudou, F., Amara, D. A., Dierich, A., LeMeur, M., Ramboz, S., Segu, L., et al. (1994, September 23). Enhanced aggressive behavior in mice lacking 5-HT ${ }_{1 \mathrm{~B}}$ receptor. Science, $265,1875-1878$.

Scarpa, A., Fikretoglu, D., \& Luscher, K. (2000). Community violence exposure in a young adult sample: II. Psychophysiology and aggressive behavior. Journal of Community Psychology, 28, 417-425.

Scarpa, A., \& Raine, A. (1997). Psychophysiology of anger and violent behavior. Psychiatric Clinics of North America, 20, 375-394.

Scerbo, A. S., \& Kolko, D. J. (1994). Salivary testosterone and cortisol in disruptive children: Relationship to aggressive, hyperactive and internalizing behaviors. Journal of the American Academy of Child and Adolescent Psychiatry, 33, 1174-1184.

Schulz, K. P., Halperin, J. M., Newcorn, J. H., Sharma, V., \& Gabriel, S. (1997). Plasma cortisol and aggression in boys with ADHD. Journal of the American Academy of Child and Adolescent Psychiatry, 36, 605609.

Schulz, K. P., Newcorn, J. H., McKay, K. E., Himelstein, J., Koda, V. H., Siever, L. J., et al. (2001). Relationship between central serotonergic function and aggression in prepubertal boys: Effect of age and attentiondeficit/hyperactivity disorder. Psychiatry Research, 101, 1-10.

Shoal, G. D., Giancola, P. R., \& Kirillova, G. P. (2003). Salivary cortisol, personality, and aggressive behavior in adolescent boys: A 5-year longitudinal study. Journal of the American Academy of Child and Adolescent Psychiatry, 42, 1101-1107.

Shors, T. J., Weiss, C., \& Thompson, R. F. (1992, July 24). Stress-induced facilitation of classical conditioning. Science, 257, 537-539.

Silberg, J. L., Parr, T., Neale, M. C., Rutter, M., Angold, A., \& Eaves, L. J. (2003). Maternal smoking during pregnancy and risk to boys' conduct disturbance: an examination of the causal hypothesis. Biological Psychiatry, 53, 130-135.

Snoek, H. (2002). Psychoneuroendocrinological aspects of aggressive behavior in children. Unpublished doctoral dissertation, University of Utrecht, Utrecht, the Netherlands.

Snoek, H., Van Goozen, S. H. M., Matthys, W., Buitelaar, J. K., \& Van Engeland, H. (2004). Stress responsivity in children with externalizing behavior disorders. Development and Psychopathology, 16, 389-406.

Snoek, H., Van Goozen, S. H. M., Matthys, W., Sigling, H. O., Koppeschaar, H. P. F., Westenberg, H. G. M., et al. (2002). Serotonergic functioning in children with oppositional defiant disorder: A sumitriptan challenge study. Biological Psychiatry, 51, 319-325.

Sobczak, S., Honig, A., Nicolson, N., \& Riedel, W. J. (2002). Effects of acute tryptophan depletion on mood and cortisol release in first-degree relatives of Type I and Type II bipolar patients and healthy matched controls. Neuropsychopharmacology, 27, 834-842.

Soloff, P. H., Lynch, K. G., \& Moss, H. B. (2000). Serotonin, impulsivity, and alcohol use disorders in the older adolescent: A psychobiological study. Alcoholism, Clinical and Experimental Research, 24, 1609-1619.

Spoont, M. R. (1992). Modulatory role of serotonin in neural information processing: Implications for human psychopathology. Psychological Bulletin, 112, 330-350.

Sterzer, P., Stadler, C., Krebs, A., Kleinschmidt, A., \& Poustka, F. (2005). 
Abnormal neural responses to emotional visual stimuli in adolescents with conduct disorder. Biological Psychiatry, 57, 7-15.

Stewart, M. A., deBlois, C. S., \& Cummings, C. (1980). Psychiatric disorder in the parents of hyperactive boys and those with conduct disorder. Journal of Child Psychology and Psychiatry, 21, 283-292.

Stoff, D. M., Ieni, J., Friedman, E., Bridger, W. H., Pollock, L., \& Vitiello, B. (1991). Platelet 3H-imipramine binding, serotonin reuptake, and plasma alpha 1 acid glycoprotein in disruptive behavior disorders. Biological Psychiatry, 29, 494-498.

Stoff, D. M., Pasatiempo, A. P., Yeung, J., Cooper, T. B., Bridger, W. H., \& Rabinovich, H. (1992). Neuroendocrine responses to challenge to dl-fenfluramine and aggression in disruptive behavior disorders of children and adolescents. Psychiatry Research, 43, 263-276.

Stoff, D. M., Pollock, L., Vitiello, B., Behar, D., \& Bridger, W. H. (1987). Reduction of $[3 \mathrm{H}]$-imipramine binding sites on platelets of conduct disordered-children. Neuropsychopharmacology, 1, 55-62.

Stoff, D. M., \& Vitiello, B. (1996). Role of serotonin in aggression of children and adolescents: Biochemical and pharmacological studies. In D. M. Stoff \& R. B. Cairns (Eds.), Aggression and violence: Genetic, neurobiological and biological perspectives (pp. 67-85). Mahwah, NJ: Erlbaum.

Stroud, L. R., Salovey, P., \& Epel, E. S. (2002). Sex differences in stress responses: Social rejection versus achievement stress. Biological Psychiatry, 52, 318-327.

Stutzmann, G. E., McEwen, B. S., \& LeDoux, J. E. (1998). Serotonin modulation of sensory inputs to the lateral amygdala: Dependency on corticosterone. Journal of Neuroscience, 18, 9529-9538.

Susman, E. J. (2006). Psychobiology of persistent antisocial behavior: Stress, early vulnerabilities and the attenuation hypothesis. Neuroscience and Biobehavioral Reviews, 30, 376-389.

Susman, E. J., Schmeelk, K. H., Worrall, B. K., Granger, D. A., Ponirakis, A., \& Chrousos, G. P. (1999). Corticotropin-releasing hormone and cortisol: Longitudinal associations with depression and antisocial behavior in pregnant adolescents. Journal of the American Academy of Child and Adolescent Psychiatry, 38, 460-467.

Tackett, J. L., Krueger, R. F., Iacono, W. G., \& McGue, M. (2005). Symptom-based subfactors of DSM-defined conduct disorder: Evidence for etiologic distinctions. Journal of Abnormal Psychology, 114, 483487.

Teicher, M. H., Dumont, N. L., Vaituzis, C., Giedd, J. N., \& Andersen, S. L. (2004). Childhood neglect is associated with reduced corpus callosum area. Biological Psychiatry, 56, 80-85.

Tennes, K., \& Kreye, M. (1985). Children's adrenocortical responses to classroom activities and tests in elementary school. Psychosomatic Medicine, 47, 451-460.

Tennes, K., Kreye, M., Avitable, N., \& Wells, R. (1986). Behavioral correlates of excreted catecholamines and cortisol in second-grade children. Journal of the American Academy of Child and Adolescent Psychiatry, 25, 764-770.

Thapar, A., Fowler, T., Rice, F., Scourfield, J., van den Bree, M., Thomas, H., et al. (2003). Maternal smoking during pregnancy and attention deficit hyperactivity disorder symptoms in offspring. American Journal of Psychiatry, 160, 1985-1989.

Tuinier, S., Verhoeven, W. M. A., \& Van Praag, H. M. (1995). Cerebrospinal fluid 5-hydroxyindoleacetic acid and aggression: A critical reappraisal of the clinical data. International Clinical Psychopharmacology, 10, 147-156.

Twitchell, G. R., Hanna, G. L., Cook, E. H., Fitzgerald, H. E., \& Zucker, R. A. (2000). Serotonergic function, behavioral disinhibition, and negative affect in children of alcoholics: The moderating effect of puberty. Alcoholism, Clinical and Experimental Research, 24, 972-979.

Twitchell, G. R., Hanna, G. L., Cook, E. H., Stoltenberg, S. F., Fitzgerald, H. E., \& Zucker, R. A. (2001). Serotonin transporter promoter polymorphism genotype is associated with behavioral disinhibition and negative affect in children of alcoholics. Alcoholism, Clinical and Experimental Research, 25, 953-959.

Unis, A. S., Cook, E. H., Vincent, J. G., Gjerde, D. K., Perry, B. D., Mason, C., et al. (1997). Platelet serotonin measures in adolescents with conduct disorder. Biological Psychiatry, 42, 553-559.

Van Bokhoven, I., Matthys, W., Van Goozen, S. H. M., \& Van Engeland, H. (2005). Prediction of adolescent outcome in children with disruptive behaviour disorders: A study of neurobiological, psychological and family factors. European Child and Adolescent Psychiatry, 14, 153-163.

Van Bokhoven, I., Van Goozen, S. H. M., van Engeland, H., Schaal, B., Arseneault, L., Séguin, J. R., et al. (2005). Salivary cortisol and aggression in a population-based longitudinal study of adolescent males. Journal of Neural Transmission, 112, 1083-1096.

Van de Wiel, N. M. H., Van Goozen, S. H. M., Matthys, W., Snoek, H., \& Van Engeland, H. (2004). Cortisol and treatment effect in children with disruptive behavior disorders: A preliminary study. Journal of the American Academy of Child and Adolescent Psychiatry, 43, 1011-1018.

Van Goozen, S. H. M., Cohen-Kettenis, P. T., Snoek, H., Matthys, W., Swaab-Barneveld, H., \& Van Engeland, H. (2004). Executive functioning in children: A comparison of hospitalized ODD and ODD/ADHD children and normal controls. Journal of Child Psychology and Psychiatry, 45, 284-292.

Van Goozen, S. H. M., Matthys, W., Cohen-Kettenis, P. T., Buitelaar, J. K., \& Van Engeland, H. (2000). Hypothalamic-pituitary-adrenal axis and autonomic nervous system activity in disruptive children and matched controls. Journal of the American Academy of Child and Adolescent Psychiatry, 39, 1438-1445.

Van Goozen, S. H. M., Matthys, W., Cohen-Kettenis, P. T., Gispen-de Wied, C., Wiegant, V. M., \& Van Engeland, H. (1998). Salivary cortisol and cardiovascular activity during stress in oppositional-defiant disorder boys and normal controls. Biological Psychiatry, 43, 531-539.

Van Goozen, S. H. M., Matthys, W., Cohen-Kettenis, P. T., Thijssen, J. H. H., \& Van Engeland, H. (1998). Adrenal androgens and aggression in conduct disorder prepubertal boys and normal controls. Biological Psychiatry, 43, 156-158.

Van Goozen, S. H. M., Matthys, W., Cohen-Kettenis, P. T., Westenberg, H., \& Van Engeland, H. (1999). Plasma monoamine metabolites and aggression: Two studies of normal and oppositional defiant disorder children. European Neuropsychopharmacology, 9, 141-147.

Van Goozen, S. H. M., Snoek, H., Matthys, W., Van Rossum, I., \& Van Engeland, H. (2004). Evidence of fearlessness in behaviourally disordered children: A study on startle reflex modulation. Journal of Child Psychology and Psychiatry, 45, 884-892.

Van Goozen, S. H. M., Van den Ban, E., Matthys, W., Cohen-Kettenis, P. T., Thijssen, J. H. H., \& Van Engeland, H. (2000). Increased adrenal androgen functioning in children with oppositional defiant disorder: A comparison with psychiatric and normal controls. Journal of the American Academy of Child and Adolescent Psychiatry, 39, 1446-1451.

Van Oers, H. J. J., de Kloet, E. R., \& Levine, S. (1998). Early vs. late maternal deprivation differentially alters the endocrine and hypothalamic responses to stress. Developmental Brain Research, 111, 245-252.

Van Riel, E., Van Gemert, N. G., Meijer, O. C., \& Joëls, M. (2004). Effect of early life stress on serotonin responses in the hippocampus of young adult rats. Synapse, 53, 11-19.

Vanyukov, M. M., Moss, H. B., Plail, J. A., Blackson, T., Mezzich, A. C., \& Tarter, R. E. (1993). Antisocial symptoms in preadolescent boys and in their parents: Associations with cortisol. Psychiatry Research, 46, $9-17$.

Vermeiren, R., De Clippele, A., Schwab-Stone, M., Ruchkin, V., \& Deboutte, D. (2002). Neuropsychological characteristics of three subgroups of Flemish delinquent adolescents. Neuropsychology, 16, 49-55.

Vielhaber, K., Riemann, D., Feige, B., Kuelz, A., Kirschbaum, C., \& Voderholzer, U. (2005). Impact of experimentally induced serotonin 
deficiency by tryptophan depletion on saliva cortisol concentrations.

Pharmacopsychiatry, 38, 87-94.

Virkkunen, M. (1985). Urinary free cortisol secretion in habitually violent offenders. Acta Psychiatrica Scandinavica, 72, 40-44.

Virkkunen, M., \& Linnoila, M. (1993). Brain serotonin, Type II alcoholism and impulsive violence. Journal of Studies on Alcohol, 11(Suppl.), 163-169.

Virkkunen, M., Nuutila, A., Goodwin, F. K., \& Linnoila, M. (1987). Cerebrospinal fluid monoamine metabolites in male arsonists. Archives of General Psychiatry, 44, 241-247.

Virkkunen, M., Rawlings, R., Tokola, R., Poland, R. E., Guidotti, A., Nemeroff, C., et al. (1994). CSF biochemistries, glucose metabolism, and diurnal activity rhythms in alcoholic, violent offenders, fire setters and healthy volunteers. Archives of General Psychiatry, 51, 28-33.

Vitiello, B., \& Stoff, D. M. (1997). Subtypes of aggression and their relevance to child psychiatry. Journal of the American Academy of Child and Adolescent Psychiatry, 36, 307-315.

Watson, D., \& Pennebaker, J. W. (1989). Health complaints, stress, and distress: Exploring the central role of negative affectivity. Psychological Review, 96, 234-254.

Wetzler, S., Kahn, R. S., Asnis, G. M., Korn, M., \& Van Praag, H. M. (1991). Serotonin receptor sensitivity and aggression. Psychiatry Research, 37, 271-279.

Whalen, P. J., Rauch, S. L., Etcoff, N. L., McInerney, S. C., Lee, M. B., \& Jenike, M. A. (1998). Masked presentations of emotional facial expressions modulate amygdala activity without explicit knowledge. Journal of Neuroscience, 18, 411-418.

Woodman, D. D., Hinton, J. W., \& O’Neill, M. T. (1978). Cortisol secretion and stress in maximum security hospital patients. Journal of Psychosomatic Research, 22, 133-136.

World Health Organization. (2002). World report on violence and health. E. G. Krug, L. L. Dahlman, J. A. Mercy, A. B. Zwi, \& R. Lozano (Eds.) Geneva, Switzerland: Author.

Wright, D. E., Seroogy, K. B., Lundgren, K. H., Davis, B. M., \& Jennes, L. (1995). Comparative localization of serotonin1A, 1C, and 2 receptor subtype mRNAs in rat brain. Journal of Comparative Neurology, 351, 357-373.

Zahn, T. P., \& Kruesi, M. J. P. (1993). Autonomic activity in boys with disruptive behavior disorders. Psychophysiology, 30, 605-614.

Zoccolillo, M., Pickles, A., Quinton, D., \& Rutter, M. (1992). The outcome of childhood conduct disorder: Implications for defining adult personality disorder and conduct disorder. Psychological Medicine, 22, 971986

Zoccolillo, M., \& Rogers, K. (1991). Characteristics and outcome of hospitalized adolescent girls with conduct disorder. Journal of the American Academy of Child and Adolescent Psychiatry, 30, 973-981.

Zubieta, J. K., \& Alessi, N. E. (1992). Acute and chronic administration of trazodone in the treatment of disruptive behavior disorders in children. Journal of Clinical Psychopharmacology, 12, 346-351.

Zuckerman, M. (1979). Sensation seeking: Beyond the optimum level of arousal. Hillsdale, NJ: Erlbaum.

Received June 23, 2005

Revision received April 19, 2006

Accepted April 25, 2006

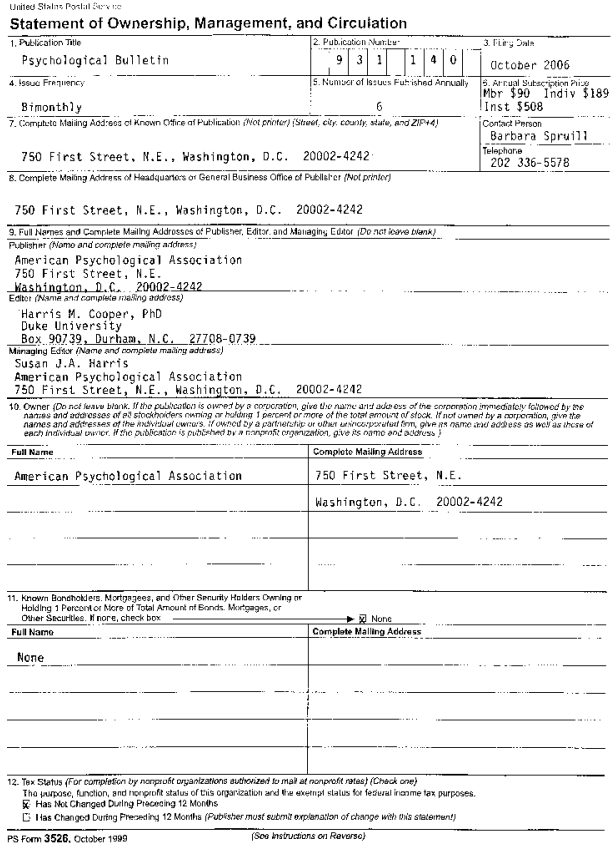

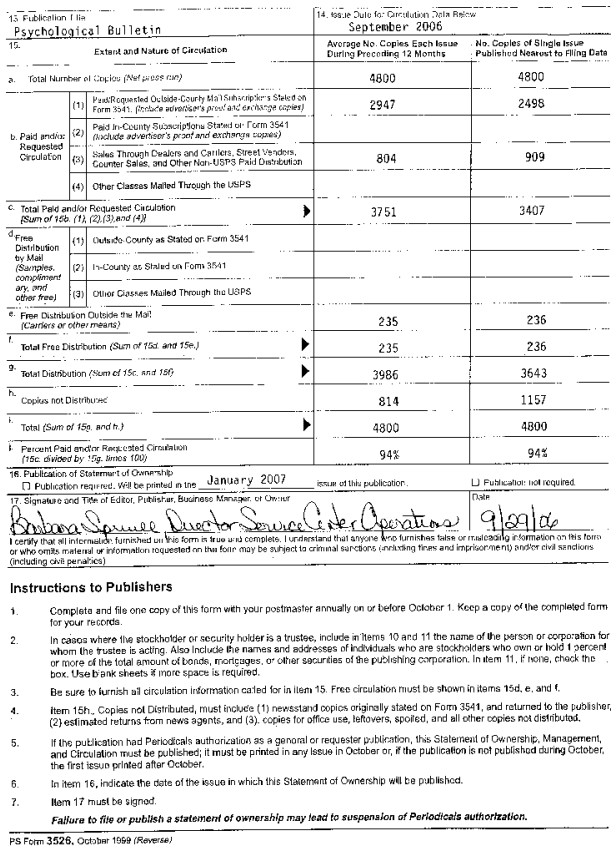

